NISTIR 6903

\title{
Distribution of Earthquake Input Energy in Structures
}

Payam Khashaee

Bijan Mohraz

Fahim Sadek

H.S. Lew

John L. Gross

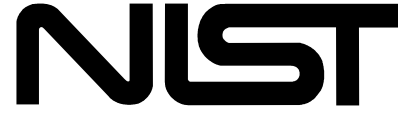

United States Department of Commerce

Technology Administration

National Institute of Standards and Technology 


\section{Distribution of Earthquake Input Energy in Structures}

Payam Khashaee

Bijan Mohraz

Fahim Sadek

H.S. Lew

John L. Gross

Building and Fire Research Laboratory

National Institute of Standards and Technology

Gaithersburg, MD 20899

January 2003

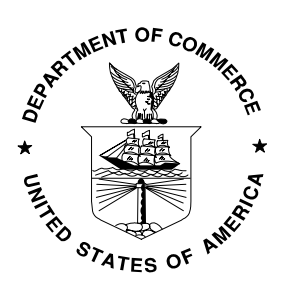

U.S. Department of Commerce

Donald L. Evans, Secretary

Technology Administration

Philip J. Bond, Under Secretary of Commerce for Technology

National Institute of Standards and Technology

Arden L. Bement, Jr., Director 



\begin{abstract}
In developing an energy-based design approach and assessing the damage potential of structures, one must know the distribution of earthquake input energy among energy components: kinetic, elastic strain, hysteretic, and damping. This report examines the influences of the ground motion characteristics: intensity, frequency content, and duration of strong motion and the structural properties: ductility, damping, and hysteretic behavior on the distribution of input energy for a one- and a five-story building using 20 accelerograms, ten with short and ten with long duration of strong motion.

Results indicate that for certain damping ratios, ductility has a significant influence on input energy and its distribution among energy components in a structure. For a given ductility ratio, small damping ratio (less than 5\%) has a minor effect on input energy, but a major influence on the energy distribution. Damping ratios larger than $5 \%$ have a significant influence on the input energy and its distribution. Three energy ratios that relate to hysteretic energy were computed: the maximum ratio of hysteretic to input energy $\left(E_{h} / E_{i r}\right)_{m}$, the ratio of the maximum hysteretic energy to the maximum input energy $E_{h m} / E_{i r m}$, and the equivalent number of yield excursions $N_{e q}=E_{h m} /\left(F_{y} \cdot u_{p}\right)$ where $F_{y}$ is the yield strength, and $u_{p}$ is the plastic deformation. It is found that $\left(E_{h} / E_{i r}\right)_{m}$ generally reflects the energy demand for the largest yield excursion, and $E_{h m} / E_{i r m}$ and $N_{e q}$ reflect the energy demand for the entire duration of accelerogram. The study shows that $\left(E_{h} / E_{i r}\right)_{m}$ is independent of the duration of strong motion and period of structure; however, $E_{h m} / E_{i r m}$ is independent of both only for periods less than $1 \mathrm{~s}$. Results indicate that as the duration becomes longer the equivalent number of yield excursions $N_{e q}$ increases indicating more structural damage.

The influence of ground motion characteristics and structural properties on the distribution of energy parameters for a five-story building with fixed-base, base-isolation, supplemental damping, and semi-active control are examined using the 20 accelerograms. The results show that: 1) the distribution of energy through the height of the building is mostly independent of the frequency content and the duration of strong motion, 2) baseisolation, supplemental damping, and semi-active control reduce the damage potential by reducing the input and hysteretic energy demands and have significant influences on the distribution of energy through the height of the building.
\end{abstract}





\section{ACKNOWLEDGEMENT}

This study was supported by the Structures Division, Building and Fire Research Laboratory, National Institute of Standards and Technology, U.S. Department of Commerce through a contract with Southern Methodist University. 



\section{TABLE OF CONTENTS}

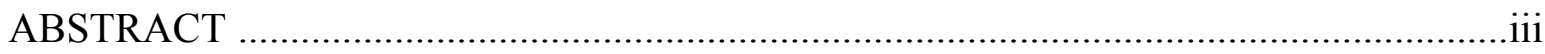

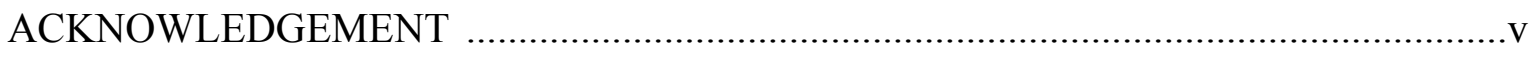

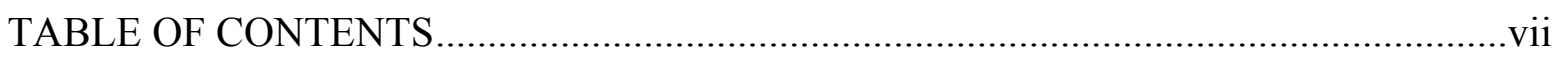

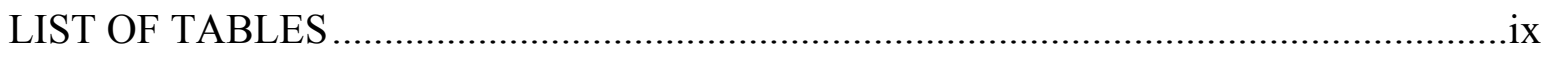

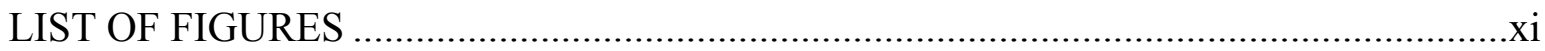

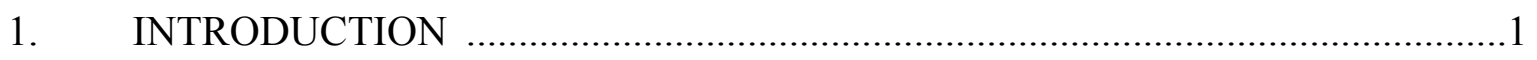

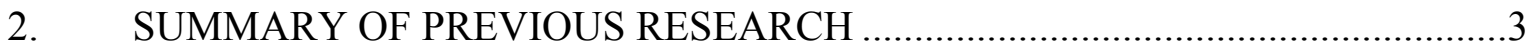

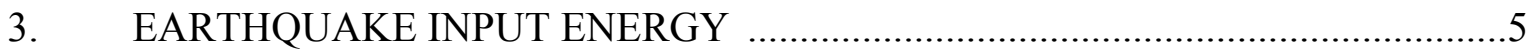

$3.1 \quad$ Energy Balance Equation ……………….............................................

3.2 Energy Ratio Time-histories ..................................................................6

4. ESTIMATING THE EARTHQUAKE INPUT ENERGY ………………..............11

4.1 Existing Procedures for Computing Input Energy ……..................................11

4.2 The Influence of Ground Motion Characteristics on Energy Spectra.............14

4.3 The Influence of Structural Properties on Energy Spectra .............................20

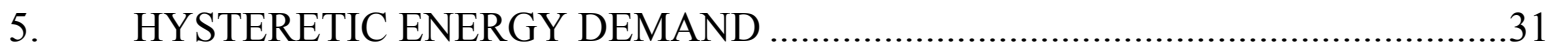

6. ENERGY RATIOS IN AN MDOF STRUCTURE …………………….................

7. DISTRIBUTION OF INPUT ENERGY IN STRUCTURES WITH BASEISOLATION, SUPPLEMENTAL DAMPING AND SEMI-ACTIVE CONTROL .45

7.1 Energy Equations for Buildings with Base-Isolation and Semi-Active

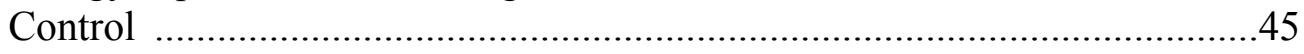

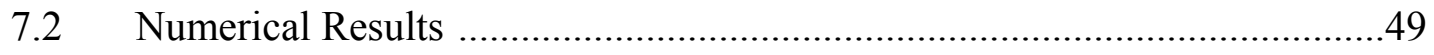

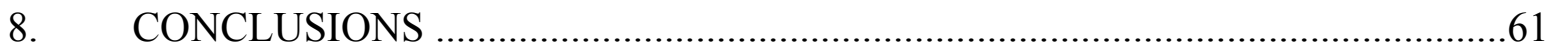

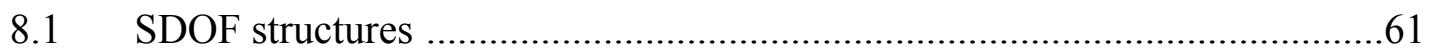

8.2 A 5-story building with fixed base, base-isolation, supplemental damping, and semi-active control

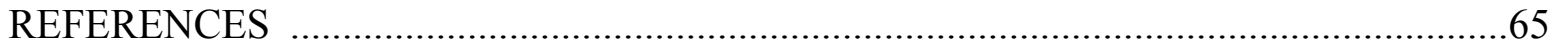




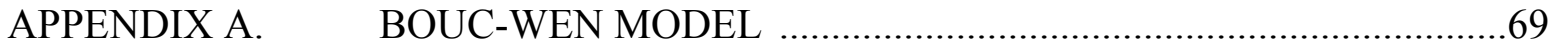

APPENDIX B. EARTHQUAKE INPUT ENERGY FOR MDOF STRUCTURES ...71

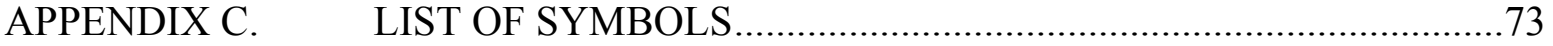




\section{LIST OF TABLES}

Table 4.1 Strong motion records used in the analysis

Table 6.1 Inter-story ductility, normalized story shear, percentage of energy in each story, and the energy ratios $\left(E_{h} / E_{i r}\right)_{m}, E_{h m} / E_{i r m}$, and $E_{d m} / E_{d m}$ for the five-story building subjected to the S00E component of El Centro, the Imperial Valley, CA earthquake of May 18, 1940 scaled to an $E P A=$ $0.4 g$.

Table 6.2 Influence of yield deformation on maximum inter-story ductility $\mu_{\max }$, base shear $Q_{b}$, and total energy parameters for the five-story building subjected to the S00E component of El Centro, the Imperial Valley, CA earthquake of May 18, 1940 scaled to an $E P A=0.4 g$.

Table 7.1 The average percentage of hysteretic energy, input energy, and story shear in each story for the five-story building with fixed-base, base isolation, supplemental damping, and semi-active control subjected to 20 accelerograms scaled to an $E P A=0.4 g$.

Table 7.2 (a) Maximum drift, maximum relative displacement, ductility ratio, and maximum story shear for each story, and (b) maximum damping, maximum hysteretic, maximum controller, and maximum input energies for the four buildings (with fixed-base, base-isolation, supplemental damping, and semi-active control) subjected to the S00E component of El Centro, the Imperial Valley, CA earthquake of May 18, 1940 scaled to an $E P A=0.4 g$.

Table 7.3 The energy ratios $E_{k r} / E_{i r}, E_{d} / E_{i r}, E_{s} / E_{i r}, E_{h} / E_{i r}$, and $E_{c} / E_{i r}$ for the the four buildings (a) fixed-base, (b) base-isolated, (c) semi-active with small control forces, (d) and semi-active with large control forces subjected to the S00E component of El Centro, the Imperial Valley, CA earthquake of May 18, 1940 scaled to an $E P A=0.4 g$. 



\section{LIST OF FIGURES}

Figure 3.1. Energy time-histories for a bilinear SDOF structure with $T_{n}=0.5 \mathrm{~s}, \mu=$ $3, \alpha=0.02$, and $\xi=5 \%$ subjected to the S00E component of El Centro, the Imperial Valley, CA earthquake of May 18, 1940 .....................

Figure 3.2. Time-histories of the ratio of energy components to relative input energy for a bilinear SDOF structure with $T_{n}=0.5 \mathrm{~s}$, a ductility ratio $\mu=3$, and $5 \%$ damping subjected to the S00E component of El Centro, the

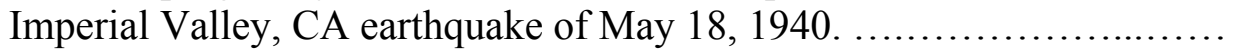

Figure 3.3. Time-histories of $E_{h} / E_{h m}$ and $E_{h} / E_{i r}$ for a bilinear SDOF structure with $T_{n}$ $=0.5 \mathrm{~s}$, a ductility ratio $\mu=3$, and $5 \%$ damping subjected to the $\mathrm{S} 00 \mathrm{E}$ component of El Centro, the Imperial Valley, CA earthquake of May 18, 1940.

Figure 4.1. Relative input energy for ductility ratio $\mu=3$ and a damping ratio $\xi=$ $5 \%$ for the S00E component of El Centro, the Imperial Valley, CA earthquake of May 18, 1940 scaled to $E P A=0.3 g, 0.4 g$, and $0.6 g$........

Figure 4.2. Ratio of the maximum hysteretic energy to the maximum input energy for ductility ratio $\mu=3$ and a damping ratio $\xi=5 \%$ for the S00E component of El Centro, the Imperial Valley, CA earthquake of May 18, 1940 scaled to $E P A=0.3 g, 0.4 g$, and $0.6 g$.

Figure 4.3. (a) Earthquake input energy and (b) hysteretic energy for the N65W component of Temblor, Park-field, CA earthquake of June 27, $1966\left(t_{d i}\right.$ $=6 \mathrm{~s})$ and the S69E component of Taft Lincoln School Tunnel, Kern County, CA earthquake of July 21, $1952\left(t_{d i}=29 \mathrm{~s}\right)$ for $\mu=1,3$, and 5, and a damping ratio $\xi=5 \%$ scaled to an $E P A=0.4 g$..................

Figure 4.4. Predominant periods $T_{p a}$ and $T_{p e}$ from the elastic acceleration and input energy spectra, respectively, for three accelerograms with short duration of strong motion and three accelerograms with long duration.

Figure 4.5. Elastic input energy spectra for the $90^{\circ}$ component of Sylmar County Hospital Parking Lot, Northridge, CA earthquake of January 17, 1994 and the S16E component of Pacoima Dam, San Fernando, CA earthquake of March 22, 1971 scaled to an $E P A=0.4 g \ldots \ldots \ldots \ldots \ldots \ldots \ldots$.

Figure 4.6. Relative input energy $E_{i r}$ for ductility ratios $\mu=1,2,3$, and 5, and a damping ratio $\xi=5 \%$ for three accelerograms with short, and three accelerograms with long duration of strong motion 
Figure 4.7. Relative input energy $E_{\text {ir }}$ for a ductility ratio of 3, and damping ratios $\xi=$ $0,2,5,10,20$, and $40 \%$ for three accelerograms with short duration of strong motion, and three accelerograms with long duration

Figure 4.8. Energy ratio spectra for bilinear behavior with a ductility ratio $\mu=3$ and damping ratios $0 \%, 2 \%, 5 \%, 10 \%, 20 \%$, and $40 \%$ subjected to the $360^{\circ}$ component of Sylmar County Hospital Parking Lot Station, Northridge earthquake of January 17,1994 . (a) $E_{k r m} / E_{i r m}$, (b) $E_{s m} / E_{i r m}$, (c) $E_{h m} / E_{i r m}$, (d) $\left(E_{h} / E_{i r}\right)_{m}$, (e) $E_{d m} / E_{\text {irm }}$, and (f) $E_{\text {dism }} / E_{\text {irm }}$.

Figure 4.9. Force-displacement diagram for an SDOF MRF and an SDOF EBF with $T_{n}=2.0 \mathrm{~s}$, a ductility ratio of 3 , and a $5 \%$ damping ratio subjected to the $360^{\circ}$ component of Sylmar County Hospital Parking Lot, Northridge, CA earthquake of January 17, 1994.

Figure 4.10. Relative input energy $E_{\text {ir }}$ for a ductility ratio of 3, damping ratio $\xi=5 \%$, and two hysteretic behaviors for (a) the $360^{\circ}$ component of Sylmar County Hospital Parking Lot, Northridge, CA earthquake of January 17, 1994, and (b) the S00E component of Mexico City earthquake of Sep $19,1985$.

Figure 5.1. (a, b) Maximum ratio of the hysteretic to input energy $\left(E_{h} / E_{i r}\right)_{m}$ for records with short and long durations of strong motion, respectively. (c, d) Ratio of the maximum hysteretic energy to the maximum input energy $E_{h m} / E_{\text {irm }}$ for records with short and long durations, respectively. $(\mathrm{e}, \mathrm{f})$ Equivalent number of yield excursions $N_{e q}$ for records with short and long durations, respectively for a ductility ratio $\mu=3$ and a $5 \%$ damping ratio.

Figure 5.2. Time-histories of $E_{h} / E_{h m}$ and $E_{h} / E_{\text {ir }}$ for a bilinear SDOF structure with $T_{n}$ $=1.0 \mathrm{~s}$, a ductility ratio $\mu=3$, and $5 \%$ damping subjected to the $90^{\circ}$ component of Sylmar County Hospital Parking Lot, Northridge, CA earthquake of January 17, 1994.

Figure 5.3. Time-histories of $E_{h} / E_{h m}$ and $E_{h} / E_{\text {ir }}$ for a bilinear SDOF structure with $T_{n}$ $=2.0 \mathrm{~s}$, a ductility ratio $\mu=3$, and $5 \%$ damping subjected to the $90^{\circ}$ component of Sylmar County Hospital Parking Lot, Northridge, CA earthquake of January 17, 1994.

Figure 5.4. The mean $\left(E_{h} / E_{i r}\right)_{m}$ and $E_{h m} / E_{\text {irm }}$ spectra for bilinear behavior with $5 \%$ damping and ductility ratios $\mu=2,3$, and 5 for 20 accelerograms.

Figure 6.1. Total hysteretic and total input energies for the five-story building with $u_{y l}=0.5 \mathrm{~cm}$ subjected to the 20 accelerograms scaled to an $E P A=0.4 \mathrm{~g}$. 
Figure 6.2. $\quad$ (a) Relative displacement $u_{r e l}$, (b) ductility demand $\mu$, (c) normalized story shear, (d) $E_{h m} / E_{i r m}$, (e) distribution of $E_{h}$ though the height, and (f) distribution of $E_{i r}$ through the height for the 5-story building with yield deformations of the first story $u_{y l}=0.3,0.5,0.7,1.0$, and 1.5 subjected to S00E component of El Centro, the Imperial Valley, CA earthquake of May 18, 1940 scaled to an $E P A=0.4 g$.

Figure 6.3. Distribution of energy through the height of a 5-story building with $u_{y l}=$ $0.5 \mathrm{~cm}$ subjected to 20 accelerograms scaled to an $E P A=0.4 g$. ............

Figure 7.1 (a) Five-story building with fixed base, (b) with base-isolation, and (c) with supplemental damping or semi-active control subjected to the S00E component of El Centro, the Imperial Valley, CA earthquake of May 18,

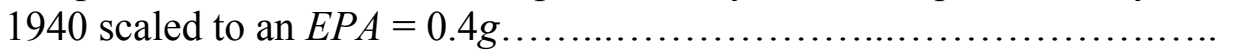

Figure 7.2. Distribution of energy through the height of a 5-story building with base isolation ( $10 \%$ damping, $T_{b}=2.0 \mathrm{~s}$, and $\left.u_{y b}=4.0 \mathrm{~cm}\right)$ with $u_{y l}=0.5 \mathrm{~cm}$ subjected to 20 records scaled to an $E P A=0.4 g$.

Figure 7.3. Distribution of energy through the height of a 5-story building with supplemental damping (total damping $40 \%$ ) with $u_{y l}=0.5 \mathrm{~cm}$ subjected to 20 records scaled to an $E P A=0.4 g$.

Figure 7.4. Distribution of energy through the height of a 5-story building with semi-active control $\left(r=10^{-5}\right.$ and $\left.q=10^{+5}\right)$ with $u_{y l}=0.5 \mathrm{~cm}$ subjected to 20 records scaled to an $E P A=0.4 g$.

Figure 7.5. Percentage of (a) hysteretic energy $E_{h}$, (b) input energy $E_{i r}$, and (c) story shear $Q$ distributed in the stories of the 5-story building with fixed base, base isolation, supplemental damping, and semi-active control subjected to 20 records scaled to an $E P A=0.4 g$.

Figure 7.6. (a) Relative displacement, (b) ductility demand, (c) story shear, (d) $E_{h m} / E_{i r m}$, (e) $\left(E_{h} / E_{i r}\right)_{m}$, and (f) $E_{d m} / E_{i r m}$ for the five-story buildings: fixedbase, base-isolated, semi-active with large control force, and semi-active with small control force with $u_{y l}=0.5 \mathrm{~cm}$ and $\xi_{l}=5 \%$ subjected to the S00E component of El Centro, the Imperial Valley earthquake of May 18,1940 scaled to an $E P A=0.4 g$.

Figure 7.7. Drift time-histories for the first story of the buildings with fixed-base, base-isolation, supplemental damping, and semi-active control subjected to the S00E component of El Centro, the Imperial Valley, CA earthquake of May 18, 1940 scaled to an $E P A=0.4 g$. 
Figure 7.8. Total input energy time-histories for the five-story buildings with fixedbase, base-isolation, supplemental damping, and semi-active control subjected to the S00E component of El Centro, the Imperial Valley, CA

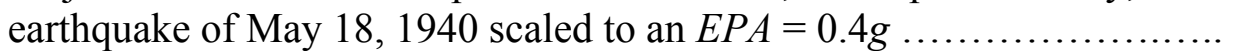

Figure A.1. Single degree of freedom system used for Bouc-Wen model 


\section{INTRODUCTION}

The current seismic design practice which is based on strength principles (using the acceleration spectra) does not directly account for the influence of the duration of strong motion nor for the hysteretic behavior of the structure. The hysteretic behavior is addressed indirectly by using the response modification factor $R$ which is based primarily on the structural system selected. A design approach based on energy (Vision 2000), on the other hand, has the potential to address the effects of the duration and hysteretic behavior directly.

The earthquake input energy transmitted to a structure consists of the kinetic energy, elastic strain energy, damping energy, and hysteretic energy. Kinetic energy reflects the work of the inertia force. Elastic strain energy is the portion of the input energy stored in the structure in the form of elastic strain. Damping energy is the work of the damping force. Hysteretic energy is the energy dissipated through the hysteretic action and is associated with the damage potential of the structure (Kuwamura and Galambos, 1989).

Input energy reflects the intensity of earthquake ground motion. It is a more appropiate measure of the intensity than the peak ground acceleration or the effective peak acceleration defined by ATC 3-06 (1978) as

$$
E P A=\bar{S}_{a} / 2.5
$$

where $\bar{S}_{a}$ is the average spectral acceleration in the constant acceleration region, or the Spectrum Intensity defined by Housner (1975) as

$$
S I=\int_{0.1}^{2.5} P S V d T_{n}
$$

where PSV is the pseudo spectral velocity and $T_{n}$ denotes the period of structure in seconds. Earthquake input energy accounts for both the ground motion characteristics (frequency content, intensity, and duration of strong motion) and structural properties (ductility, damping, period, and hysteretic behavior), whereas $P G A, E P A$, and SI account for some but not all these characteristics.

A design approach based on energy reflects the distribution of input energy and is suited for seismic design of structures with base isolation system and/or supplemental damping devices. In an energy-based design approach, once the energy demand for a structure is estimated from the earthquake ground motion, the damage potential can be quantified by a combination of response and energy parameters (see Park and Ang, 1985). Sufficient strength and energy dissipation capacity should be provided in the structure for an acceptable damage threshold, i.e. a desired performance objective. 
In seismic design of structures, the strength demand is defined by the story shear and the energy demand should be defined by the hysteretic energy for each story. While the strength and energy dissipation capacities can be increased by using members with larger area and section modulus or by using materials with greater yield strength, the energy dissipation capacity can be increased by using ductile structural systems such as the eccentrically braced frames (EBF) instead of concentrically braced frames (CBF), see Newmark and Rosenbluth 1971. The energy dissipation capacity for moment resisting frames can be increased by providing special detailing in steel and reinforced concrete buildings (refer to IBC 2000). Computing the energy dissipation capacity of various structural members is not within the scope of this report (one should refer to Uang and Bertero, 1990). Only the energy demand is addressed herein.

This report examines the influences of ground motion characteristics and structural properties on earthquake input energy and its distribution among energy components for a one- and a five-story building using 20 accelerograms, ten with short and ten with long duration of strong motion. A summary of previous research on this subject is presented in Chapter 2. Chapter 3 presents the energy balance equation and the energy timehistories for an SDOF structure. Chapter 4 examines the existing procedures for computing the earthquake input energy, and how ground motion characteristics and structural properties influence the input energy. In Chapter 5, the relationship between the hysteretic energy and damage potential is examined. The distribution of story shear and energy in a 5-story building without control devices, with base isolation system, with supplemental damping devices, and with semi-active control are presented in Chapters 6 and 7. Finally, the conclusions are discussed in Chapter 8. 


\section{SUMMARY OF PREVIOUS RESEARCH}

McKevitte et al. (1980) computed the input energy, hysteretic energy, and the ratio of the cumulative hysteretic energy to input energy for SDOF and MDOF structures (three- and ten-story) with different structural properties subjected to four earthquake records (El Centro 1940, Taft 1952, Parkville 1956, and Pacoima Dam 1971). They concluded that the energy dissipated through inelastic deformation depends on the force-deformation characteristics, yield strength, and damping. They observed that the percentage of input energy dissipated by the hysteretic action was approximately the same for different records. McKevitte et al. concluded that the ratio of the maximum hysteretic energy to the maximum input energy for an MDOF structure can be estimated from an SDOF structure with the same fundamental period, yield strength, and damping.

Zahrah and Hall (1984) computed the input energy for eight earthquake records and proposed an equivalent number of yield excursions to quantify the earthquake damage potential. They observed that ductility, damping, and the post- to pre-yield stiffness ratios have small effects on the input and hysteretic energies for a structure with bilinear behavior. They stated that the equivalent number of yield excursions may be different for different accelerograms.

Akiyama (1985) compared the input energy from the Fourier Spectra of ground acceleration for a five-story building with different structural properties, and for an equivalent one-story building having the same fundamental period, total mass, and yield strength using the S00E component of the 1940 El Centro record. He showed that the total input energy transmitted to a five-story building can be computed from the input energy transmitted to the equivalent one-story building with the same fundamental period, damping, and yield strength.

Nakashima et al. (1996) investigated the effect of large post- to pre-yield stiffness ratios (up to 0.75 ) for bilinear SDOF and MDOF structures $(5,10,13,15,17$, and 20 story) subjected to three long duration records (El Centro 1940, Taft 1952, and Miyagiken-oki 1978). They concluded that in general, large post- to pre-yield stiffness ratios have a minor effect on the input energy; however, as the post- to pre-yield stiffness ratio increases, the input energy spectra increase in the vicinity of the predominant period. They also concluded that the energy transmitted to an MDOF structure can be computed from the input energy transmitted to an equivalent SDOF structure.

Rahnama and Manuel (1996) computed the input energy, the hysteretic energy, and the ratio of the cumulative hysteretic energy to input energy for ductility ratios of 2 and 6 with 5\% damping for six sets of 19 accelerograms each: actual records, simulated records with the same duration as the actual records, and four sets of simulated records with durations of $5,10,15$, and $20 \mathrm{~s}$. They concluded that as the duration increases, the input and hysteretic energies increase. The duration, however, does not influence the ratio of cumulative hysteretic energy to input energy. 
Goel (1997) investigated the distribution of energy in asymmetric structures. $\mathrm{He}$ concluded that the input energy transmitted to a symmetric or to an asymmetric one-story building is approximately the same. He also showed that in an asymmetric building the hysteretic energy demand is larger for flexible elements, whereas it is approximately the same for stiff elements. 


\section{EARTHQUAKE INPUT ENERGY}

Uang and Bertero (1990) proposed two procedures for computing the earthquake input energy: one based on the absolute motion and the other on relative motion. The difference between the two procedures is less important in damage assessment since the hysteretic energy, which is associated with the damage potential of structures, is independent of the approach used. Chopra (1995), and Bruneau and Wang (1996) believe that the input energy in terms of the relative motion is more meaningful than the input energy in terms of the absolute motion since internal forces within a structure are computed using relative displacements and velocities. Therefore, the procedure based on the relative displacement is used herein.

\subsection{Energy Balance Equation}

The energy balance equation for an SDOF structure can be written as (Uang and Bertero 1990)

$$
\int_{0}^{t} m \ddot{u} \dot{u} d \tau+\int_{0}^{t} c \dot{u}^{2} d \tau+\int_{0}^{t} f_{s} \dot{u} d \tau=-\int_{0}^{t} m \ddot{u}_{g} \dot{u} d \tau
$$

where $m$ is mass of the structure, $c$ is the damping coefficient, $f_{s}$ is the restoring force, $u$ is the relative displacement of the mass with respect to ground, $\dot{u}$ is the velocity of the mass with respect to ground, $\ddot{u}$ is the acceleration of the mass with respect to ground, $\ddot{u}_{g}$ denotes the ground acceleration, and $t$ is time. The energy balance equation (3.1) can be written as

$$
E_{k r}+E_{d}+E_{a}=E_{i r}
$$

where $E_{k r}$ is the relative kinetic energy, $E_{d}$ is the damping energy, $E_{a}$ is the absorbed energy, and $E_{i r}$ denotes the relative input energy such that

$$
\begin{aligned}
& E_{k r}=1 / 2 m \dot{u}^{2} \\
& E_{d}=\int_{0}^{t} c \dot{u}^{2} d t \\
& E_{a}=\int_{0}^{t} f_{s} \dot{u} d \tau \\
& E_{i r}=-\int_{0}^{t} m \ddot{u}_{g} \dot{u} d \tau
\end{aligned}
$$


The absorbed energy consists of the recoverable elastic strain energy $E_{s}$ and the irrecoverable hysteretic energy $E_{h}$ where

$$
\begin{aligned}
& E_{s}=f_{s}^{2} / 2 k \\
& E_{h}=E_{a}-E_{s}
\end{aligned}
$$

in which $k$ is the pre-yield stiffness of the structure.

Figure 3.1 shows the energy time-histories for a bilinear SDOF structure with a pre-yield period $T_{n}=0.5 s$, a ductility ratio $\mu=3$, a pre-yield damping ratio $\xi=5 \%$, and a post- to pre-yield stiffness ratio $\alpha=0.02$ subjected to the S00E component of El Centro, the Imperial Valley, California earthquake of May 18, 1940. The Bouc-Wen model (Bouc, 1967; Wen, 1976) is used to characterize the nonlinear behavior of the structure, see Appendix A. Parameters used for characterizing the bilinear behavior with Bouc-Wen model are: $A=1, \beta=\gamma=0.5, n=20$, and $\alpha=0.02$. To overcome the problem associated with the non-zero initial conditions of the records, particularly in non-linear analyses (see Pecknold and Riddell, 1978), a one-second acceleration pulse is added to the beginning of the accelerogram.

Figure 3.1 shows that the maximum kinetic and elastic strain energies occur in the initial stages of the excitation, whereas the maximum damping, hysteretic, and input energies occur at the end of the excitation. Therefore, the duration of strong motion significantly affects the maximum damping energy, the maximum hysteretic energy, and the maximum input energies, but not the maximum kinetic energy and the maximum elastic strain energy.

\subsection{Energy Ratio Time-Histories}

Figure 3.2 shows the time-histories of the ratio of energy components to input energy for a bilinear SDOF structure with a pre-yield period $T_{n}=0.5 \mathrm{~s}$, a ductility ratio $\mu=3$, and a $5 \%$ pre-yield damping ratio subjected to the S00E component of the $1940 \mathrm{El}$ Centro accelerogram. The figure indicates that the time-histories of the $E_{k r} / E_{i r}$ and $E_{s} / E_{i r}$ ratios are similar and have large oscillations during the linear portion of the response. The peak $E_{k r} / E_{i r}$ and $E_{S} / E_{i r}$ ratios decay rapidly as the structure experiences nonlinear deformation because a significant portion of the input energy is distributed among hysteretic and damping energies rather than kinetic and elastic strain energies. The maximum $E_{h} / E_{i r}$ ratio occurs during the largest yield excursion where approximately $45 \%$ of the maximum hysteretic energy $E_{h m}$ is dissipated, see Figure 3.3. The hysteretic energy dissipated in the second yield excursion is $32 \%$ of $E_{h m}$.

Figures 3.2 and 3.3 indicate that the maximum ratio of the hysteretic to input energy $\left(E_{h} / E_{i r}\right)_{m}$ and the ratio of the maximum hysteretic energy to the maximum input energy $E_{h m} / E_{i r m}$ are different, i.e. $\left(E_{h} / E_{i r}\right)_{m}=77 \%$ and $E_{h m} / E_{i r m}=55 \%$. The $\left(E_{h} / E_{i r}\right)_{m}$ ratio reflects 


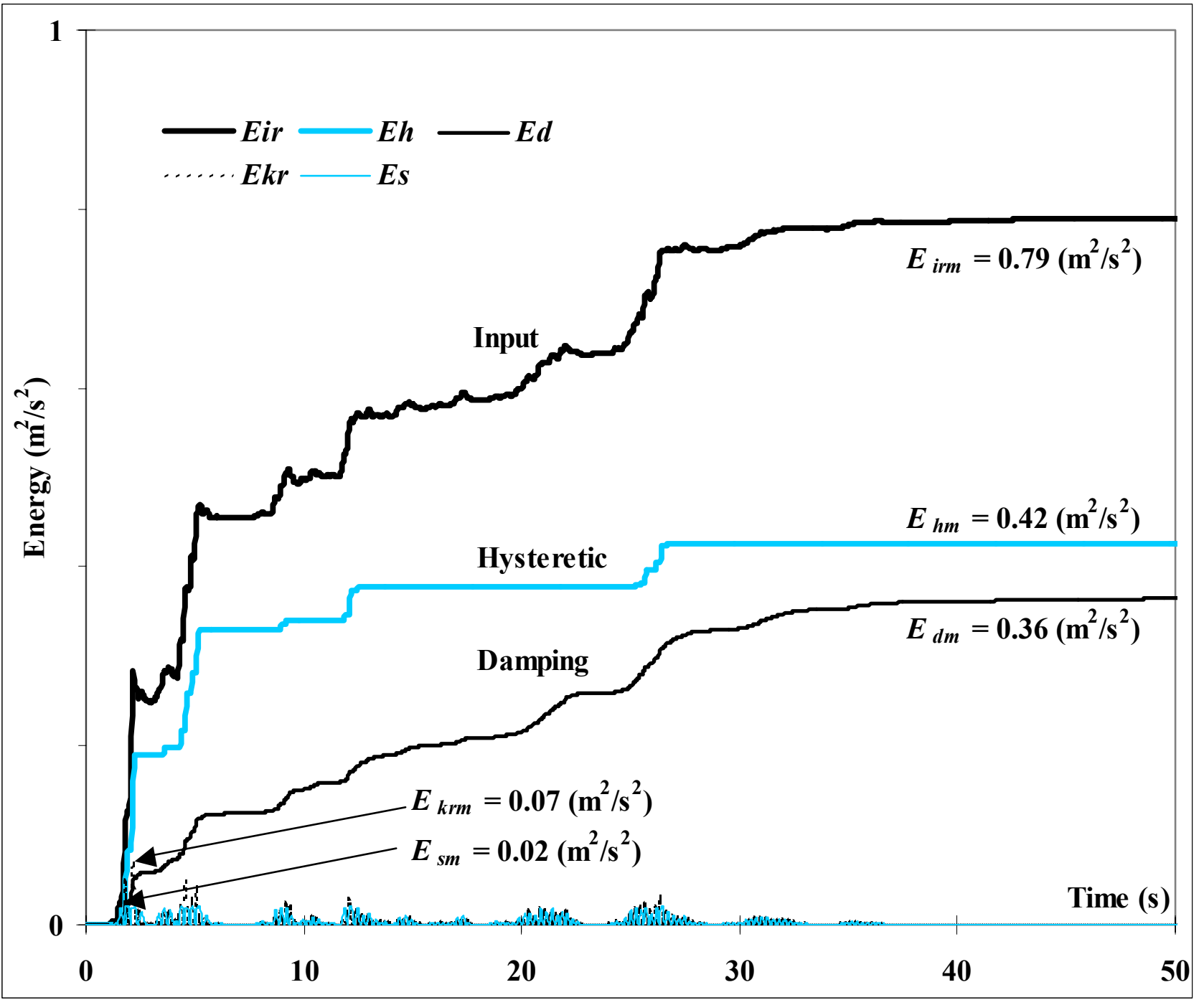

Figure 3.1. Energy time-histories for a bilinear SDOF structure with $T_{n}=0.5 \mathrm{~s}, \mu=3, \alpha=0.02$, and $\xi=5 \%$ subjected to the S00E component of El Centro, the Imperial Valley, CA earthquake of May 18,1940 


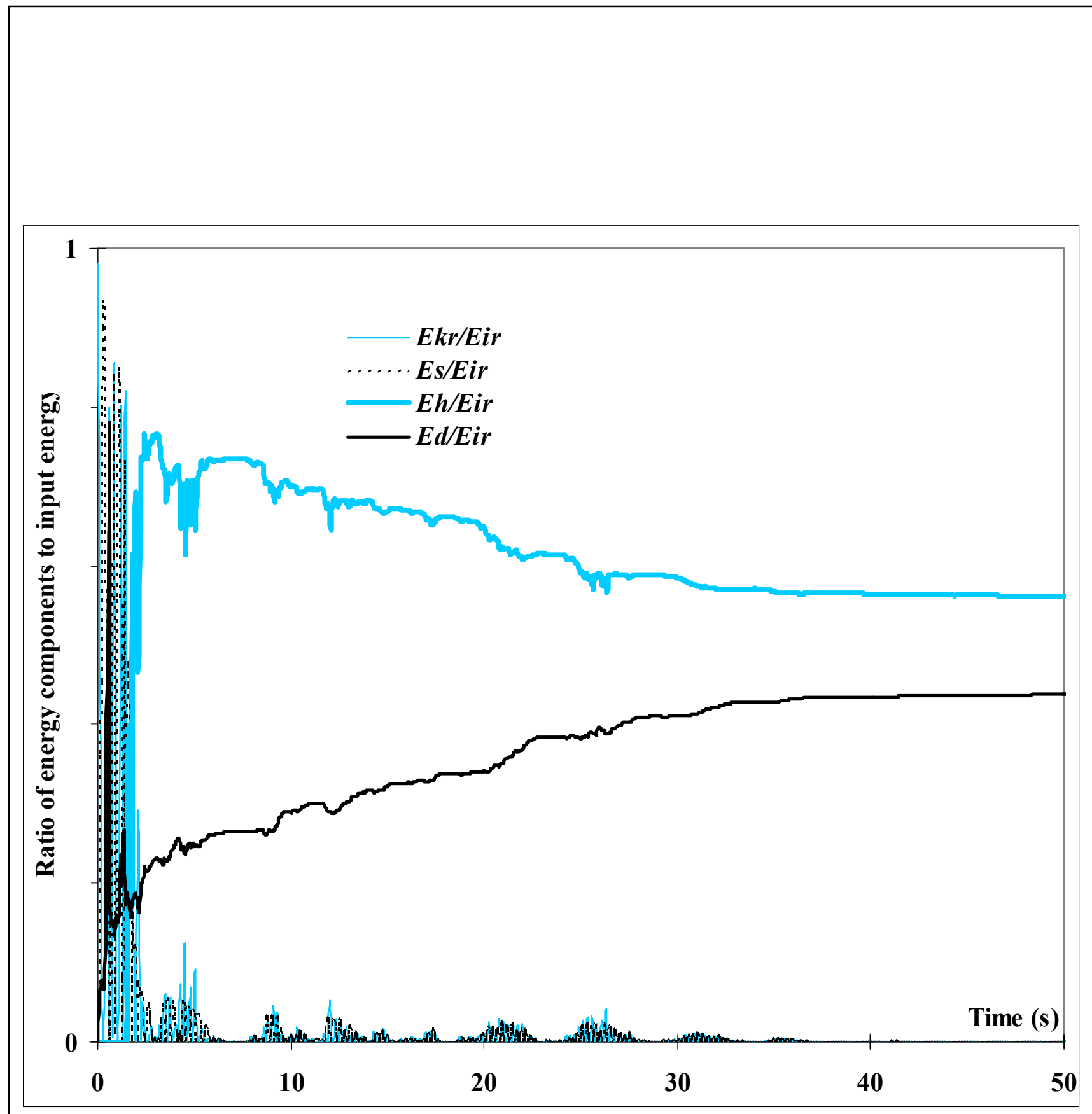

Figure 3.2. Time-histories of the ratio of energy components to relative input energy for a bilinear SDOF structure with $T_{n}=0.5 \mathrm{~s}$, a ductility ratio $\mu=3$, and $5 \%$ damping subjected to the S00E component of El Centro, the Imperial Valley, CA earthquake of May 18, 1940. Parameters for BoucWen Model are $A=1, \beta=\gamma=0.5, n=20, \alpha=0.02$ 


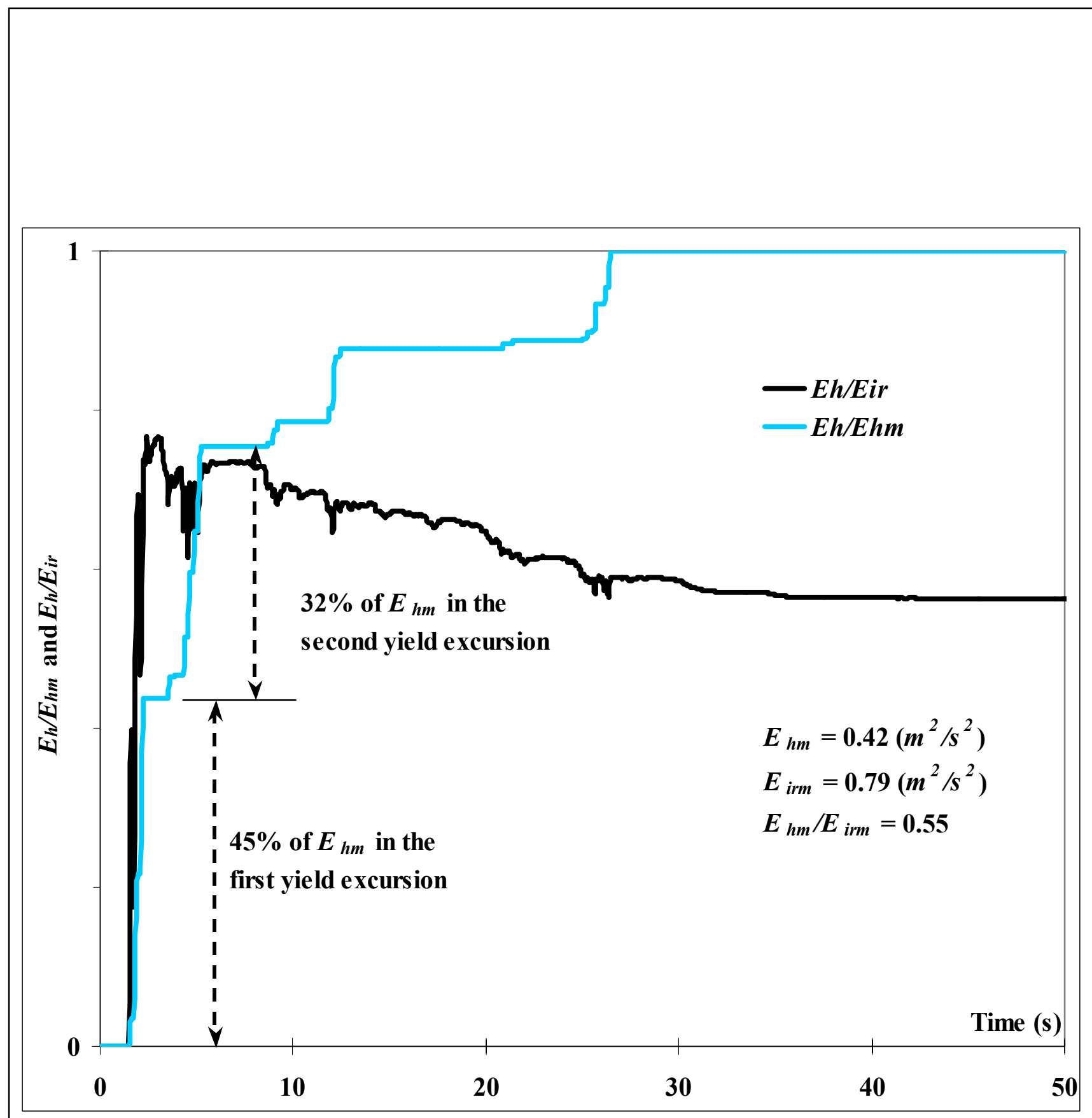

Figure 3.3. Time-histories of $E_{h} / E_{h m}$ and $E_{h} / E_{i r}$ for a bilinear SDOF structure with $T_{n}=0.5 \mathrm{~s}$, a ductility ratio $\mu=3$, and $5 \%$ damping subjected to the S00E component of El Centro, the Imperial Valley, CA earthquake of May 18, 1940. Parameters for Bouc-Wen Model are $A=1, \beta=\gamma=0.5, n=$ 20, $\alpha=\mathbf{0 . 0 2}$ 
the damage potential associated with the largest yield excursion, and the $E_{h m} / E_{i r m}$ ratio reflects the damage potential associated with the total number of yield excursions during the excitation. The differences of the two ratios are examined in Chapter 5.

In the 1994 Northridge earthquake, more than 150 buildings with steel moment resisting frames experienced brittle fracture at the welded connections, and in some cases damage occurred during the first few seconds of the excitation (SAC 95-06). Damage experienced in the initial stages of the excitation may have been caused by the insufficient energy dissipation capacity during the largest yield excursion (usually the first two yield excursions). Hence, in developing a damage index, both the damage potential for the largest yield excursion and for the entire record should be addressed. Although proposing a damage index is not within the scope of this report (refer to Park and Ang, 1985), the relationship between the hysteretic energy and damage potential is discussed in Chapter 5. 


\section{ESTIMATING THE EARTHQUAKE INPUT ENERGY}

In an energy-based seismic design, one needs to estimate the input energy in a structure and distribute it to various structural components. For an acceptable damage level, vision 2000 (SEAOC 1995) and Park et al. (1987) recommend estimating the strength and hysteretic energy demands and providing sufficient strength and energy dissipation capacity to withstand the design ground motion.

This Chapter presents: 1) the existing methods for computing the earthquake input energy, 2) the influence of ground motion characteristics on the input energy, and 3) the influence of structural properties on input energy.

\subsection{Existing Procedures for Computing Input Energy}

Housner (1956) computed the input energy per unit mass as

$$
\frac{E_{i}}{m}=1 / 2(P S V)^{2}
$$

where $m$ is the mass and PSV denotes the pseudo-spectral velocity. He used equation (4.1) for elastic and inelastic behavior.

Zahrah and Hall (1984) computed the input energy per unit mass as

$$
\frac{E_{i}}{m}=-\int_{0}^{t} \ddot{u}_{g} \dot{u} d \tau
$$

which is the same as equation (3.6).

Akiyama (1985) proposed the input energy per unit mass for an elastic SDOF structure as

$$
\frac{E_{i}}{m}=1 / 2\left(V_{E}\right)^{2}
$$

where $V_{E}$ is an equivalent velocity. He recommended the following values for $V_{E}$ (in $m / s)$ :

$$
\begin{array}{ll}
V_{E}=2.5 T_{n} & \text { for } T_{n} \leq T_{G} \\
V_{E}=2.5 T_{G} & \text { for } T_{n} \geq T_{G}
\end{array}
$$


where $T_{G}$ is the predominant period of ground motion as a function of soil type. The values of $T_{G}$ are $0.4,0.6,0.8$, and $1.0 \mathrm{~s}$ for soil types I (bed rock), II, III, and IV (softest soil), respectively.

Kuwamura and Galambos (1989) used the equation proposed by Akiyama (equation 4.3) and recommended the following values for $V_{E}$

$$
\begin{array}{ll}
V_{E}=\frac{1}{2} \sqrt{\frac{I_{E}}{T_{G}}} T & \text { for } T \leq T_{G} \\
V_{E}=\frac{1}{2} \sqrt{T_{G} I_{E}} & \text { for } T \geq T_{G}
\end{array}
$$

where $I_{E}$ is the integral of the square of the ground acceleration for the total duration of accelerogram $t_{f}$

$$
I_{E}=\int_{0}^{t_{f}} \ddot{u}_{g}^{2} d t
$$

Using 40 accelerograms Fajfar et al. (1989) computed the earthquake input energy for the intermediate-periods (constant-velocity region) with 5\% damping and strength ratios $\eta=$ $0.5-1.0$, where $\eta$ is the ratio of yield force $Q_{y}$ to $m P G A$, where $P G A$ is the peak ground acceleration. They recommended to compute the input energy per unit mass as

$$
\frac{E_{i}}{m}=2.2\left(t_{d i}\right)^{0.5}(P G V)^{2}
$$

in which $t_{d i}$ is the duration of strong motion defined by Trifunac and Brady (1975), and $P G V$ is the peak ground velocity. They did not propose any formula for short and long periods, i.e. in the constant-acceleration and constant-displacement regions.

As stated previously, Uang and Bertero (1990) proposed two procedures for computing the input energy per unit mass: one based on the absolute motion given by

$$
\frac{E_{i a}}{m}=\int_{0}^{t} \ddot{u}_{t} \dot{u}_{g} d \tau
$$

where $\ddot{u}_{t}$ denotes the total acceleration $\left(\ddot{u}_{t}=\ddot{u}+\ddot{u}_{g}\right)$, and the other based on relative motion given by

$$
\frac{E_{i r}}{m}=-\int_{0}^{t} \ddot{u}_{g} \dot{u} d \tau
$$


Using five accelerograms (El Centro 1940, Taft 1952, Pacoima Dam 1971, Mexico City 1985, and San Salvador 1986) they proposed the input energy for an SDOF structure with a ductility ratio $\mu=5$ and a $5 \%$ damping ratio be computed from

$$
\frac{E_{i a}}{m}=\frac{1}{2}\left(1+0.12 t_{d i}\right)^{2}(P G V)^{2}
$$

Kuwamura et al. (1993) computed the equivalent velocity $V_{E}$ in equation (4.3) as

$$
V_{E}=\sqrt{-2 \int_{0}^{t_{f}} \ddot{u}_{g} \dot{u} d t}
$$

It should be noted that the energy expression under the square root sign is always positive. Using a different set of five accelerograms (El Centro 1940, Parkfield 1966, Hachinohe 1968, Pacoima Dam 1971, and SCT-Mexico 1985) they showed that for an undamped elastic structure, the equivalent velocity $V_{E}$ in equation (4.11) can be estimated by smoothing $1 / 2(F S)^{2}$, where $F S$ is the Fourier spectra given by

$$
V_{E}=F S(\omega)=\sqrt{\left[\int_{0}^{t_{f}} \ddot{u}_{g} \operatorname{Cos} \omega t d t\right]^{2}+\left[\int_{0}^{t_{f}} \ddot{u}_{g} \operatorname{Sin} \omega t d t\right]^{2}}
$$

in which $\omega$ is the circular frequency. Equation (4.11) used by Kuwamura and Galambos (1989), and equation (4.2) used by Zahrah and Hall (1984) are based on relative motion, see equation (4.9).

Finally, Manfredi (2001) using 244 accelerograms examined the relation among the following three parameters:

1) the equivalent number of yield excursions $N_{e q}$ defined by Zahrah and Hall (1984) as

$$
N_{e q}=\frac{E_{h m}}{F_{y}\left(u_{m}-u_{y}\right)}=\frac{E_{h m}}{F_{y} u_{y}(\mu-1)}=\frac{E_{h m}}{k u_{y}{ }^{2}(\mu-1)}
$$

where $u_{m}$ and $u_{y}$ are the maximum and yield deformations, respectively, and $\mu=u_{m} / u_{y}$ is the ductility ratio ${ }^{\mathrm{a}}$,

2) the response modification factor $R$, and

3) the dimensionless seismic index $I_{d}$ given by

$$
I_{d}=\frac{I_{E}}{(P G A)(P G V)}
$$

${ }^{\text {a }}$ According to Zahrah and Hall (1984) the minimum value of $N_{\text {eq }}$ is 1.0 . 
where $I_{E}$ is given by equation (4.6). For ductility ratios greater than 2, Manfredi proposed to estimate the input energy spectra in the constant-velocity region by

$$
\frac{E_{i}}{m}=0.45\left(\frac{1}{\sqrt{\mu-1}}+0.23 I_{d}\right)(P S V)^{2}
$$

where $\mu$ is the ductility ratio, and $P S V$ denotes the pseudo-spectral velocity. Equations (4.6, 4.14, and 4.15) show that as the duration of strong motion increases, the input energy also increases. Equation (4.15) is similar to equation (4.1) where the term in the parentheses reflects the influence of the duration of strong motion. Equation (4.15) also shows that as the ductility increases, the input energy decreases.

\subsection{The Influence of Ground Motion Characteristics on Energy Spectra}

The influences of the earthquake intensity, the duration of strong motion, and the frequency content on earthquake input energy are examined using 10 accelerogrmas with short duration $\left(t_{d i}\right.$ shorter than $\left.8 \mathrm{~s}\right)$ and 10 with long duration $\left(t_{d i}\right.$ longer than $\left.18 \mathrm{~s}\right)$ of strong motion, see Table 4.1. The duration $t_{d i}$ is computed using the definition proposed by Trifunac and Brady (1975), known as the intensity-based duration. They defined the duration as the time interval between the five and ninety-five percent contributions to the integral of the square of ground acceleration, see equation (4.6).

Figure 4.1 shows the relative input energy spectra for a ductility ratio of 3 and a $5 \%$ damping ratio for the S00E component of El Centro with effective peak accelerations $E P A=0.3 g, 0.4 g$, and $0.6 g$, where $E P A$ is the average of the acceleration spectra in the constant-acceleration region divided by 2.5 (ATC 3-06, 1978), see equation (1.1). According to the figure, as the effective peak acceleration increases, the input energy increases; indicating that the input energy is related to the intensity of ground motion. The energy ratios such as the maximum hysteretic energy to the maximum input energy $E_{h m} / E_{\text {irm }}$ (see Figure 4.2) are not affected by EPA; indicating that the scaling of accelerograms does not influence the distribution of the earthquake input energy among the various energy components.

Figure 4.3 presents the relative input and hysteretic energy spectra for the N65W component of Temblor $\left(t_{d i}=6 s\right)$ and the S69E component of Taft $\left(t_{d i}=29 s\right)$ accelerograms scaled to an $E P A=0.4 g$ for $\mu=1,3$, and 5, and a 5\% damping ratio. Both accelerograms have the same predominant period $T_{p e}=0.44 \mathrm{~s}$, but the duration of strong motion for the Taft accelerogram is approximately 5 times longer than the duration for the Temblor accelerogram. Figure 4.3.a shows that ductility has a minor effect on the input and hysteretic energies for both Taft and Temblor accelerograms. Figure 4.3 indicates that on the average for $\mu=1,3$, and 5, the energy spectra for the Taft accelerogram is approximately 8 times larger than the energy spectra for Temblor. The hysteretic energy demand for the Taft accelerogram is approximately 5 and 6 times larger 
Table 4.1. Strong motion records used in the analysis

\begin{tabular}{|c|c|c|c|c|c|c|c|c|c|c|c|}
\hline 1 & 2 & 3 & 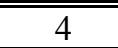 & $\overline{5}$ & 6 & 7 & 8 & 9 & 10 & 11 & 12 \\
\hline No & $\begin{array}{c}\text { Earthquake } \\
\text { Date }\end{array}$ & Station & Comp. & $M_{L}$ & $\begin{array}{c}P G A \\
(\mathrm{~g})\end{array}$ & $\begin{array}{l}P G V \\
(\mathrm{~cm} / \mathrm{s})\end{array}$ & $\begin{array}{l}t_{d i} \\
(\mathrm{~s})_{1}\end{array}$ & $\begin{array}{l}T_{p a} \\
(\mathrm{~s})_{2}\end{array}$ & $\begin{array}{l}T_{p e} \\
(\mathrm{~s})_{2}\end{array}$ & $\begin{array}{l}\text { Dis. } \\
(\mathrm{km})\end{array}$ & Geology \\
\hline \multicolumn{12}{|c|}{ Records with short strong motion duration } \\
\hline 1 & $\begin{array}{c}\text { Northridge, CA } \\
\text { Jan } 17,1994\end{array}$ & $\begin{array}{l}\text { Pacoima Dam } \\
\text { Down Stream }\end{array}$ & $175^{\circ}$ & 6.6 & 0.415 & 44.7 & 4 & 0.40 & 0.46 & 19.3 & Highly jointed diorite gneiss \\
\hline 2 & $\begin{array}{c}\text { Northridge, CA } \\
\text { Jan } 17,1994\end{array}$ & $\begin{array}{l}\text { Pacoima Dam } \\
\text { Down Stream }\end{array}$ & $265^{\circ}$ & 6.6 & 0.434 & 30.6 & 4 & 0.38 & 0.52 & 19.3 & $\ll$ \\
\hline 3 & $\begin{array}{c}\text { Northridge, CA } \\
\text { Jan } 17,1994\end{array}$ & $\begin{array}{c}\text { Sylmar County } \\
\text { Hospital Parking lot }\end{array}$ & $90^{\circ}$ & 6.6 & 0.604 & 76.9 & 7 & 0.52 & 2.28 & 15.8 & Alluvium \\
\hline 4 & $\begin{array}{c}\text { Northridge, CA } \\
\text { Jan } 17,1994\end{array}$ & $\begin{array}{c}\text { Sylmar County } \\
\text { Hospital Parking lot }\end{array}$ & $360^{\circ}$ & 6.4 & 0.843 & 128.9 & 5 & 0.36 & 1.56 & 15.8 & $\ll$ \\
\hline 5 & $\begin{array}{l}\text { Parkfield, CA } \\
\text { June 27, } 1966\end{array}$ & Temblor California & N65W & 6.0 & 0.269 & 14.5 & 6 & 0.26 & 0.44 & 43.9 & Alluvium over sandstone \\
\hline 6 & $\begin{array}{l}\text { Parkfield, CA } \\
\text { June } 27,1966\end{array}$ & Temblor California & $\mathrm{S} 25 \mathrm{~W}$ & 6.0 & 0.347 & 22.5 & 5 & 0.38 & 0.38 & 43.9 & $\ll$ \\
\hline 7 & $\begin{array}{c}\text { San Fernando, CA } \\
\text { Feb 9, } 1971\end{array}$ & Pacoima Dam & $\mathrm{S} 16 \mathrm{E}$ & 6.7 & 1.170 & 113.2 & 7 & 0.38 & 1.50 & 8.5 & Highly jointed diorite gneiss \\
\hline 8 & $\begin{array}{c}\text { San Fernando, CA } \\
\text { Feb 9, } 1971\end{array}$ & Pacoima Dam & S74W & 6.7 & 1.075 & 57.6 & 7 & 0.42 & 0.42 & 8.5 & $\ll$ \\
\hline 9 & $\begin{array}{c}\text { San Francisco,CA } \\
\text { Mar 22, } 1957\end{array}$ & Golden Gate Park & S80E & 5.3 & 0.104 & 4.6 & 3 & 0.22 & 0.24 & 11.5 & Rock \\
\hline 10 & $\begin{array}{c}\text { San Francisco,CA } \\
\text { Mar 22, } 1957\end{array}$ & Golden Gate Park & $\mathrm{N} 10 \mathrm{E}$ & 5.3 & 0.084 & 4.91 & 4 & 0.26 & 0.26 & 11.5 & $\ll$ \\
\hline
\end{tabular}


Table 4.1. Continued

\begin{tabular}{|c|c|c|c|c|c|c|c|c|c|c|c|}
\hline 1 & 2 & 3 & 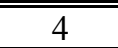 & $\overline{5}$ & 6 & 7 & 8 & 9 & 10 & 11 & 12 \\
\hline No & $\begin{array}{l}\text { Earthquake } \\
\text { Date }\end{array}$ & Station & Comp. & $M_{L}$ & $\begin{array}{c}P G A \\
(\mathrm{~g})\end{array}$ & $\begin{array}{l}P G V \\
(\mathrm{~cm} / \mathrm{s})\end{array}$ & $\begin{array}{l}t_{d i} \\
(\mathrm{~s})_{1}\end{array}$ & $\begin{array}{l}T_{p a} \\
(\mathrm{~s})_{2}\end{array}$ & $\begin{array}{l}T_{p e} \\
(\mathrm{~s})_{2}\end{array}$ & $\begin{array}{l}\text { Dis. } \\
(\mathrm{km})\end{array}$ & Geology \\
\hline \multicolumn{12}{|c|}{ Records with long strong motion duration } \\
\hline 11 & $\begin{array}{l}\text { Valparaiso, Chile } \\
\text { Mar 3,1985 }\end{array}$ & $\begin{array}{l}\text { Llolleo - basement } \\
\text { 1-story building }\end{array}$ & N10E & $7.8^{3}$ & 0.711 & 41.5 & 36 & 0.22 & 0.52 & N.A. & Sandstone, volcanic rock \\
\hline 12 & $\begin{array}{l}\text { Valparaiso, Chile } \\
\text { Mar 3,1985 }\end{array}$ & $\begin{array}{l}\text { Llolleo - basement } \\
\text { 1-story building }\end{array}$ & $100^{\circ}$ & $7.8^{3}$ & 0.445 & 23.3 & 41 & 0.14 & 0.42 & N.A. & $\ll$ \\
\hline 13 & $\begin{array}{c}\text { Imperial Valley, CA } \\
\text { May } 18,1940\end{array}$ & El Centro & S00E & 6.7 & 0.348 & 33.4 & 24 & 0.26 & 0.86 & 11.5 & $\begin{array}{c}\text { Alluvium more than several } \\
\text { thousand feet }\end{array}$ \\
\hline 14 & $\begin{array}{c}\text { Imperial Valley, CA } \\
\text { May } 18,1940\end{array}$ & El Centro & S90W & 6.7 & 0.214 & 36.9 & 25 & 0.48 & 2.14 & 11.5 & $\ll$ \\
\hline 15 & $\begin{array}{l}\text { Kern County, CA } \\
\text { July 21, } 1952\end{array}$ & $\begin{array}{c}\text { Taft, Lincoln School } \\
\text { Tunnel }\end{array}$ & S69E & 7.2 & 0.179 & 17.7 & 29 & 0.44 & 0.44 & 41.4 & $\begin{array}{l}40 \mathrm{ft} \text { alluvium over poorly } \\
\text { cemented sandstone }\end{array}$ \\
\hline 16 & $\begin{array}{l}\text { Landers, CA } \\
\text { June } 28,1992\end{array}$ & $\begin{array}{l}\text { Joshua Tree } \\
\text { Fire Station }\end{array}$ & $0^{\circ}$ & 7.3 & 0.273 & 28.1 & 31 & 0.42 & 1.18 & 13.7 & Alluvium \\
\hline 17 & $\begin{array}{l}\text { Landers, CA } \\
\text { June 28,1992 }\end{array}$ & $\begin{array}{l}\text { Joshua Tree } \\
\text { Fire Station }\end{array}$ & $90^{\circ}$ & 7.3 & 0.283 & 42.7 & 28 & 0.72 & 0.74 & 13.7 & $\ll$ \\
\hline 18 & $\begin{array}{c}\text { Michoacan, Mexico } \\
\text { Sep 19, } 1985\end{array}$ & $\begin{array}{l}\text { Mexico City } \\
\text { SCT }\end{array}$ & S00E & 8.5 & 0.100 & 38.7 & 71 & 2.04 & 2.06 & 350 & $\begin{array}{c}\text { Thick deposits of saturated } \\
\text { soft soils }\end{array}$ \\
\hline 19 & $\begin{array}{c}\text { Tabas, Iran } \\
\text { Sep 16, } 1978\end{array}$ & Tabas & $74^{\circ}$ & 7.4 & 0.879 & 97.8 & 18 & 0.24 & 0.88 & 1.2 & Stiff soil \\
\hline 20 & $\begin{array}{c}\text { Tabas, Iran } \\
\text { Sep } 16,1978\end{array}$ & Tabas & $344^{\circ}$ & 7.4 & 0.937 & 114.1 & 18 & 0.20 & 4.72 & 1.2 & Stiff soil \\
\hline
\end{tabular}

${ }^{1} t_{d i}$ is the duration of strong motion defined by Trifunac and Brady (1975).

${ }^{2} T_{p a}$ and $T_{p e}$ are the predominant periods based on the elastic acceleration and input energy spectra, see Figure 4.4.

${ }^{3}$ Surface magnitude $M_{s}$. 


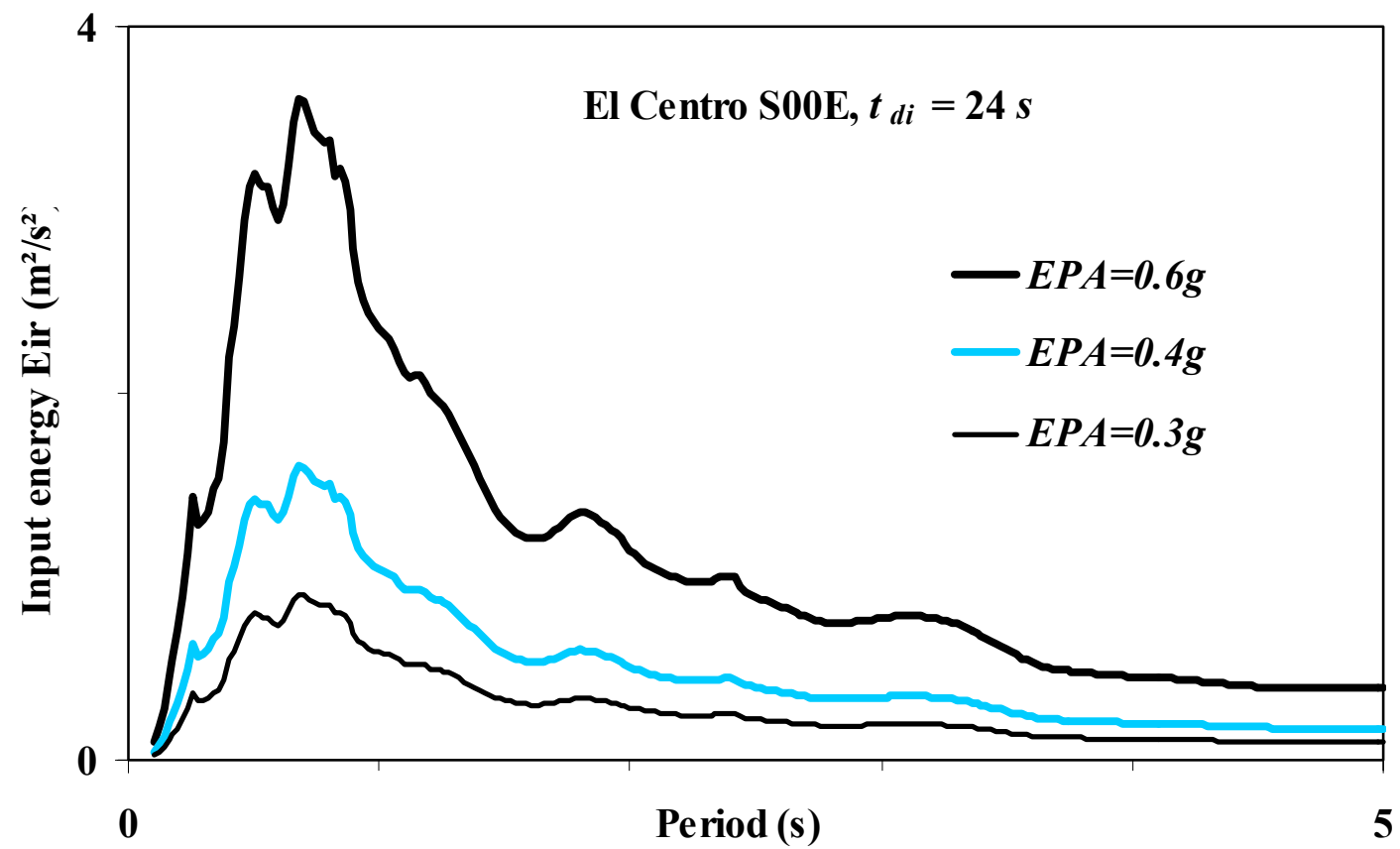

Figure 4.1. Relative input energy for ductility ratio $\mu=3$ and a damping ratio $\xi=5 \%$ for the S00E component of EI Centro, the Imperial Valley, CA earthquake of May 18, 1940 scaled to $E P A=0.3 g$, 0.4g, and 0.6g. Parameters for Bouc-Wen Model are $A=1, \beta=\gamma=0.5, n=20, \alpha=0.02$ 


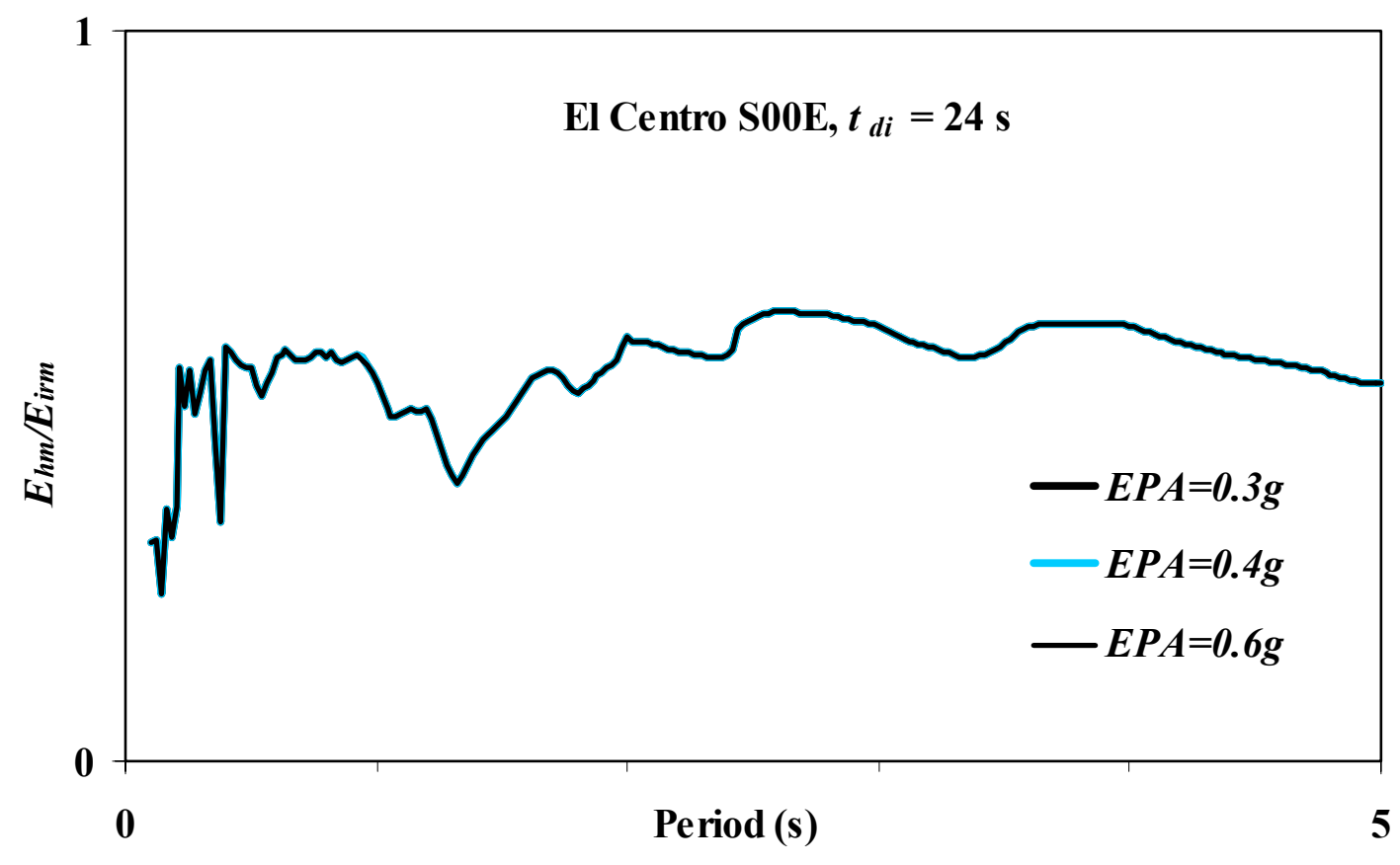

Figure 4.2. Ratio of the maximum hysteretic energy to the maximum input energy for ductility ratio $\mu=3$ and a damping ratio $\xi=5 \%$ for the S00E component of El Centro, the Imperial Valley, CA earthquake of May 18, 1940 scaled to $E P A=0.3 g, 0.4 g$, and $0.6 g$. Parameters for Bouc-Wen Model are $A=1, \beta=\gamma=0.5, n=20, \alpha=0.02$ 

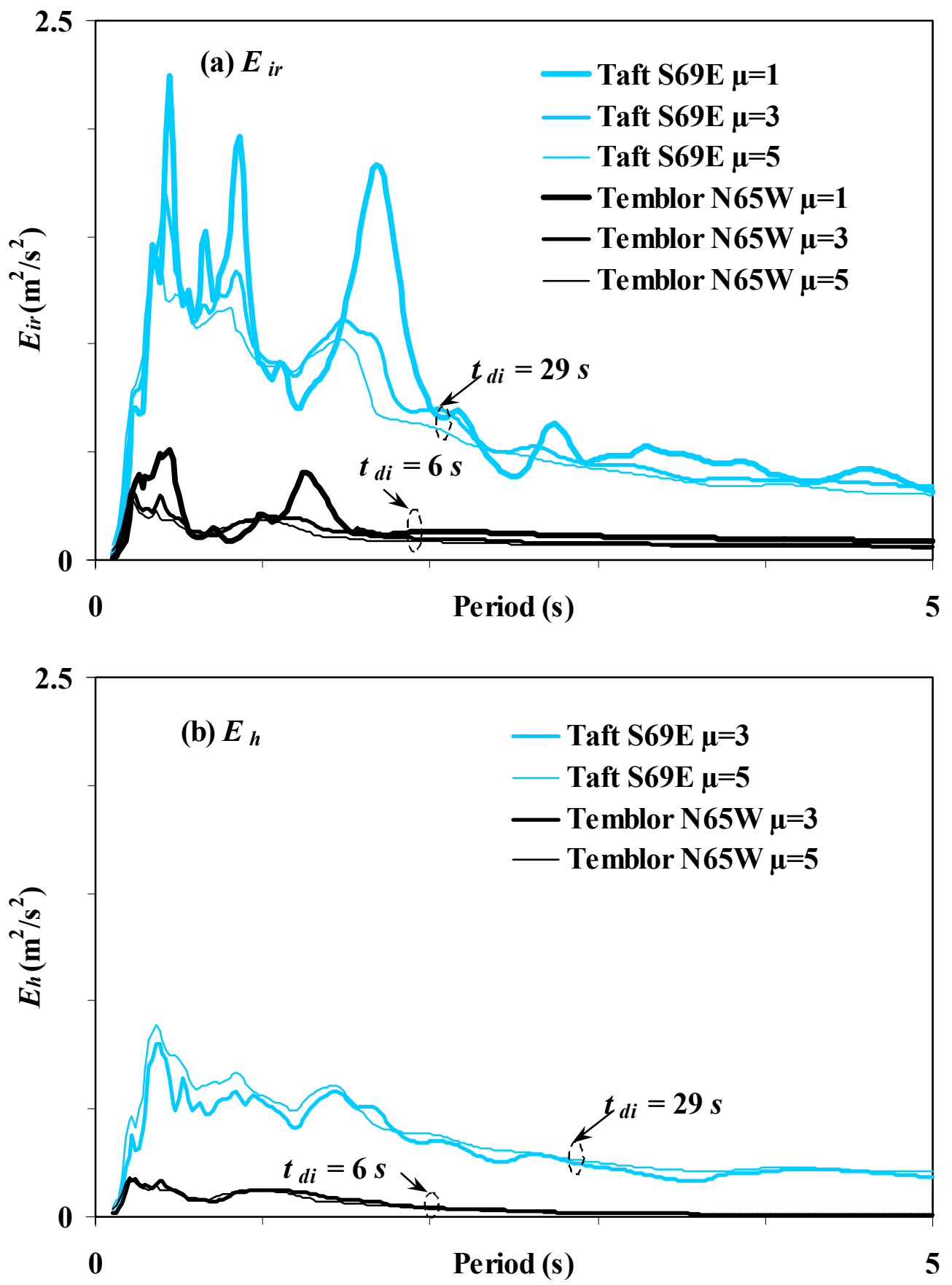

Figure 4.3. (a) Earthquake input energy $E_{i r}$ and (b) hysteretic energy $E_{h}$ for the N65W component of Temblor, Park-field, CA earthquake of June 27, $1966\left(t_{d i}=6 \mathrm{~s}\right)$ and the S69E component of Taft Lincoln School Tunnel, Kern County, CA earthquake of July 21, $1952\left(t_{d i}=29 \mathrm{~s}\right)$ for $\mu=1,3$, and 5, and a damping ratio $\xi=5 \%$ scaled to an $E P A=0.4 g$. Both accelerograms have the same predominant period $T_{p e}=0.44 \mathrm{~s}$. Parameters for Bouc-Wen Model are: $A=1, \beta=\gamma=0.5, n=20$, and $\alpha=0.02$. The hysteretic energy for $\mu=1$ is not shown in Figure 4.3.b since it is null. 
than the hysteretic energy demand for the Temblor accelerogram for $\mu=3$ and 5 , respectively. Figure 4.3.b indicates that as the duration of strong motion increases, the hysteretic energy demand also increases.

For the 20 accelerograms used, the predominant periods $T_{p e}$ computed from the input energy spectra are larger than $T_{p a}$ computed from the acceleration spectra, see columns 9 and 10 of Table 4.1. Predominant periods $T_{p a}$ and $T_{p e}$ primarily depend on the soil conditions. The average $T_{p e} / T_{p a}$ ratio for the twenty accelerograms is 3.3 . Figure 4.4 shows the normalized acceleration and input energy spectra for three accelerograms with short duration of strong motion (Figures 4.4.a - 4.4.c), and three accelerograms with long duration (Figures 4.4.d-4.4.f). Since $T_{p a}$ is generally different from $T_{p e}$, the strength and energy demands do not necessarily occur at the same period. Therefore, both strength and energy demands should be examined in design.

Figure 4.5 shows the elastic input energy spectra for the $90^{\circ}$ component of Sylmar and the $\mathrm{S} 16 \mathrm{E}$ component of Pacoima Dam records scaled to an $E P A=0.4 g$. Both accelerograms have the same duration of strong motion $\left(t_{d i}=7 \mathrm{~s}\right)$. The bracketed duration of the scaled accelerograms are also close $\left(t_{d b}=12 \mathrm{~s}\right.$ for Sylmar accelerogram and $t_{d b}=11 \mathrm{~s}$ for Pacoima Dam accelerogram). Figure 4.5 indicates that frequency content has a significant influence on input energy spectra, even for the same intensity and duration of strong motion. Figures $4.2-4.5$ conclude that for a given effective peak acceleration the influence of the duration of strong motion on the input energy is as significant as the influence of the frequency content.

\subsection{The Influence of Structural Properties on Energy Spectra}

McKevitt et al. (1980), Zahrah and Hall (1984), Akiyama (1985), and Nakashima et al. (1996) believe that ductility and damping do not have a significant influence on the earthquake input energy. It should be noted that these studies used 4, 8, 1, and 3 accelerograms, respectively. Housner (1956), and Berg and Thomaides (1966) believe that in designing a structure to satisfy the energy demand, the elastic input energy computed from $1 / 2 m(P S V)^{2}$ can be used conservatively in lieu of inelastic input energy. Kato and Akiyama (1982), and Leelataviwat et al. (1999) used Housner's recommendation, equation (4.1), to develop an energy-based design method for steel buildings. This section examines the influences of structural properties on the energy spectra.

Figures 4.6.a - 4.6.c and 4.6.d - 4.6.f show the relative input energy $E_{i r}$, equation (4.9), for three accelerograms with short and three accelerograms with long duration of strong motion for ductility ratios $\mu=1,2,3$, and 5 , and a damping ratio $\xi=5 \%$. It is observed that ductility has a significant influence on the magnitude and frequency content of the input energy spectra for the 1994 Sylmar, 1971 Pacoima Dam, and 1985 Mexico City accelerograms (Figures 4.6.a, 4.6.c, and 4.6.f), particularly in the vicinity of the predominant periods $T_{p e}$ (definition of $T_{p e}$ is illustrated in Figure 4.4). Although the elastic input energy $E_{i r}$ does not provide a conservative estimate of the inelastic input 

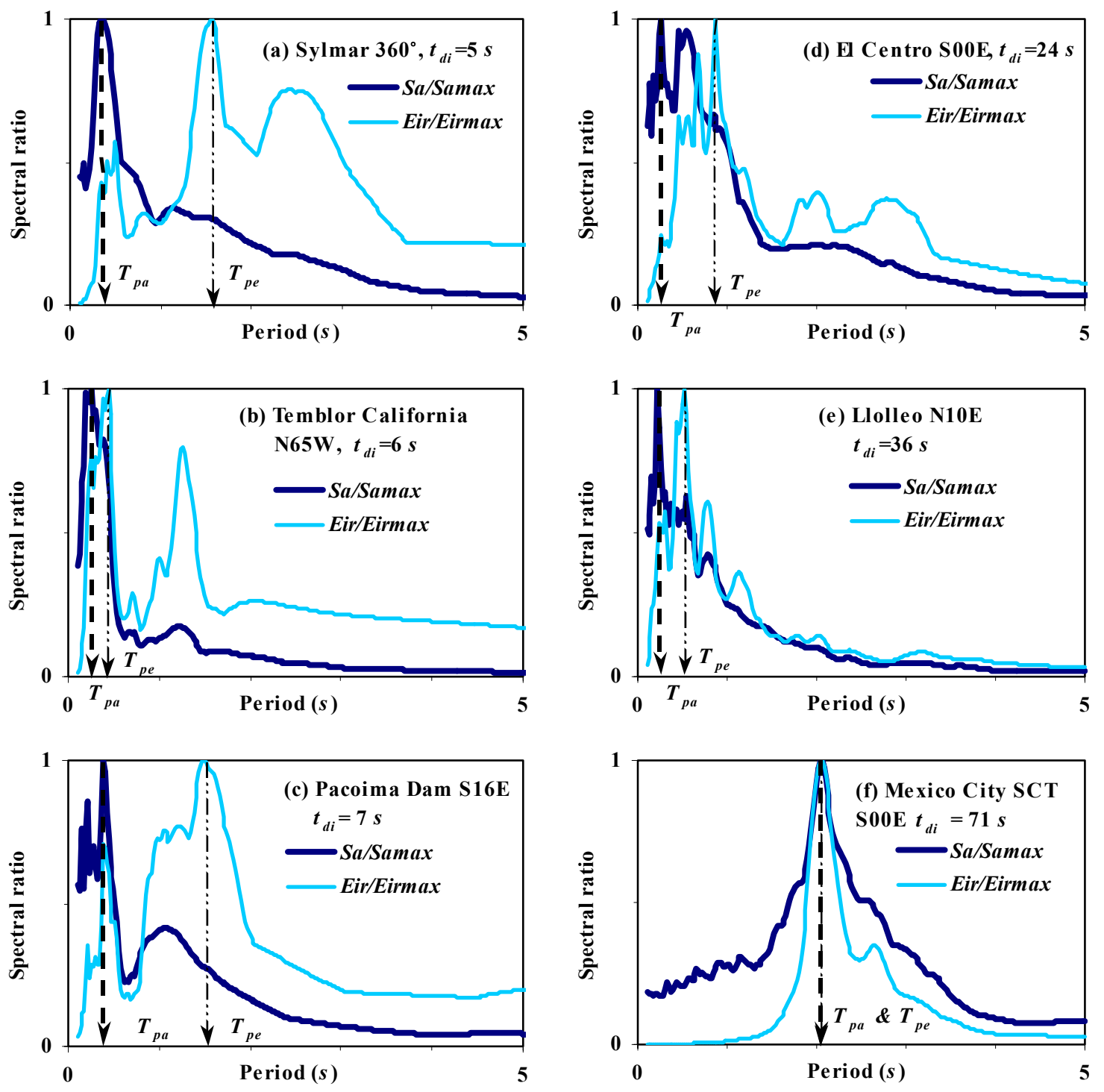

Figure 4.4. Predominant periods $T_{p a}$ and $T_{p e}$ from the elastic acceleration and input energy spectra, respectively, for three accelerograms with short duration of strong motion (a - c), and three accelerograms with long duration (d - f) in Table 4.1. Parameters for Bouc-Wen Model are: $A=1, \beta$ $=\gamma=0.5, n=20$, and $\alpha=0.02$ 


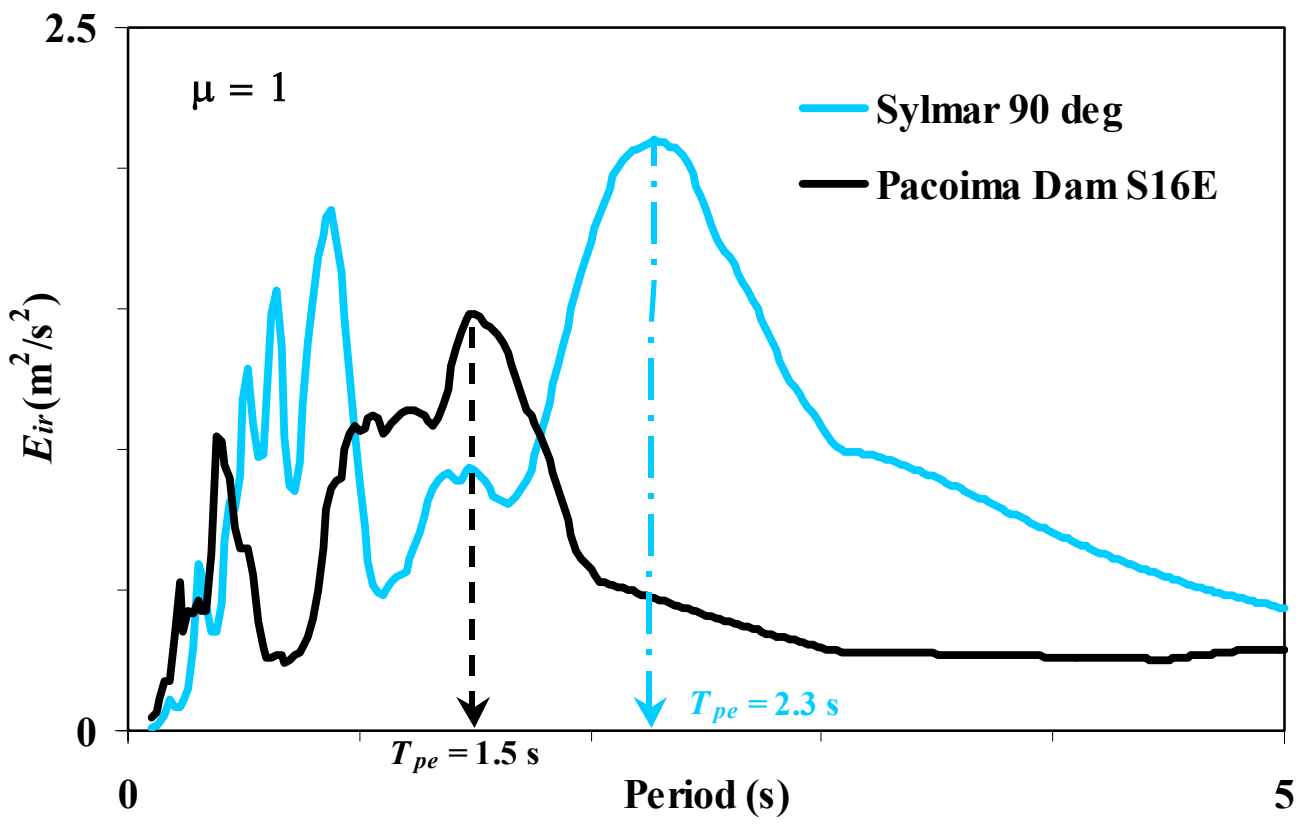

Figure 4.5. Elastic input energy spectra for the $90^{\circ}$ component of Sylmar County Hospital Parking Lot, Northridge, CA earthquake of January 17, 1994 and the S16E component of Pacoima Dam, San Fernando, CA earthquake of March 22, 1971 scaled to an $E P A=0.4 g$. Parameters for Bouc-Wen Model are: $A=1, \beta=\gamma=0.5, n=20$, and $\alpha=0.02$ 

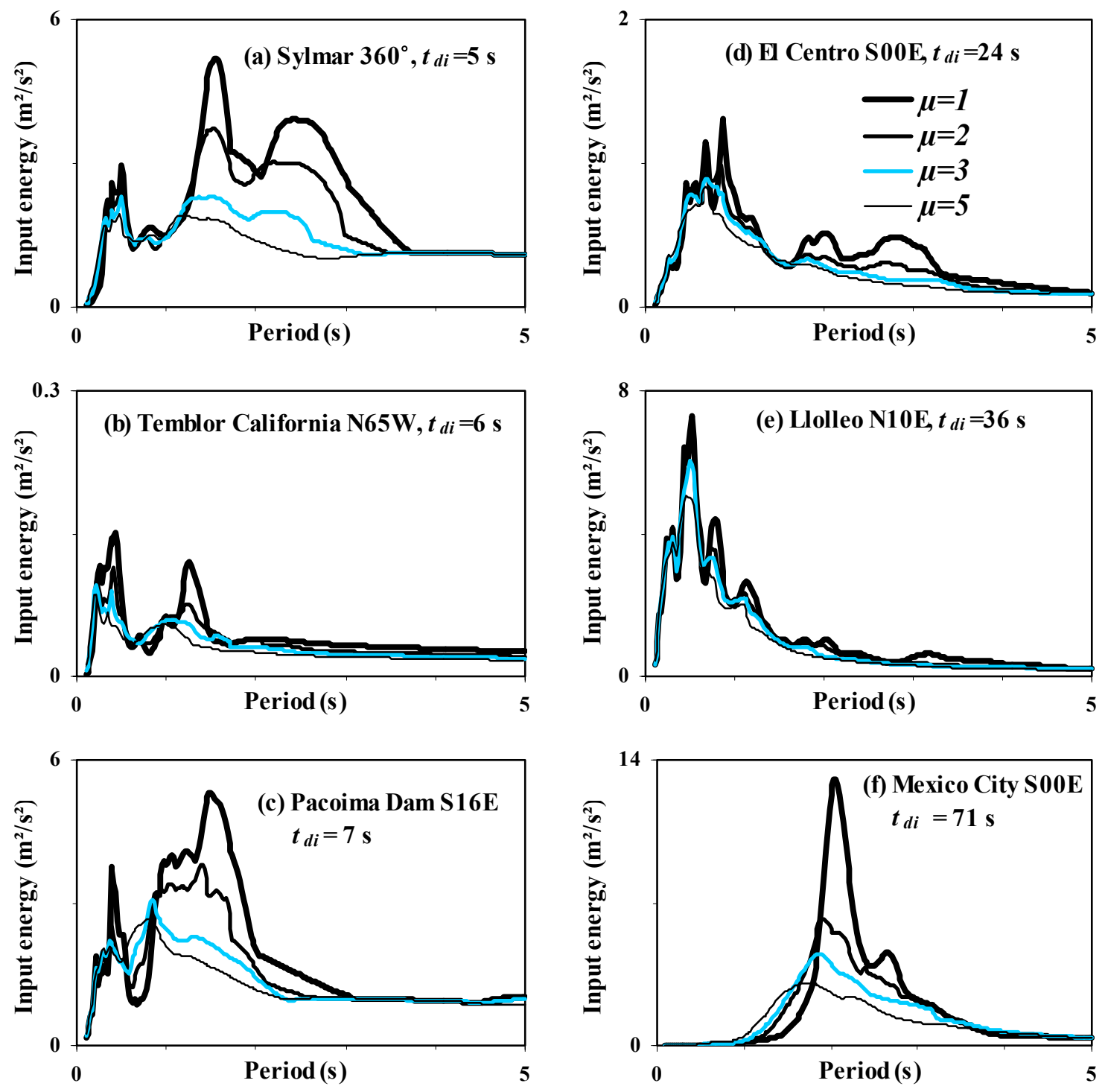

Figure 4.6. Relative input energy $E_{i r}$ for ductility ratios $\mu=1,2,3$, and 5 , and a damping ratio $\xi=$ $5 \%$ for three accelerograms with short $(a-c)$, and three accelerograms with long duration of strong motion (d - f) in Table 4.1. Parameters for Bouc-Wen Model are: $A=1, \beta=\gamma=0.5, n=20$, and $\alpha=$ $\mathbf{0 . 0 2}$ 
energy for Pacoima Dam and Mexico City accelerograms (Figures 4.6.c and 4.6.f), it generally overestimates the inelastic input energy.

Figure 4.7 shows that the relative input energy for a ductility ratio $\mu=3$, a post- to preyield stiffness ratio $\alpha=0.02$, and damping ratios $\xi=0,2,5,10,20$, and $40 \%$ for three accelerograms with short duration of strong motion $(\mathrm{a}-\mathrm{c})$, and three with long duration $(\mathrm{d}-\mathrm{f}$ ) in Table 4.1. The reason for including damping ratios larger than 5\% is that large damping ratios may are encountered when using supplemental damping devices in a structure. Figure 4.7 shows that for damping ratios smaller than 5\%, damping has little effect on the input energy. For damping ratios greater than $5 \%$, on the other hand, damping has a significant influence on the input energy spectra, particularly for periods close to $T_{p e}$. A damping ratio $\xi=40 \%$ may reduce the input energy by approximately $50 \%$ for periods close to $T_{p e}$. For very long periods as the damping increases, the input energy increases.

Figure 4.8 shows the energy ratios for a ductility ratio $\mu=3$ and damping ratios $0,2,5$, 10,20 , and $40 \%$ subjected to the $360^{\circ}$ component of the 1994 Sylmar record with $t_{d i}=5$ s. It is observed that as the damping increases, the $E_{h m} / E_{i r m}$ and $\left(E_{h} / E_{i r}\right)_{m}$ ratios decrease, Figures 4.8.c and 4.8.d. Figure 4.8.c indicates that for a structure with a 5\% damping ratio approximately $75 \%$ of the input energy is dissipated through hysteretic action, and for a structure with a $40 \%$ damping only $20 \%$ of the input energy is dissipated through hysteretic action. The figure indicates that damping significantly influences the distribution of input energy among the energy components.

Fajfar et al. (1989), and Uang and Bertero (1990) recommended that the input energy be used as a damage index. Results of the study by Bruneau and Wang (1996) and this study (see Figure 4.7) indicate that damping ratios smaller than 5\% have a minor influence on the input energy. On the other hand, damping affects the damage potential of structures to a large degree (see Figures 4.8.c and 4.8.d). Therefore, the input energy should not be used as a sole damage index. Earthquake input energy, however, can be used as a measure of the intensity of ground motion. Peak ground acceleration $P G A$, effective peak acceleration EPA defined by Equation (1.1), and Spectrum Intensity $S I$ defined by equation (1.2) have all been used in measuring the intensity of ground motion, but they do not account for the influence of the duration. Earthquake input energy, on the other hand, accounts for the duration of strong motion, frequency content, and structural properties and is more meaningful than $P G A, E P A$, and $S I$ for measuring the intensity. The maximum ordinate of the elastic input energy spectrum with $5 \%$ damping may be used for scaling the records to the same intensity.

The hysteretic behavior of a structure depends on the material and the structural system such as moment resisting frame, braced frame, etc. Two cases of material non-linearities are considered in this study: (a) bilinear behavior with $A=1, \beta=\gamma=0.5$, and $n=20$, and $\alpha=0.02$ proposed by Wen (1976) for a moment resisting steel frame (MRF), and (b) hysteretic behavior with $A=1.4704, \beta=0.042, \gamma=-0.121, n=2$, and $\alpha=0.2325$ proposed by Loh and Chung (1993) for an eccentrically braced steel frame (EBF). Figure 4.9 shows the hysteresis loops for an MRF and an EBF structure with $T_{n}=2.0 \mathrm{~s}, \mu=3$, 

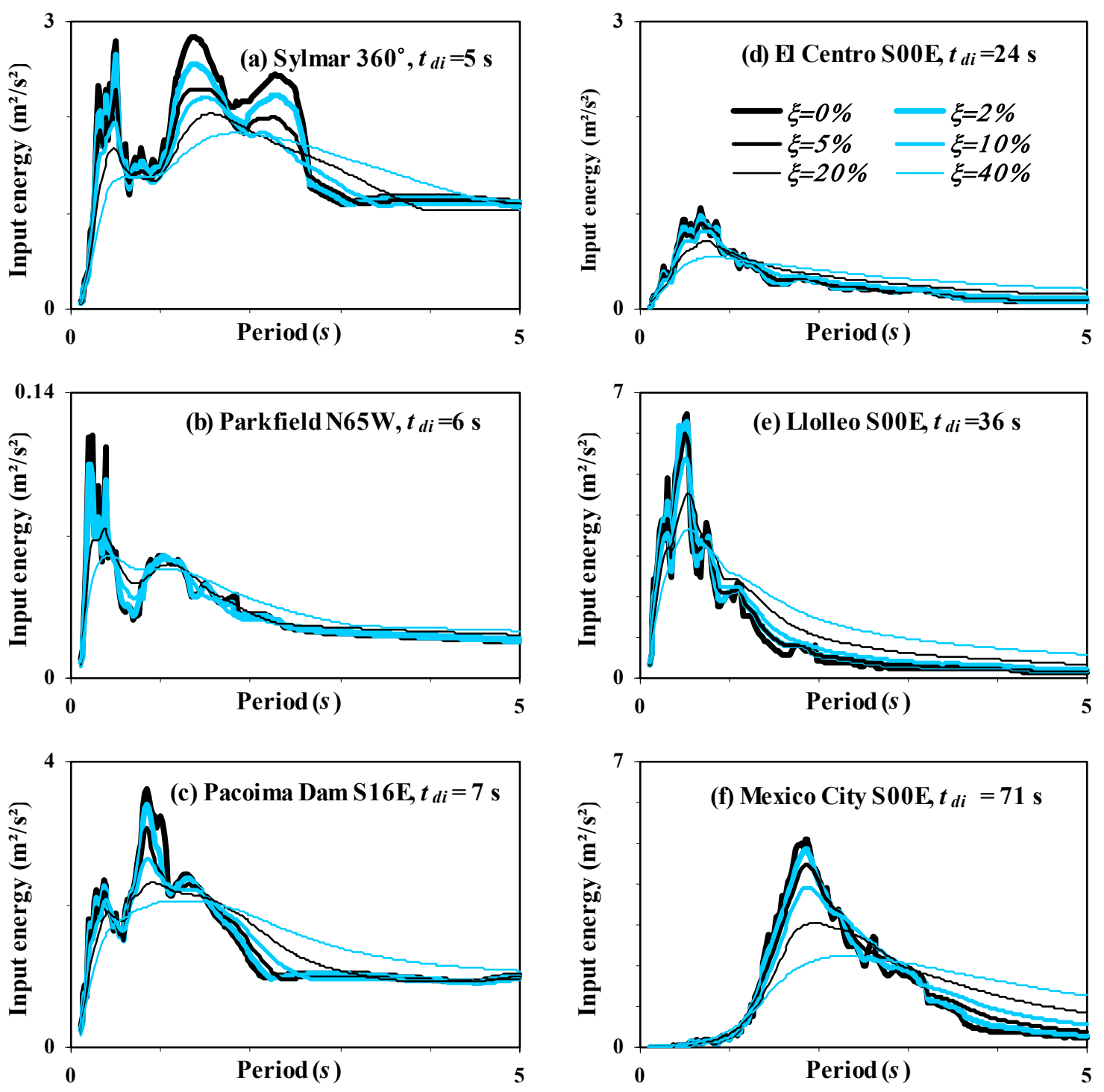

Figure 4.7. Relative input energy $E_{i r}$ for a ductility ratio of 3 , and damping ratios $\xi=0,2,5,10,20$, and $40 \%$ for three accelerograms with short duration of strong motion (a - c), and three accelerograms with long duration (d - f) in Table 4.1. Parameters for Bouc-Wen Model are: $A=1, \beta$ $=\gamma=0.5, n=20$, and $\alpha=0.02$ 

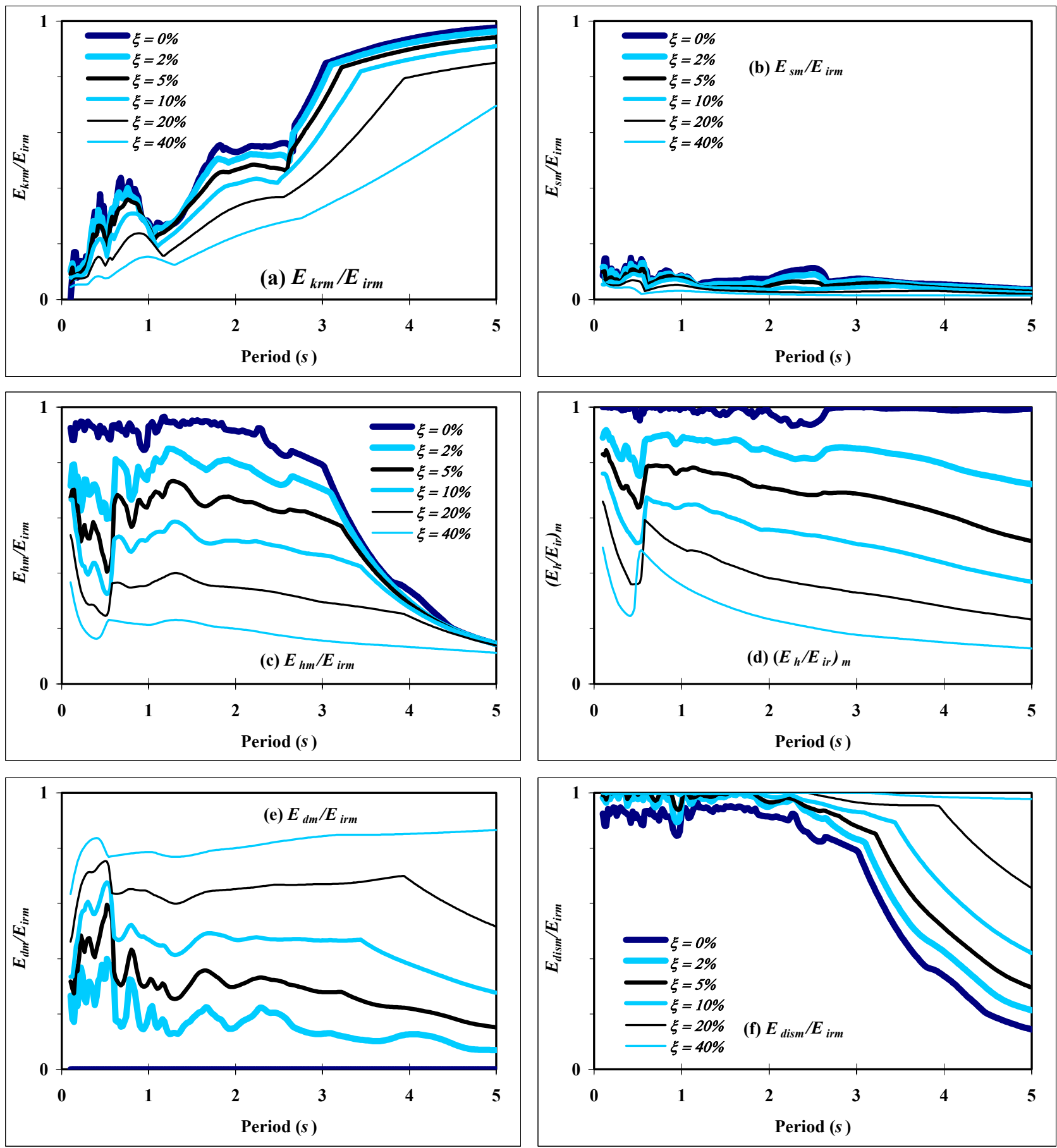

Figure 4.8. Energy ratio spectra for bilinear behavior with a ductility ratio $\mu=3$ and damping ratios $0 \%, 2 \%, 5 \%, 10 \%, 20 \%$, and $40 \%$ subjected to the $360^{\circ}$ component of Sylmar County Hospital Parking Lot Station, Northridge earthquake of January 17, 1994. (a) $E_{k r m} / E_{i r m}$, (b) $E_{\text {sm }} / E_{\text {irm }}$, (c) $E_{h m} / E_{i r m},(\mathrm{~d})\left(E_{h} / E_{i r}\right)_{m}$, (e) $E_{d m} / E_{i r m}$, and (f) $E_{d i s m} / E_{i r m}$. Parameters for Bouc-Wen Model are: $A=1, \beta=$ $\gamma=0.5, n=20$, and $\alpha=0.02$ 

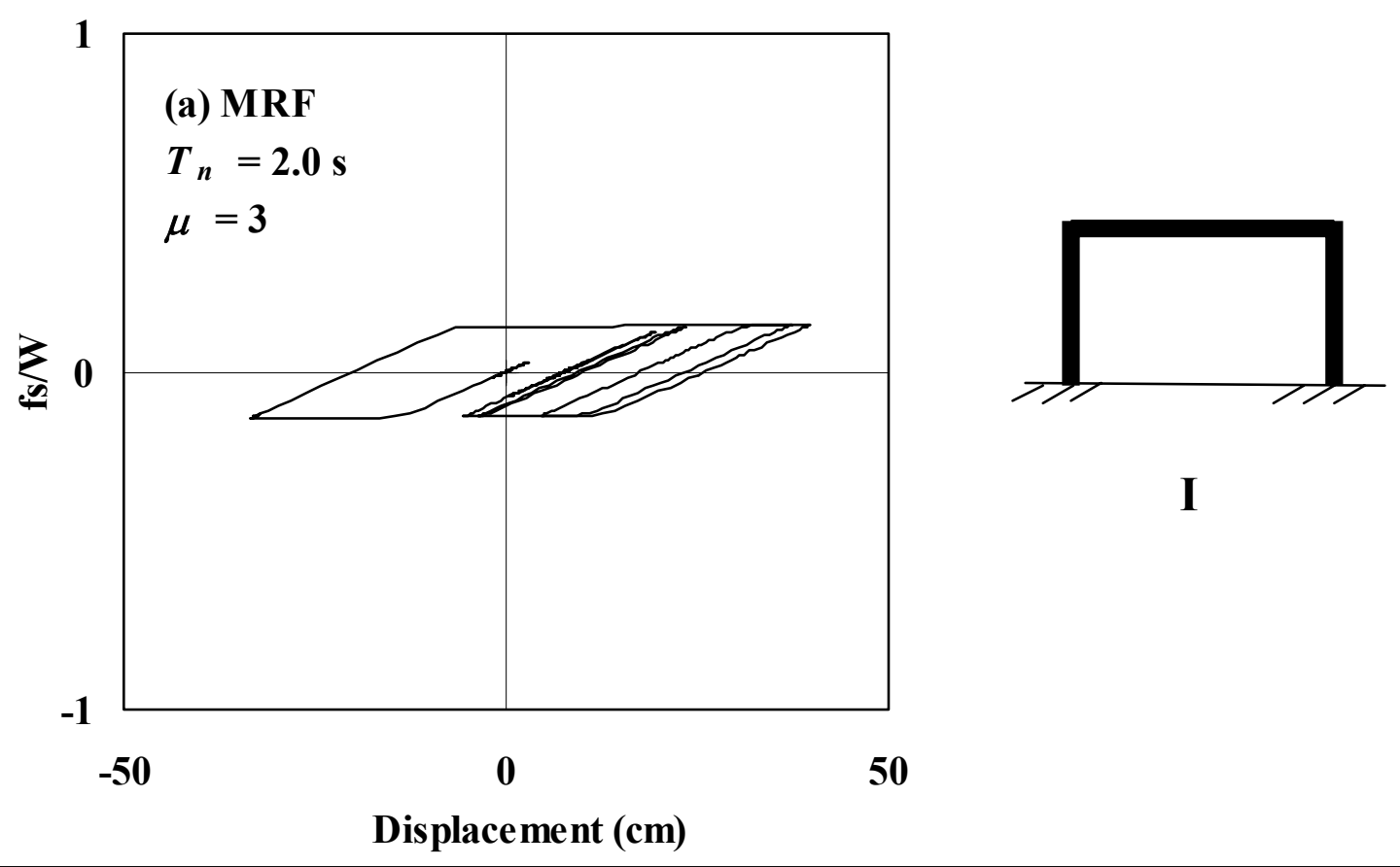

I

50
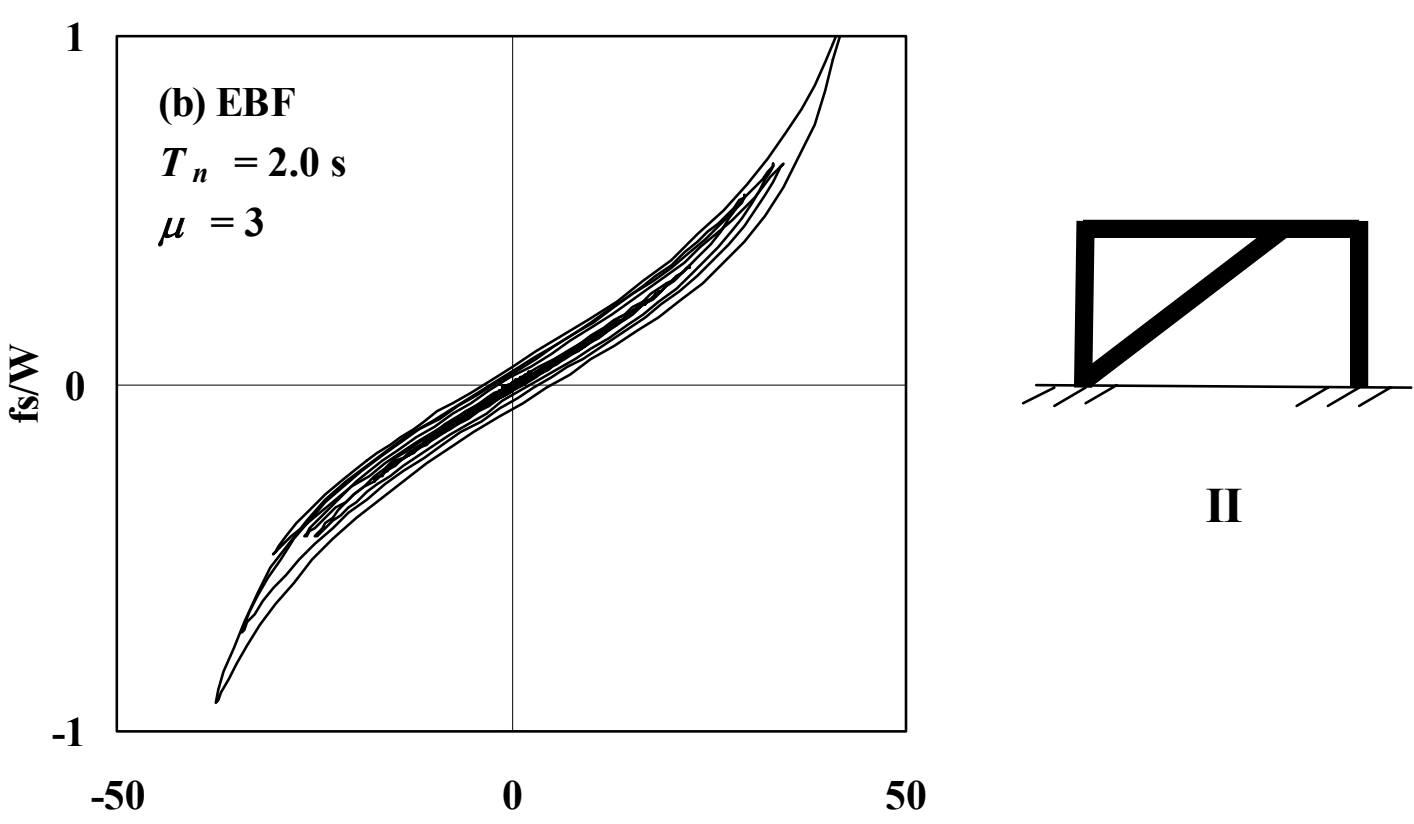

II

Displacement (cm)

Figure 4.9. Force-displacement diagram for an SDOF MRF and an SDOF EBF with $T_{n}=2.0 \mathrm{~s}$, a ductility ratio of 3 , and a $5 \%$ damping ratio subjected to the $360^{\circ}$ component of Sylmar County Hospital Parking Lot, Northridge, CA earthquake of January 17, 1994. Parameters for Bouc-Wen Model are: (a) $A=1, \beta=\gamma=0.5, n=20$, and $\alpha=0.02$, and (b) $A=1.4704, \beta=0.042, \gamma=-0.121, n=2$, and $\alpha=\mathbf{0 . 2 3 2 5}$ 
and a 5\% damping ratio subjected to the $360^{\circ}$ component of the Sylmar record. The total input energy transmitted by that record to the MRF and EBF structures at a period of $2 \mathrm{~s}$ are approximately 1.9 and $4.5 \mathrm{~m}^{2} / \mathrm{s}^{2}$ (see Figure 4.10 )

Figure 4.10 shows the input energy spectra for a ductility ratio of 5, a 5\% damping ratio, and the two types of hysteretic behavior for the $360^{\circ}$ component of the Sylmar record and the S00E component of the Mexico City record. The figure indicates that the shape of the hysteresis loop has a significant influence on the magnitude and variation of the input energy spectra.

The results of this study indicate that the influences of structural properties on earthquake input energy are as important as the influences of ground motion characteristics. Nonetheless, the empirical equations proposed by Akiyama (1985), Kuwamura and Galambos (1989), Fajfar et al. (1989), Uang and Bertero (1990), and Kuwamura et al. (1993) for estimating the earthquake input energy are based on the ground motion characteristics only. The equation proposed by Housner (1956) does not account for the influence of the duration of strong motion. The procedure proposed by Manfredi (2001) for the constant-velocity region of response spectra accounts for the influences of the ground motion characteristics as well as structural properties in estimating the earthquake input energy.

A procedure for computing the earthquake input energy from the response spectra by accounting for the soil type is needed. A large number of accelerograms recorded on different soil should be used to compute the energy spectra for various hysteretic behaviors. 

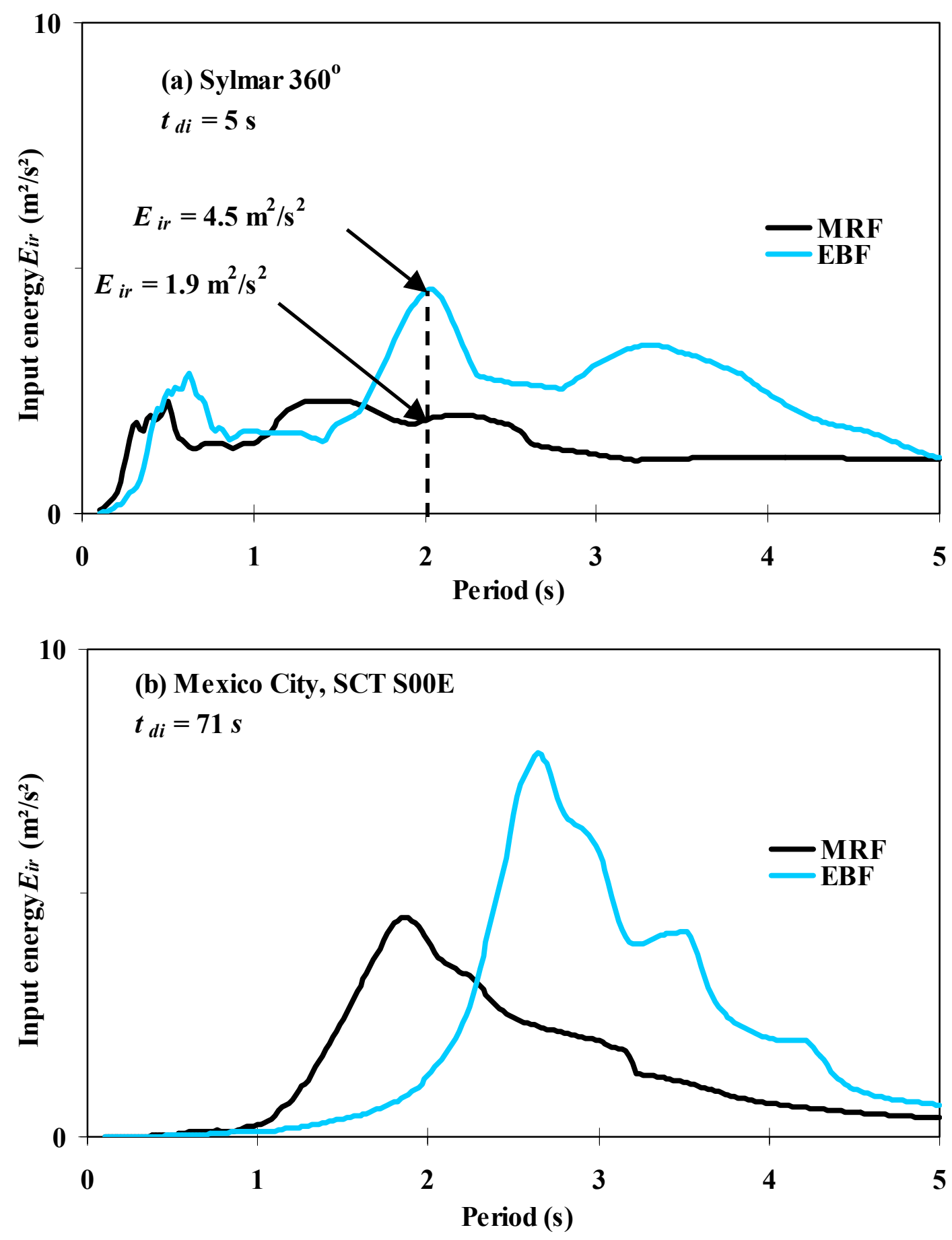

Figure 4.10. Relative input energy $E_{i r}$ for a ductility ratio of 3, damping ratio $\xi=5 \%$, and two hysteretic behaviors for (a) the $360^{\circ}$ component of Sylmar County Hospital Parking Lot, Northridge, CA earthquake of January 17, 1994, and (b) the S00E component of Mexico City earthquake of September 19, 1985. Parameters for Bouc-Wen Model are (I) for MRF structure: $A=1, \beta=\gamma=0.5$, $n=20$, and $\alpha=0.02$, and (II) for EBF structure $A=1.4704, \beta=0.042, \gamma=-0.121, n=2$, and $\alpha=0.2325$ 



\section{HYSTERETIC ENERGY DEMAND}

In a seismic design procedure based on energy, one should limit the structural damage by providing sufficient ductility and energy dissipation capacity by hysteretic action and/or damping in the structure. The damage potential is associated with the maximum hysteretic energy demand during the excitation and during the largest yield excursion (see Figures $3.1-3.3$ ). The hysteretic energy demand can be computed from the input energy spectra if the ratio of the maximum hysteretic energy to the maximum input energy $E_{h m} / E_{\text {irm }}$ is known. To examine the relationship between hysteretic energy and damage potential three energy ratios are considered: 1) the maximum ratio of hysteretic to input energy $\left(E_{h} / E_{i r}\right)_{m}$ generally occurring during the largest yield excursion, 2) the ratio of the maximum hysteretic energy to the maximum input energy $E_{h m} / E_{i r m}$ occurring at the end of the excitation, and 3 ) the equivalent number of yield excursions $N_{\text {eq }}$, see equation (4.13).

Figure 5.1 shows $\left(E_{h} / E_{i r}\right)_{m}, E_{h m} / E_{i r m}$, and $N_{e q}$ for a ductility ratio $\mu=3$ and a $5 \%$ damping ratio for the records with short and long duration of strong motion. Figures 5.1.a to 5.1.d indicate that, on the average, $\left(E_{h} / E_{i r}\right)_{m}$ are approximately $20 \%$ larger than $E_{h m} / E_{i r m}$ regardless of the period of structure. Ground motion characteristics have a minor influence on the $\left(E_{h} / E_{i r}\right)_{m}$ ratio (Figures 5.1.a and 5.1.b) and a major influence on the $\left(E_{h} / E_{i r}\right)_{m}$ ratio (Figures 5.1.c and 5.1.d). For example, for an SDOF structure with $T_{n}=$ $1.0 \mathrm{~s}$ (Figure 5.2) subjected to the $360^{\circ}$ component of 1994 Sylmar record $\left(t_{d i}=5 \mathrm{~s}\right)$, approximately $90 \%$ of the total hysteretic energy is dissipated during the first (largest) yield excursion where $\left(E_{h} / E_{i r}\right)_{m}=0.77$ and $E_{h m} / E_{\text {irm }}=0.67$. Similarly for a structure with $T_{n}=2.0 \mathrm{~s}$ (Figure 5.3), 70\% of $E_{h m}$ is dissipated in the first (largest) yield excursion where $\left(E_{h} / E_{i r}\right)_{m}=0.71$ and $E_{h m} / E_{\text {irm }}=0.69$. Therefore, when a flexible structure (long period) is subjected to a short duration earthquake, the damage potential during the largest yield excursion, indicated by $\left(E_{h} / E_{i r}\right)_{m}$, may be more important than the damage potential due to the total number of yield excursions indicated by $E_{h m} / E_{i r m}$.

Figures 5.1.e and 5.1.f show that generally for the same ductility and damping, the equivalent number of yield excursions $N_{e q}$ is larger for the records with long duration of strong motion than for the records with short duration, indicating a larger damage potential for the long duration records. For the two longest duration records, the 1985 Mexico City - S00E $\left(t_{d i}=71 \mathrm{~s}\right)$ and 1985 Llolleo $-100^{\circ}\left(t_{d i}=41 \mathrm{~s}\right), N_{e q}$ is the largest in the vicinity of the predominant period where $T_{p e}=2.0 \mathrm{~s}$ and $0.52 \mathrm{~s}$ for the Mexico City and Llolleo records, respectively (see Figure 5.1.f). Figure 5.1 indicates that the structures with $T_{n}=1.0$ to $2.5 \mathrm{~s}$ and $T_{n}=0.2$ to $0.7 \mathrm{~s}$ have the potential for significant damage when subjected to the Mexico City and Llolleo records, respectively. One cannot make a definitive conclusion from Figures 5.1.e and 5.1.f, however, for the damage potential of structures subjected to the other 18 accelerograms. 

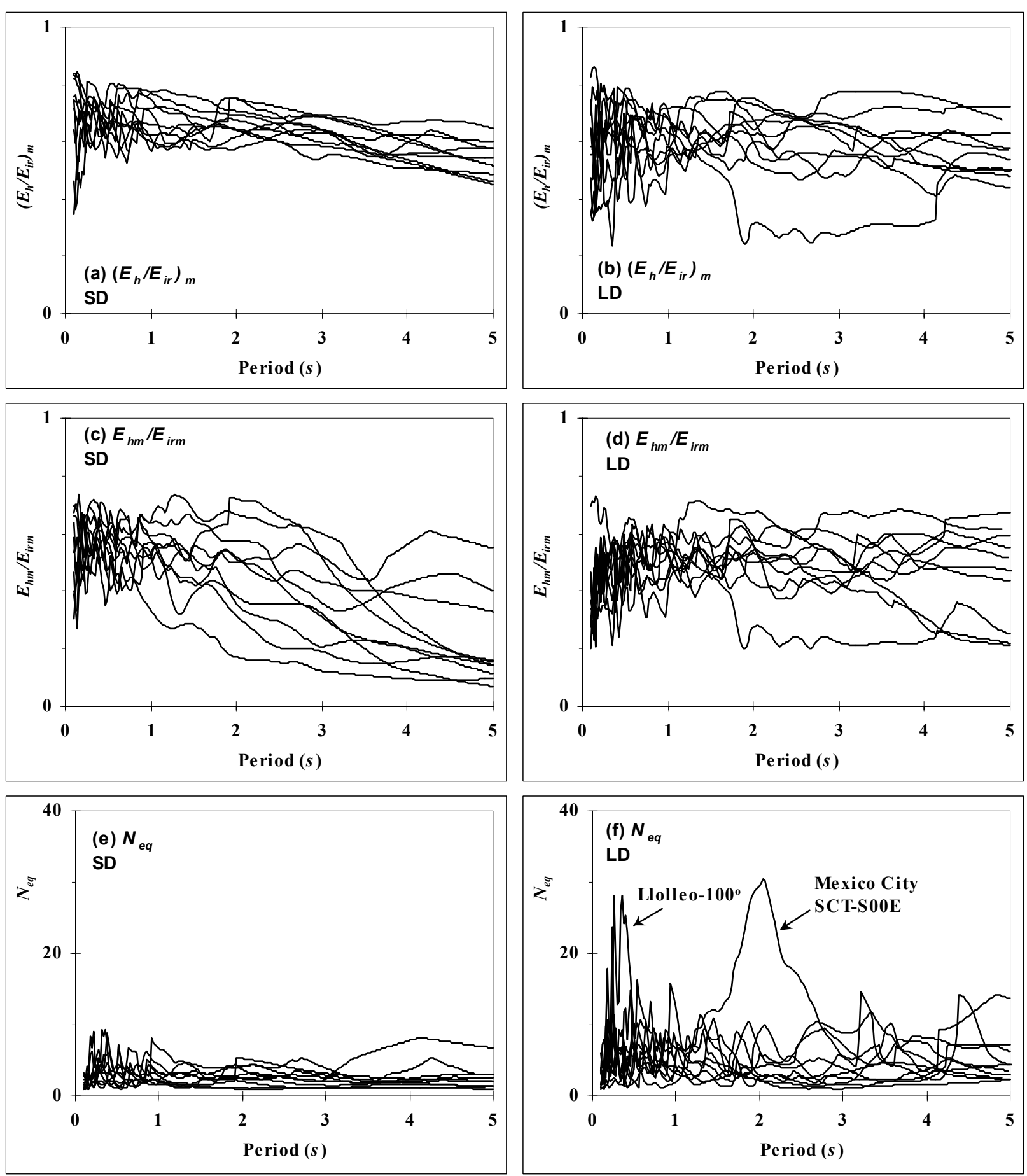

Figure 5.1. (a, b) Maximum ratio of the hysteretic to input energy $\left(E_{h} / E_{i r}\right)_{m}$, (c, d) Ratio of the maximum hysteretic energy to the maximum input energy $E_{h m} / E_{i r m}$, (e, f) Equivalent number of yield excursions $N_{e q}$ for records with short and long durations for a ductility ratio $\mu=3$ and a $5 \%$ damping ratio. Parameters for Bouc-Wen Model are: $A=1, \beta=\gamma=0.5, n=20$, and $\alpha=0.02$. 


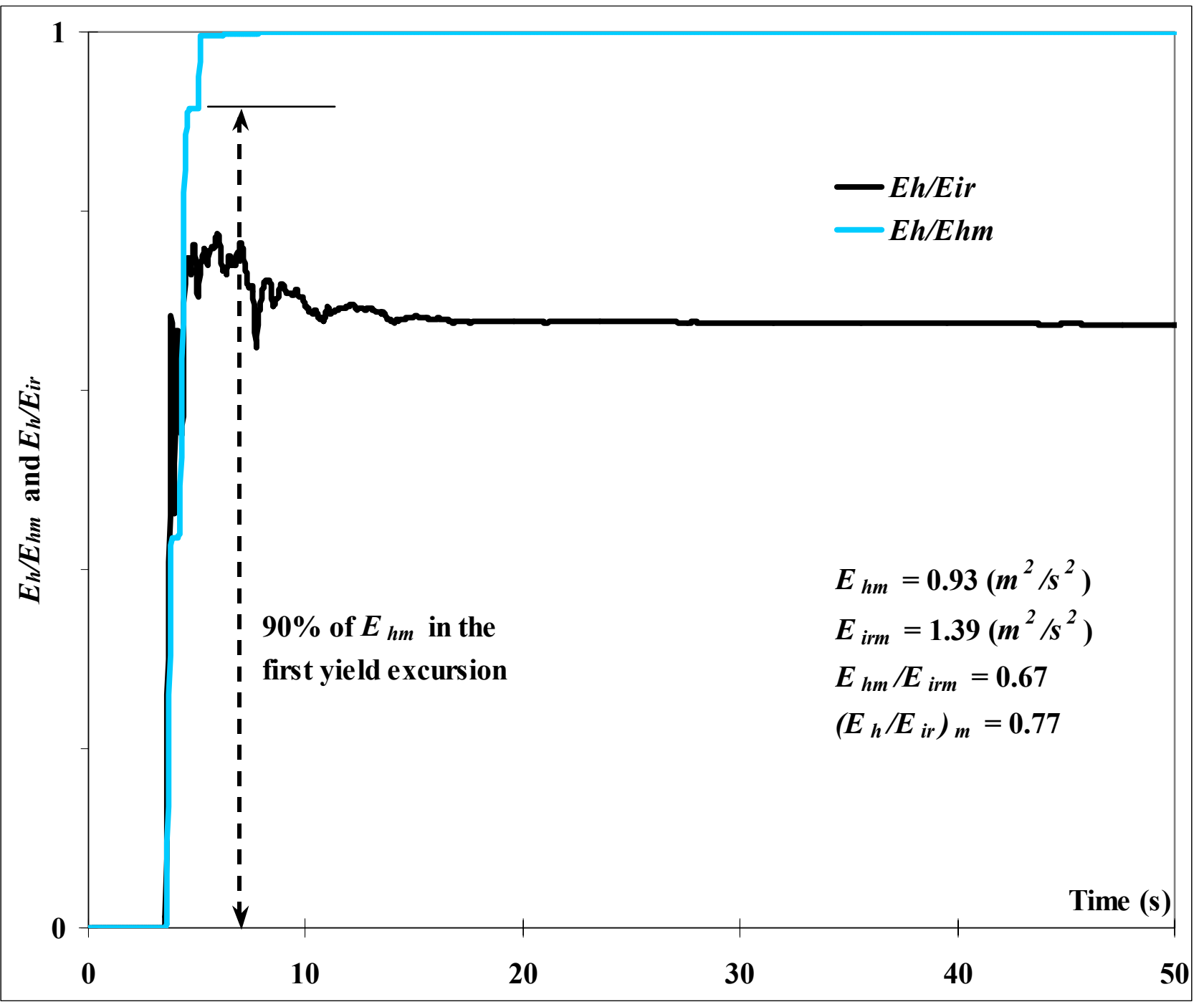

Figure 5.2. Time-histories of $E_{h} / E_{h m}$ and $E_{h} / E_{i r}$ for a bilinear SDOF structure with $T_{n}=1.0 \mathrm{~s}$, a ductility ratio $\mu=3$, and $5 \%$ damping subjected to the $90^{\circ}$ component of Sylmar County Hospital Parking Lot, Northridge, CA earthquake of January 17, 1994. Parameters for Bouc-Wen Model are $A=1, \beta=\gamma=0.5, n=20, \alpha=0.02$ 
Figure 5.3 demonstrates that, in general, the energy ratios considered provide different information about the damage potential of a structure. The ratio $\left(E_{h} / E_{i r}\right)_{m}$ reflects the damage due to the largest yield excursion and is independent of the duration of strong motion and period of structure. The energy ratios $E_{h m} / E_{i r m}$ and $N_{e q}$, on the other hand, reflect the damage potential due to cumulative inelastic deformation for the entire duration of accelerogram. The equivalent number of yield excursions $N_{e q}$ depends on the duration of strong motion and the period of structure, whereas the $E_{h m} / E_{i r m}$ ratio is independent of both only for periods less than $1 \mathrm{~s}$. For quantifying the damage potential, the $E_{h m} / E_{i r m}$ and $\left(E_{h} / E_{i r}\right)_{m}$ ratios may be used to define a damage index to address the damage potential for the largest yield excursion and the total number of yield excursions during the earthquake.

Figures 5.4.a and 5.4.b show the mean $\left(E_{h} / E_{i r}\right)_{m}$ and $E_{h m} / E_{i r m}$ ratios, respectively, for the 20 accelerograms for $5 \%$ damping and ductility ratios $\mu=2,3$, and 5 . In general, as the ductility increases both ratios increase, indicating a larger dissipation of input energy through hysteretic action. Figure 5.4.b can be used to estimate the hysteretic energy spectra from input energy spectra if the relationship among the $E_{h m} / E_{i r m}$ ratio, the duration of strong motion, and the period of structure is determined. A large number of accelerograms recorded on different soil should be used and energy spectra for various hysteretic behaviors should be computed to develop a procedure for estimating the hysteretic energy demand. 


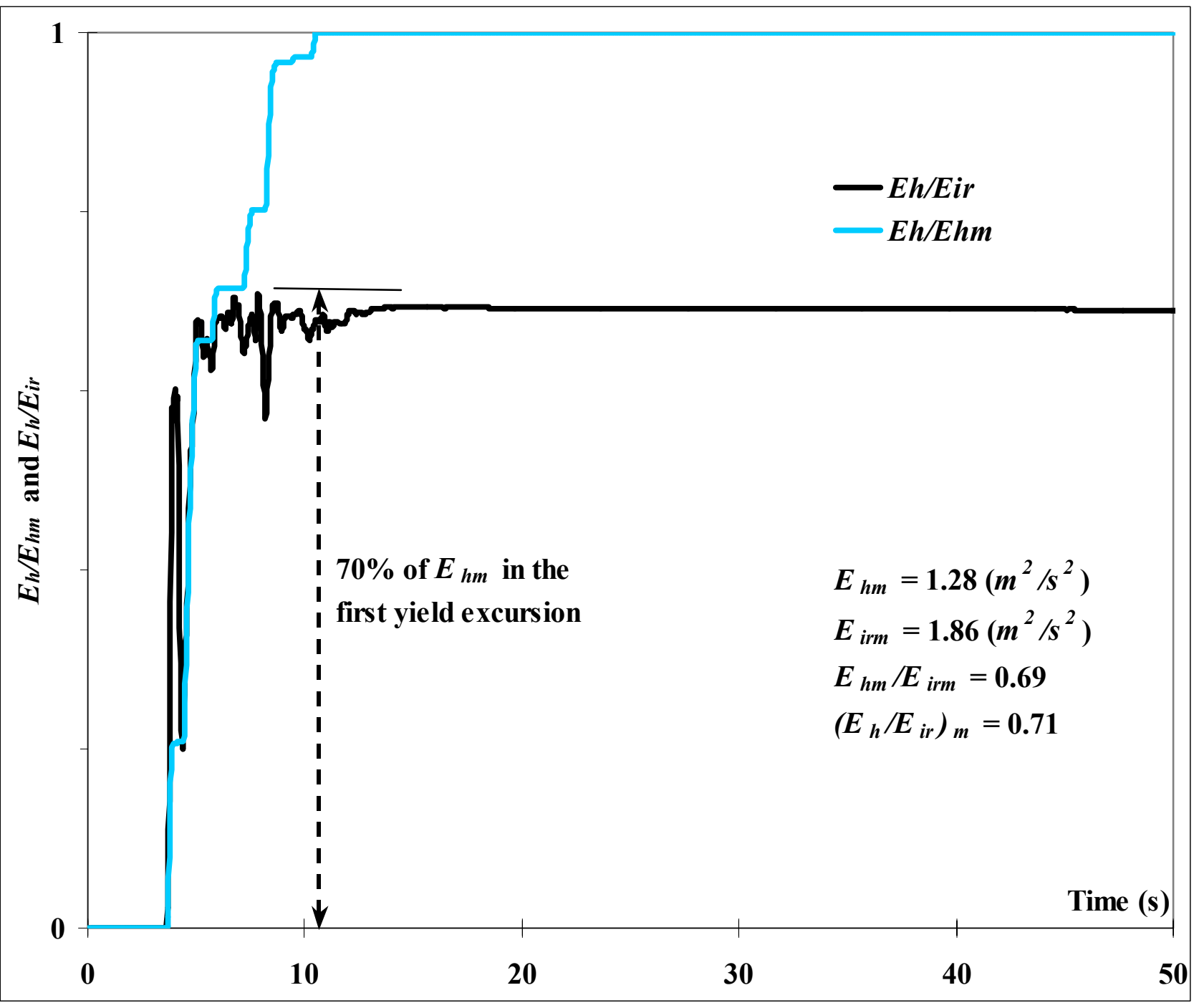

Figure 5.3. Time-histories of $E_{h} / E_{h m}$ and $E_{h} / E_{i r}$ for a bilinear SDOF structure with $T_{n}=2.0 \mathrm{~s}$, a ductility ratio $\mu=3$, and $5 \%$ damping subjected to the $90^{\circ}$ component of Sylmar County Hospital Parking Lot, Northridge, CA earthquake of January 17, 1994. Parameters for Bouc-Wen Model are $A=1, \beta=\gamma=0.5, n=20, \alpha=0.02$ 

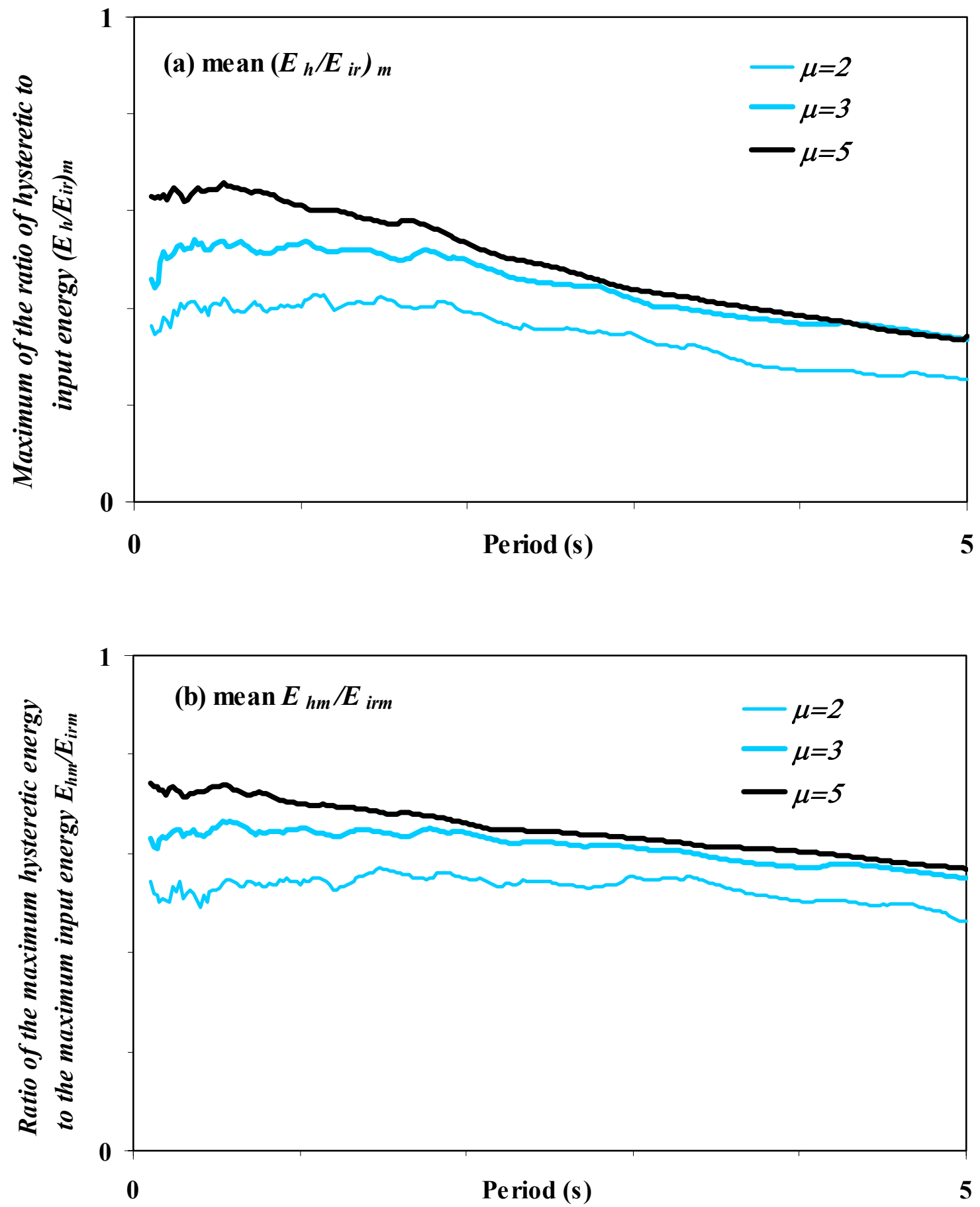

Figure 5.4. The mean $\left(E_{h} / E_{i r}\right)_{m}$ and $E_{h m} / E_{i r m}$ spectra for bilinear behavior with $5 \%$ damping and ductility ratios $\mu=2,3$, and 5 for 20 accelerograms. Parameters for Bouc-Wen Model are: $A=1, \beta=$ $\gamma=0.5, n=20$, and $\alpha=0.02$. 


\section{ENERGY RATIOS IN AN MDOF STRUCTURE}

Studies by McKevitt et al. (1980) and Nakashima et al. (1996) suggest that the energy transmitted to an MDOF structure can be estimated from the energy transmitted to an equivalent SDOF structure. Once the input and the hysteretic energies for a structure are estimated, one needs to distribute the energies through the height of the structure. Sufficient strength and energy dissipation capacity should be provided in structural members to limit the damage potential of the structure to acceptable thresholds (refer to Vision 2000). This Chapter examines the distribution of earthquake input energy and its components in a five-story building using the 20 accelerograms in Table 4.1 scaled to an effective peak acceleration $E P A=0.4 g$.

The structural properties for the building are as follows: all floors have a weight $W=$ $1000 \mathrm{KN}$. The pre-yield stiffness of the first story is $K_{l}=228,898 \mathrm{KN} / \mathrm{m}$ and the stiffnesses for stories $2-5$ are reduced linearly by $10 \%$, i.e. $K_{j} / K_{1}=0.9,0.8,0.7$, and 0.6 for $j=2$ to 5 , respectively. Damping is assumed proportional to stiffness. Considering a $5 \%$ damping in the first mode of vibration of the elastic structure, the damping coefficient for the first story is $C_{1}=3643 \mathrm{KN}-\mathrm{s} / \mathrm{m}$ and the damping distribution through the height is $C_{j} / C_{1}=0.9,0.8,0.7$, and 0.6 for $j=2$ to 5 , respectively. The yield deformation for each story varies proportionally to the stiffness (Yang et al. 1992), where $u_{y j} / u_{y l}=0.9,0.8,0.7$, and 0.6 for $j=2$ to 5 , respectively, and $u_{y l}$ is the yield deformation for the first story. The pre-yield periods of the building are $T_{n}=0.50,0.17,0.11,0.08$, and $0.07 \mathrm{~s}$. The BoucWen parameters (Appendix A) used in the analyses are $A=1, \beta=\gamma=0.5, n=6, \alpha=0.02$ for all floors. The energy balance equation for MDOF structures is presented in Appendix B.

Figure 6.1 shows the total hysteretic and input energies for the five-story building with $u_{y l}=0.5 \mathrm{~cm}$ vs. the intensity-based duration computed for the 20 records. As expected, the figure shows that the total input and hysteretic energies for the records with long duration are greater than those for the records with short duration. The standard deviations of $E_{h}$ for the records with short and long duration are 0.1 MN.m and 0.4 MN.m, respectively, and the standard deviations of $E_{i r}$ for the short and long duration records are 0.1 MN.m and 0.5 MN.m, respectively. The large dispersion from the means in Figure 6.1 is caused by the influence of the frequency content on input energy, i.e. the input and hysteretic energies for a structure with a period approximately equal to the predominant period $T_{p e}$, see Table 4.1, are larger than those for a structure with period different than the predominant period. Figure 6.1 indicates that the duration of strong motion has a significant influence on energy demand.

Table 6.1 shows the inter-story ductility, normalized story shear, energy distribution, and the ratios $\left(E_{h} / E_{i r}\right)_{m}, E_{h m} / E_{i r m}$, and $E_{d m} / E_{i r m}$ for each story when the building is subjected to the S00E component of El Centro accelerogram scaled to an $E P A=0.4 g$. The yield deformation for the first story is $u_{y l}=0.5 \mathrm{~cm}$. Table 6.1 shows that the ductility demand 

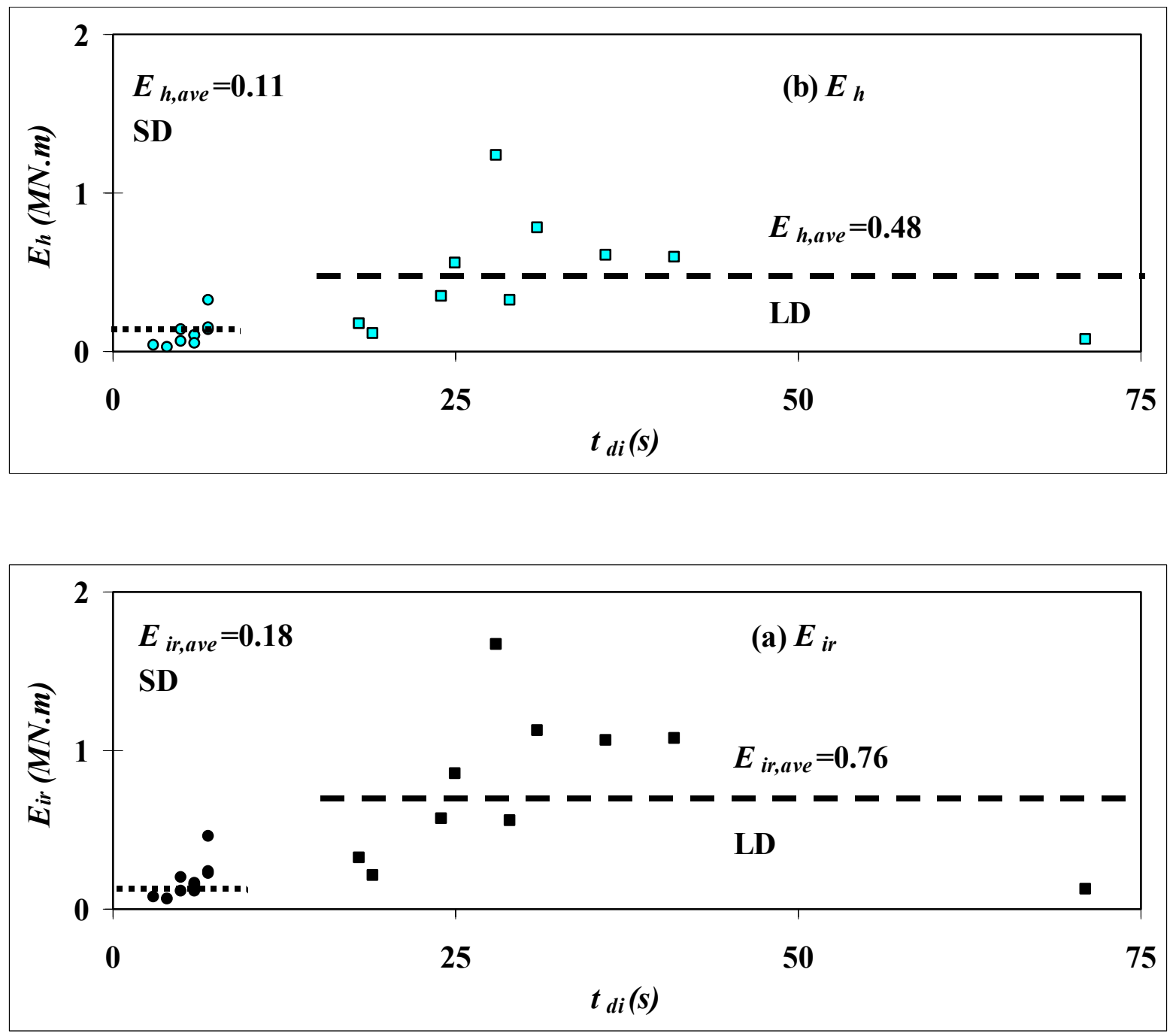

Figure 6.1. Total hysteretic and input energies for the five-story building with $u_{y 1}=0.5 \mathrm{~cm}$ subjected to the 20 accelerograms scaled to an $E P A=0.4 g$. Parameters for Bouc-Wen Model are $A=1, \beta=\gamma=$ $0.5, n=6, \alpha=0.02$ 
Table 6.1. Inter-story ductility, normalized story shear, percentage of energy in each story, and the energy ratios $\left(E_{h} / E_{i r}\right)_{m}, E_{h m} / E_{i r m}$, and $E_{d m} / E_{d m}$ for the five-story building subjected to the $\mathrm{S00E}$ component of El Centro, the Imperial Valley, CA earthquake of May 18, 1940 scaled to an EPA = 0.4g.

\begin{tabular}{|c|c|c|c|c|c|c|c|c|c|c|c|}
\hline 1 & 2 & 3 & 4 & 5 & 6 & 7 & 8 & 9 & 10 & 11 & 12 \\
\hline Story & $\mu_{j}$ & $Q_{j} / Q_{b}$ & $\begin{array}{c}E_{k r} \\
(\%)\end{array}$ & $\begin{array}{c}E_{d} \\
(\%)\end{array}$ & $\begin{array}{c}E_{s} \\
(\%)\end{array}$ & $\begin{array}{c}E_{h} \\
(\%)\end{array}$ & $\begin{array}{l}E_{d i s} \\
(\%)\end{array}$ & $\begin{array}{c}E_{i r} \\
(\%)\end{array}$ & $\left(E_{h} / E_{i r}\right)_{m}$ & $E_{h m} / E_{i r m}$ & $E_{d m} / E_{i r m}$ \\
\hline 5 & 1.3 & 0.32 & 31 & 36 & 5 & 6 & 1 & 2 & 0.34 & 0.09 & 0.51 \\
\hline 4 & 3.3 & 0.49 & 32 & 30 & 14 & 12 & 12 & 13 & 0.74 & 0.57 & 0.43 \\
\hline 3 & 4.6 & 0.68 & 23 & 23 & 25 & 21 & 31 & 29 & 0.76 & 0.67 & 0.33 \\
\hline 2 & 4.2 & 0.85 & 12 & 16 & 29 & 29 & 33 & 31 & 0.76 & 0.65 & 0.35 \\
\hline 1 & 3.2 & 1.00 & 3 & 16 & 28 & 36 & 24 & 25 & 0.76 & 0.58 & 0.42 \\
\hline
\end{tabular}


is the largest in the third story (column 2), whereas the hysteretic energy demand is the largest in the first story (column 7). The ductility ratio does not consider the influence of the duration, whereas the hysteretic energy does. Therefore, it is reasonable that in design both ductility and energy demands be examined for each story. It is observed that for higher stories the relative kinetic energy $E_{k r}$ is larger (column 4) since it is computed from the relative velocity, whereas elastic strain energy $E_{s}$ is smaller (column 6) since it is computed from the drift ${ }^{b}$ which for a shear building is smaller in higher stories. The maxima of $E_{h} / E_{i r}$ are presented in column 10 of Table 6.1 which are approximately equal for the four lower stories. The fifth story behaves approximately elasticly $(\mu=1.3$ in column 2). Only $9 \%$ of the input energy is dissipated through hysteresis (column 11) and $51 \%$ of the energy is dissipated through damping. It is also observed that $\left(E_{h} / E_{i r}\right)_{m}$ is generally larger than $E_{h m} / E_{i r m}$ for each story and the difference between the two ratios increases for higher stories which have smaller ductility demands.

Table 6.2 shows the influence of the yield deformation on the maximum inter-story ductility, base shear, and total energy parameters for the five-story building subjected to the S00E component of the $1940 \mathrm{El}$ Centro accelerogram scaled to an $E P A=0.4 g$. It is observed that as the yield deformation decreases ductility demand increases (column 2), and base shear decreases significantly (column 3), whereas the total dissipated and input energies remain approximately the same (columns 8 and 9). Nonetheless, ductility has a pronounced influence on the distribution of input energy among energy components, specially for ductility demands less than 3 (columns 4 - 7).

Figure 6.2 shows the relative displacement, ductility demand, normalized story shear, the energy ratio $E_{h m} / E_{i r m}$, and the distribution of the hysteretic and input energies though the height of the 5-story building with yield deformations $u_{y l}=0.3,0.5,0.7,1.0$, and $1.5 \mathrm{~cm}$, subjected to the S00E component of the $1940 \mathrm{El}$ Centro accelerogram scaled to an $E P A=$ $0.4 \mathrm{~g}$. Also presented are the results for the elastic case. The figure indicates that as the yield deformation decreases the relative displacement for each story decreases, and the ductility and hysteretic energy demands increase. It is observed that structural nonlinearity has a small effect on the distribution of story shear, hysteretic energy, and input energy for this building, see Figures 6.2.c, 6.2.e, and 6.2.f. Even though displacement is largest at the top, the ductility and hysteretic energy demands are largest in the lower three stories.

Figure 6.3 compares the percentage of energy distributed through the height of the fivestory building, with a yield deformation for the first story $u_{y l}=0.5 \mathrm{~cm}$, subjected to the 20 accelerograms scaled to an $E P A=0.4 g$. The figure indicates that in general, the distribution of energy through the height of the building is not affected by ground motion characteristics. On the average, $23,28,27,15$, and $7 \%$ of the total input energy is transmitted to stories 1 to 5 , respectively. Similarly, 22, 30, 31, 16, and $1 \%$ of the total hysteretic energy is dissipated in stories 1 to 5 , respectively. While the above percentages provide rough estimates and trend in distribution and dissipation of energy, a large number of structures and records should be examined to arrive at a rational formula for distribution of energy through the height of a structure.

\footnotetext{
${ }^{\mathrm{b}}$ The difference between two consecutive floor displacements.
} 
Table 6.2. Influence of yield deformation on maximum inter-story ductility $\mu_{\max }$, base shear $Q_{b}$, and total energy for the five-story building subjected to the $\mathrm{SOOE}$ component of El Centro, the Imperial Valley, CA earthquake of May 18, 1940 scaled to an EPA $=0.4 g$.

\begin{tabular}{c||c||c||cccccc}
\hline \hline 1 & 2 & 3 & 4 & 5 & 6 & 7 & 8 & 9 \\
\hline $\begin{array}{c}\boldsymbol{u}_{\boldsymbol{y} 1} \\
(\mathbf{c m})\end{array}$ & $\mu_{\max }$ & $\begin{array}{c}Q_{b} \\
(\mathbf{K N})\end{array}$ & $\begin{array}{c}\boldsymbol{E}_{\boldsymbol{k r t}} \\
(\mathbf{K N}-\mathbf{m})\end{array}$ & $\begin{array}{c}\boldsymbol{E}_{\boldsymbol{d t}} \\
(\mathbf{K N}-\mathbf{m})\end{array}$ & $\begin{array}{c}\boldsymbol{E}_{\mathbf{s t}} \\
(\mathbf{K N}-\mathbf{m})\end{array}$ & $\begin{array}{c}\boldsymbol{E}_{\boldsymbol{h t}} \\
(\mathbf{K N}-\mathbf{m})\end{array}$ & $\begin{array}{c}\boldsymbol{E}_{\text {dist }} \\
(\mathbf{K N}-\mathbf{m})\end{array}$ & $\begin{array}{c}\boldsymbol{E}_{\text {irt }} \\
(\mathbf{K N}-\mathbf{m})\end{array}$ \\
\hline \hline Elastic & 1.0 & 5038 & 193 & 583 & 162 & 0 & 583 & 584 \\
$\mathbf{1 . 5}$ & 1.8 & 3439 & 82 & 443 & 70 & 202 & 645 & 645 \\
$\mathbf{1 . 0}$ & 2.4 & 2333 & 52 & 342 & 31 & 300 & 642 & 642 \\
$\mathbf{0 . 7}$ & 3.8 & 1642 & 53 & 272 & 16 & 339 & 611 & 611 \\
$\mathbf{0 . 6}$ & 4.2 & 1420 & 54 & 245 & 12 & 343 & 588 & 588 \\
$\mathbf{0 . 5}$ & 4.6 & 1196 & 54 & 215 & 9 & 347 & 562 & 562 \\
$\mathbf{0 . 4}$ & 5.0 & 968 & 52 & 185 & 6 & 355 & 540 & 540 \\
$\mathbf{0 . 3}$ & 8.3 & 762 & 49 & 160 & 3 & 364 & 524 & 524 \\
$\mathbf{0 . 2}$ & 12.8 & 550 & 43 & 144 & 2 & 353 & 497 & 497 \\
\hline \hline
\end{tabular}



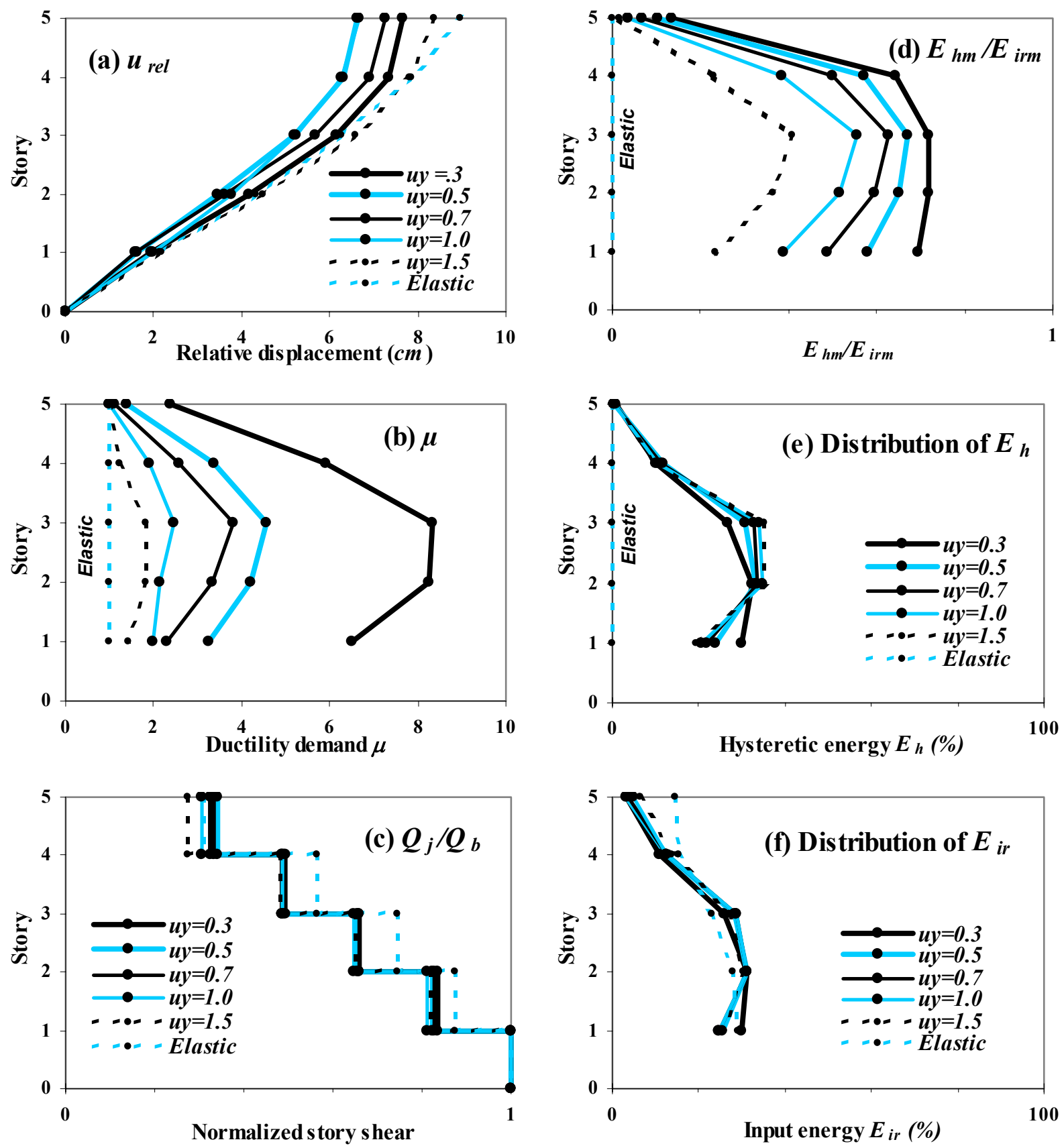

Figure 6.2. (a) Relative displacement $u_{\text {rel }}$, (b) ductility demand $\mu$, (c) normalized story shear, (d) $E_{h m} / E_{i r m}$, (e) distribution of $E_{h}$ though the height, and (f) distribution of $E_{i r}$ through the height for the 5-story building with yield deformations of the first story $u_{y 1}=0.3,0.5,0.7,1.0$, and $1.5 \mathrm{~cm}$ subjected to S00E component of El Centro, the Imperial Valley, CA earthquake of May 18, 1940 scaled to an $E P A=0.4 g$. Also presented are the results for elastic behavior. Parameters for Bouc-Wen Model are: $A=1, \beta=\gamma=0.5, n=20$, and $\alpha=0.02$ 

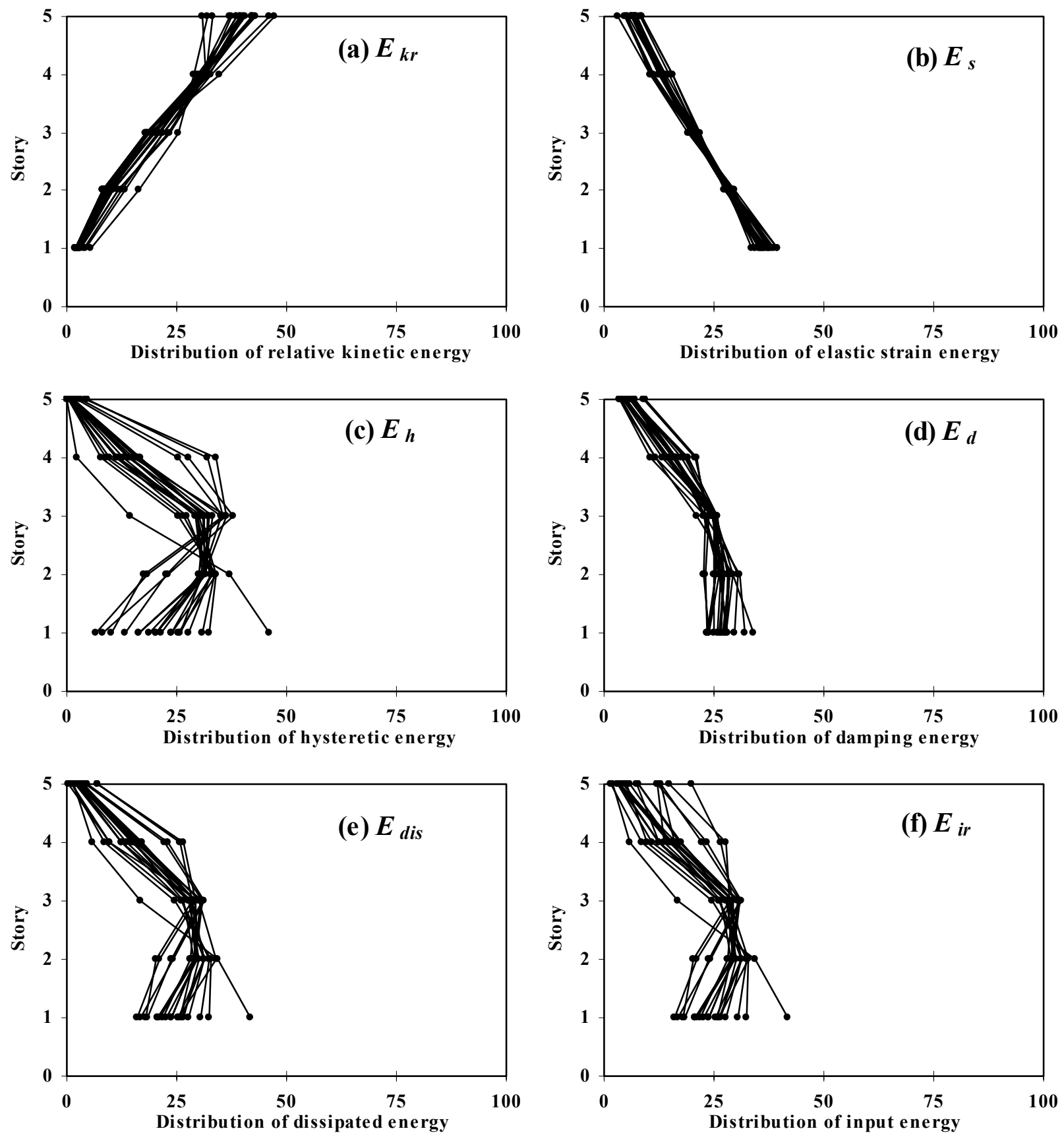

Figure 6.3 Distribution of energy through the height of a 5-story building with $\boldsymbol{u}_{y 1}=0.5 \mathrm{~cm}$ subjected to 20 accelerograms scaled to an $E P A=0.4 g$. Parameters for Bouc-Wen Model are: $A=1, \beta=\gamma=$ $0.5, n=20$, and $\alpha=0.02$ 



\section{DISTRIBUTION OF INPUT ENERGY IN STRUCTURES WITH BASE-ISOLATION, SUPPLEMENTAL DAMPING AND SEMI- ACTIVE CONTROL}

Base isolation, Figure 7.1.b, supplemental damping, and semi-active control are used to reduce the damaging effects of earthquakes. Base isolation reduces the motion transmitted to the structure and the base shear by increasing the period of structure. Supplemental damping reduces the hysteretic energy demand on the structure by dissipating a portion of the input energy. Semi-active control combines the features of active and passive control. Similar to passive systems, control forces are generated by the response of the building, and similar to active systems, controllers are used to monitor feedbacks and apply the control forces. Unlike active systems which require a large power source to generate the control forces, semi-active systems require a smaller power source.

Semi-active control (Figure 7.1.c) includes active variable stiffness and active variable damping. In variable stiffness control, the stiffness of the building is adjusted to prevent resonance of the building from the excitation. In variable damping control, supplemental energy dissipation devices such as friction and fluid dampers are used to reduce the structural response. This chapter presents the energy balance equation for structures with base-isolation and semi-active control, Section 7.1, and the energy distribution for four five-story buildings with: fixed-base, base-isolation, supplemental damping, and semiactive control in Section 7.2.

\subsection{Energy Equations for Buildings with Base-Isolation and Semi- Active Control}

The energy balance equation for a base-isolated building with a base mass $m_{b}$ (Figure 7.1.b) is similar to a fixed-base building (Figure 7.1.a) with an additional degree of freedom for the base isolation, see equation B.2 in Appendix B. Assuming that the building undergoes a rigid body motion, the period of the base-isolated building can be approximated as

$$
T_{b}=2 \pi \sqrt{\frac{\left(\sum_{j=1}^{5} m_{j}\right)+m_{b}}{k_{b}}} \quad \text { and } \quad \omega_{b}=\frac{2 \pi}{T_{b}}
$$

and the damping ratio of the base isolation system as 


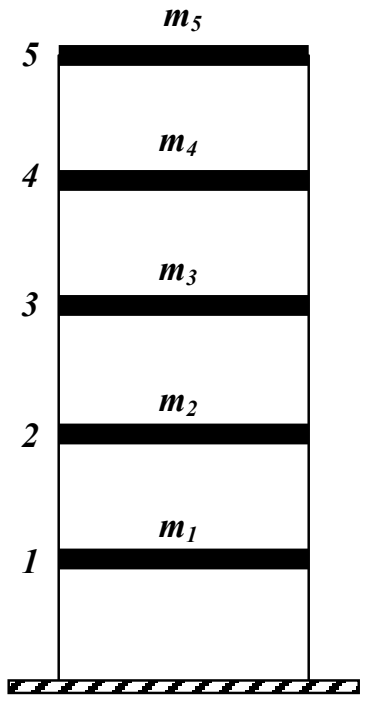

(a)

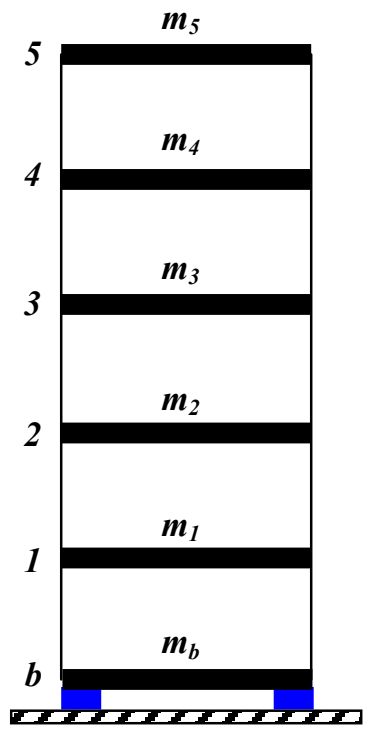

(b)

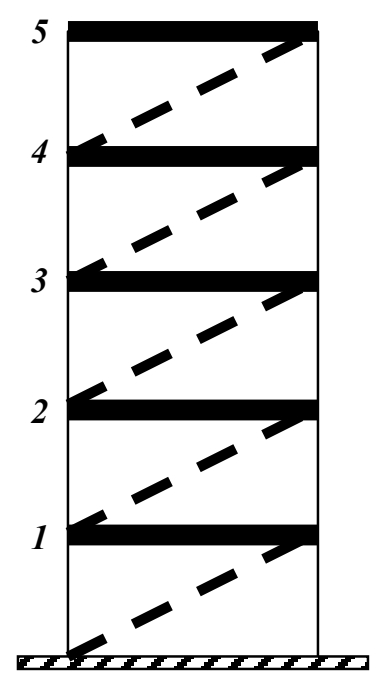

(c)

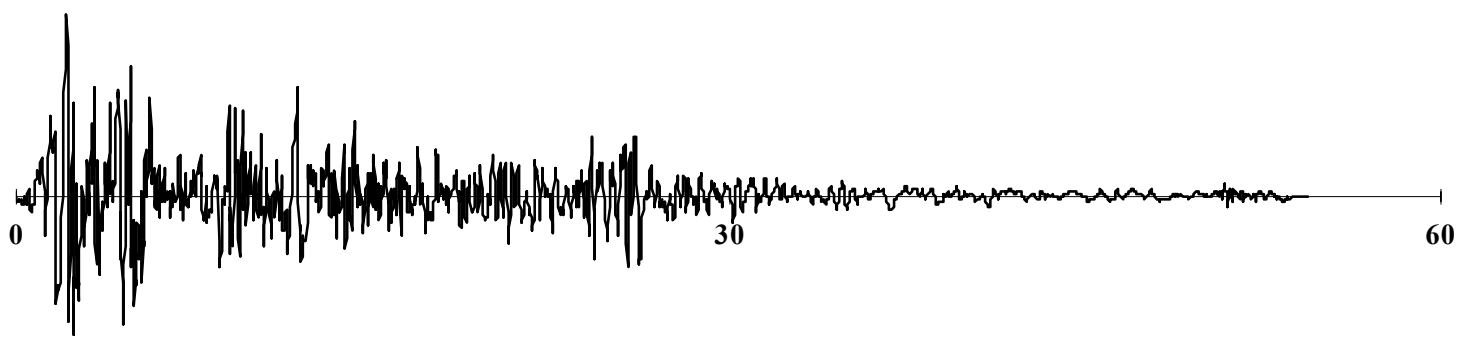

Figure 7.1. (a) Five-story building with fixed base, (b) with base-isolation, and (c) with supplemental damping or semi-active control subjected to the SOOE component of El Centro, the Imperial Valley, CA earthquake of May 18, 1940 scaled to an $E P A=0.4 \mathrm{~g}$ 


$$
\xi_{b}=\frac{c_{b}}{2\left(\sum_{j=1}^{5} m_{j}+m_{b}\right) \omega_{b}}
$$

The energy balance equation for a building with supplemental damping (Figure 7.1.c) is similar to a fixed-base building, see equation B.2 in Appendix B. The total damping of the structure (inherent and supplemental) should be used in the analysis.

The governing differential equation of motion for a non-linear $n$-story shear building with $m$ semi-active dampers (Figure 7.1.c) is (see Yang et al. 1992)

$$
F_{i}(t)+F_{d}(t)+F_{s}(t)=-\xi \ddot{u}_{g}(t)+D F_{c}(t)
$$

where $F_{i}$ is an $n$-dimensional inertia force vector, $F_{d}$ is an $n$-dimensional damping force vector, $F_{s}$ is an $n$-dimensional non-linear restoring force vector, $\xi$ is an $n$ dimensional mass vector, $\ddot{u}_{g}$ is ground acceleration, $D$ is an $n \times m$ matrix defining the locations of control forces, and $F_{c}$ denotes an $m$-dimensional control force vector. The inertia force vector can be written as $F_{i}=M \ddot{u}$ where $M$ is an $n \times n$ mass matrix and $\ddot{u}$ is an $n$-dimensional acceleration vector. The damping force can be written as $F_{d}=C \dot{u}$ where $C$ is an $n \times n$ damping matrix and $\dot{u}$ is an $n$-dimensional velocity vector. The restoring force, however, is a non-linear function of $u$ and $\dot{u}$.

Using the state-space representation, equation (7.3) can be written as

$$
\dot{z}(t)=g[z(t)]+B u(t)+H \ddot{u}_{g}(t)
$$

in which the $2 n$ - dimensional vector $g[z(t)]$ is given by

$$
g[z(t)]=\left\{\begin{array}{c}
\dot{u}(t) \\
-M^{-1}\left[F_{d}+F_{s}\right]
\end{array}\right\}
$$

and $z(t)$ is

$$
z(t)=\left\{\begin{array}{c}
u(t) \\
\dot{u}(t)
\end{array}\right\}
$$

The control input matrix $B$ is 


$$
B=\left[\begin{array}{c}
0 \\
M^{-1} D
\end{array}\right]
$$

and the disturbance input vector $H$ is

$$
H=\left\{\begin{array}{c}
0 \\
M^{-1} \xi
\end{array}\right\}
$$

For the linear quadratic regulator algorithm (LQR), the optimal control force $F_{c}(t)$ in equation (7.3) is selected by minimizing the performance index $J$

$$
J=\int_{0}^{t_{f}}\left[z^{T}(t) Q z(t)+F_{c}^{T}(t) R F_{c}(t)\right] d t
$$

where $t_{f}$ is the duration of accelerogram, $Q=q I$ is a $2 n \times 2 n$ symmetric positive semi-definite weighting matrix ( $q$ is a scalar and $I$ is unit matrix), and $R=r I$ is an $m \times m$ positive definite weighting matrix ( $r$ is a scalar and $I$ is unit matrix). By linearizing the hysteretic behavior of the structure at the initial equilibrium state and minimizing the performance index subject to the constraint of equation (7.4), the control forces are obtained as

$$
F_{c}(t)=-0.5 R^{-1} B^{T} P z(t)=G z(t)
$$

where $G$ is an $m \times 2 n$ feedback gain matrix and $P$ is a $2 n \times 2 n$ matrix obtained from the solution of the classical Riccati equation

$$
2 Q z+\Lambda(z) P z+\dot{P} z+P \dot{z}=0
$$

where

$$
\Lambda(z)=\partial g(z) / \partial z
$$

Transposing equation (7.3), multiplying both sides by $d u=\dot{u} d t$ and integrating, one obtains the energy balance equation as

$$
\int_{0}^{u} F_{i}^{T}(t) d u+\int_{0}^{u} F_{d}^{T}(t) d u+\int_{0}^{u} F_{s}^{T}(t) d u=-\int_{0}^{u} \xi \ddot{u}_{g}(t) d u+\int_{0}^{u} F_{c}^{T}(t) D^{T} d u
$$

The energy corresponding to the controller is 


$$
E_{c}=\int_{0}^{t} F_{c}^{T} D^{T} \dot{u} d t
$$

Other energy vectors are defined in Appendix B. Equation (7.13) can be written as

$$
E_{k r}+E_{d}+E_{s}+E_{h}=E_{i r}+E_{c}
$$

where each term is an $n$-dimensional vector.

\subsection{Numerical results}

The lead-core rubber isolation bearing used in the example has a period $T_{b}=2.0 \mathrm{~s}$ and a damping ratio $\xi_{b}=10 \%$. The weight of the base is equal to the weight of individual floors $W_{b}=1000 \mathrm{KN}$, the stiffness of the base isolation system $k_{b}=6036 \mathrm{KN} / \mathrm{m}$, and the damping coefficient $c_{b}=384 \mathrm{KN}-\mathrm{s} / \mathrm{m}$. The Bouc-Wen parameters for the lead-core rubber bearing are $A=1, \beta=\gamma=0.5, n=3$, and $\alpha=0.6$ (Yang et al., 1992). For the building with supplemental damping one damper is used at each story and the total damping (inherent and supplemental) is $40 \%$. For the building with semi-active control one damper is used at each story. The weight parameters used for 20 accelerograms are $r$ $=10^{-5}$ and $q=10^{+5}$. As $q$ increases, the control force increases. The yield deformation for the first story is $u_{y l}=0.5 \mathrm{~cm}$ for all buildings.

Figure 7.2, 7.3, and 7.4 show the percentage of energy distributed through the height of the five-story building with base isolation, supplemental damping, and semi-active control subjected to the 20 records scaled to an $E P A=0.4 g$. Figures 6.3, 7.2, 7.3, and 7.4 conclude that ground motion characteristics have a minor influence on the distribution of energy through the height of the buildings. Figure 7.2 shows that base isolation is effective for structures subjected to all accelerograms, except the Mexico City accelerogram since the period of base-isolation $\left(T_{b}=2.0 \mathrm{~s}\right)$ is close to the predominant period of the accelerogram $\left(T_{p e}=2.0 \mathrm{~s}\right)$. Therefore, using base-isolation for a 5 story building in Mexico City is detrimental, while it is effective in reducing the ductility and energy dissipation demand for building in other locations.

The average percentage of hysteretic energy, input energy, and story shear in each story for the four buildings subjected to the 20 accelerograms scaled to an $E P A=0.4 g$ are given in Table 7.1 and plotted in Figure 7.5. The figure indicates that the energy distribution for the buildings with fixed base, supplemental damping, and semi-active control are similar, whereas the energy distribution for the building with base isolation is significantly affected by the isolator, i.e. the majority of the input energy is absorbed and dissipated in the isolator. The story shear distribution is also similar for the four buildings.

Table 7.2.a presents the maximum drift, the maximum relative displacement, the ductility ratio, and the maximum story shear, and Table 7.2.b shows the maximum energy 

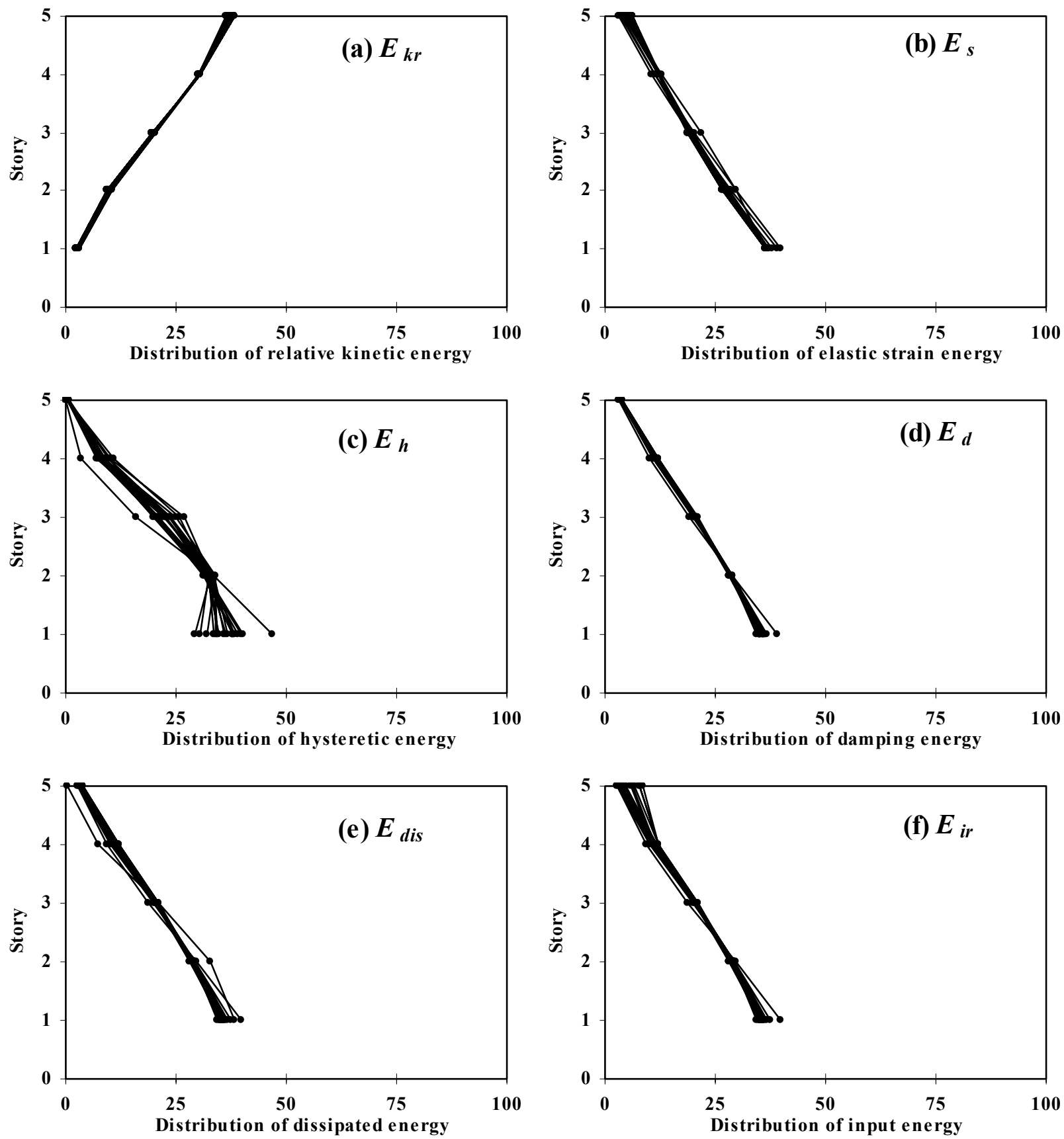

Figure 7.2 Distribution of energy through the height of a 5-story building with base isolation (10\% damping, $T_{b}=2.0 \mathrm{~s}$, and $u_{y b}=4.0 \mathrm{~cm}$ ) with $u_{y 1}=0.5 \mathrm{~cm}$ subjected to 20 records scaled to an $E P A=$ 0.4g. Parameters for Bouc-Wen Model for the stories are: $A=1, \beta=\gamma=0.5, n=20$, and $\alpha=0.02$ and for base isolation system are: $A=1, \beta=\gamma=0.5, n=3$, and $\alpha=0.6$ 

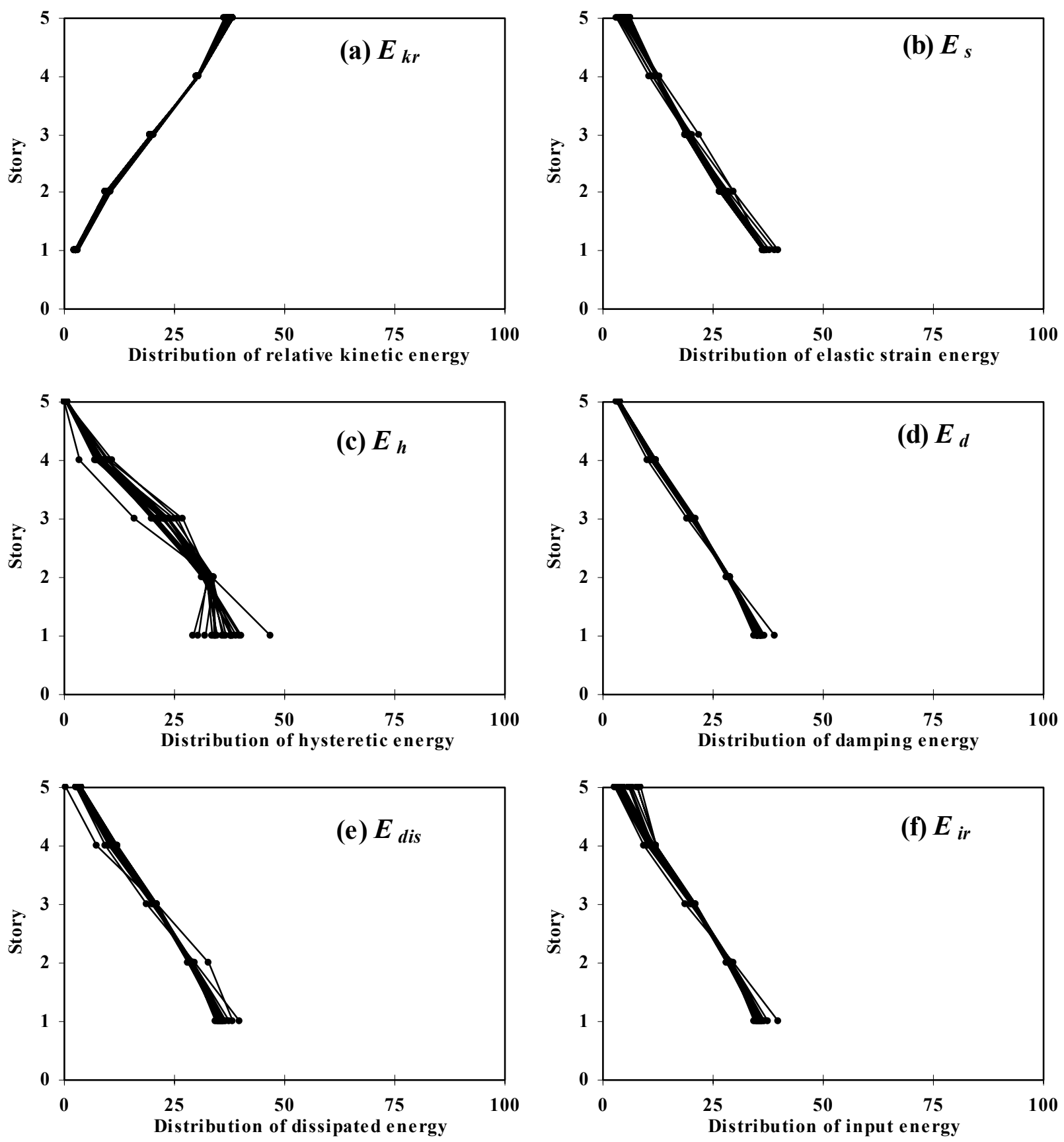

Figure 7.3. Distribution of energy through the height of a 5-story building with supplemental damping (total damping $40 \%$ ) with $u_{y 1}=0.5 \mathrm{~cm}$ subjected to 20 records scaled to an $E P A=0.4 g$. Parameters for Bouc-Wen Model for the stories are: $A=1, \beta=\gamma=0.5, n=20$, and $\alpha=0.02$ 

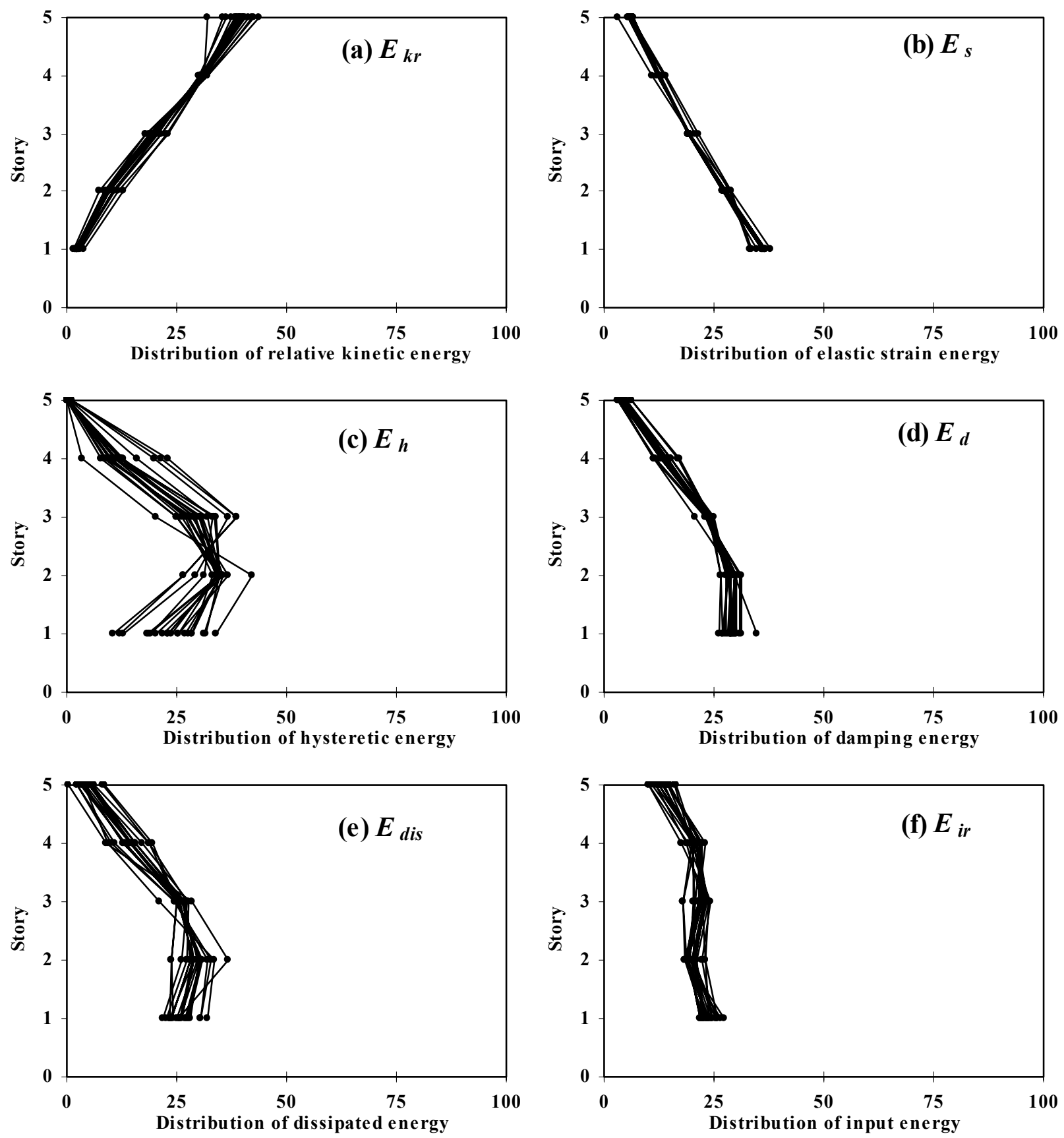

Figure 7.4. Distribution of energy through the height of a 5-story building with semi-active control $(r$ $=10^{-5}$ and $q=10^{+5}$ ) with $u_{y l}=0.5 \mathrm{~cm}$ subjected to 20 records scaled to an $E P A=0.4 \mathrm{~g}$. Parameters for Bouc-Wen Model for the stories are: $A=1, \beta=\gamma=0.5, n=20$, and $\alpha=0.02$ 
Table 7.1. The average distribution percentage of hysteretic energy, input energy, and story shear, in percent, in each story of the five-story building with fixed-base, base isolation, supplemental damping, and semi-active control subjected to 20 accelerograms scaled to an $E P A=0.4 g$.

Table 7.1.a Distribution of hysteretic energy $E_{h}(\%)$

\begin{tabular}{c||cccc}
\hline \hline 1 & 2 & 3 & 4 & 5 \\
\hline \multirow{2}{*}{ Story } & $\begin{array}{c}\text { Fixed } \\
\text { Base }\end{array}$ & $\begin{array}{c}\text { Base } \\
\text { Isolation }\end{array}$ & $\begin{array}{c}\text { Suppl. } \\
\text { Damp. }\end{array}$ & $\begin{array}{c}\text { Semi } \\
\text { Active }\end{array}$ \\
\hline \hline $\mathbf{5}$ & 1 & 0 & 1 & 1 \\
$\mathbf{4}$ & 16 & 0 & 8 & 12 \\
$\mathbf{3}$ & 31 & 0 & 22 & 30 \\
$\mathbf{2}$ & 30 & 1 & 33 & 34 \\
$\mathbf{1}$ & 22 & 1 & 36 & 23 \\
Base & - & 98 & - & - \\
\hline \hline
\end{tabular}

Table 7.1.b Distribution of input energy $E_{i r}(\%)$

\begin{tabular}{c||cccc}
\hline \hline 1 & 2 & 3 & 4 & 5 \\
\hline \multirow{2}{*}{ Story } & $\begin{array}{c}\text { Fixed } \\
\text { Base }\end{array}$ & $\begin{array}{c}\text { Base } \\
\text { Isolation }\end{array}$ & $\begin{array}{c}\text { Suppl. } \\
\text { Damp. }\end{array}$ & $\begin{array}{c}\text { Semi } \\
\text { Active }\end{array}$ \\
\hline \hline $\mathbf{5}$ & 7 & 6 & 6 & 7 \\
$\mathbf{4}$ & 15 & 6 & 11 & 20 \\
$\mathbf{3}$ & 27 & 6 & 20 & 21 \\
$\mathbf{2}$ & 28 & 6 & 28 & 19 \\
$\mathbf{1}$ & 23 & 6 & 35 & 23 \\
Base & - & 71 & - & - \\
\hline \hline
\end{tabular}

Table 7.1.c Distribution of story shear $Q(\%)$

\begin{tabular}{c||cccc}
\hline 1 & 2 & $3^{*}$ & 4 & 5 \\
\hline \multirow{2}{*}{ Story } & $\begin{array}{c}\text { Fixed } \\
\text { Base }\end{array}$ & $\begin{array}{c}\text { Base } \\
\text { Isolation }\end{array}$ & $\begin{array}{c}\text { Suppl. } \\
\text { Damp. }\end{array}$ & $\begin{array}{c}\text { Semi } \\
\text { Active }\end{array}$ \\
\hline \hline $\mathbf{5}$ & 32 & 26 & 29 & 31 \\
$\mathbf{4}$ & 50 & 49 & 48 & 49 \\
$\mathbf{3}$ & 67 & 68 & 64 & 66 \\
$\mathbf{2}$ & 84 & 85 & 82 & 83 \\
$\mathbf{1}$ & 100 & 100 & 100 & 100 \\
\hline \hline
\end{tabular}

\footnotetext{
* The distribution of story shear for the building with base isolation is given for the super structure.
} 

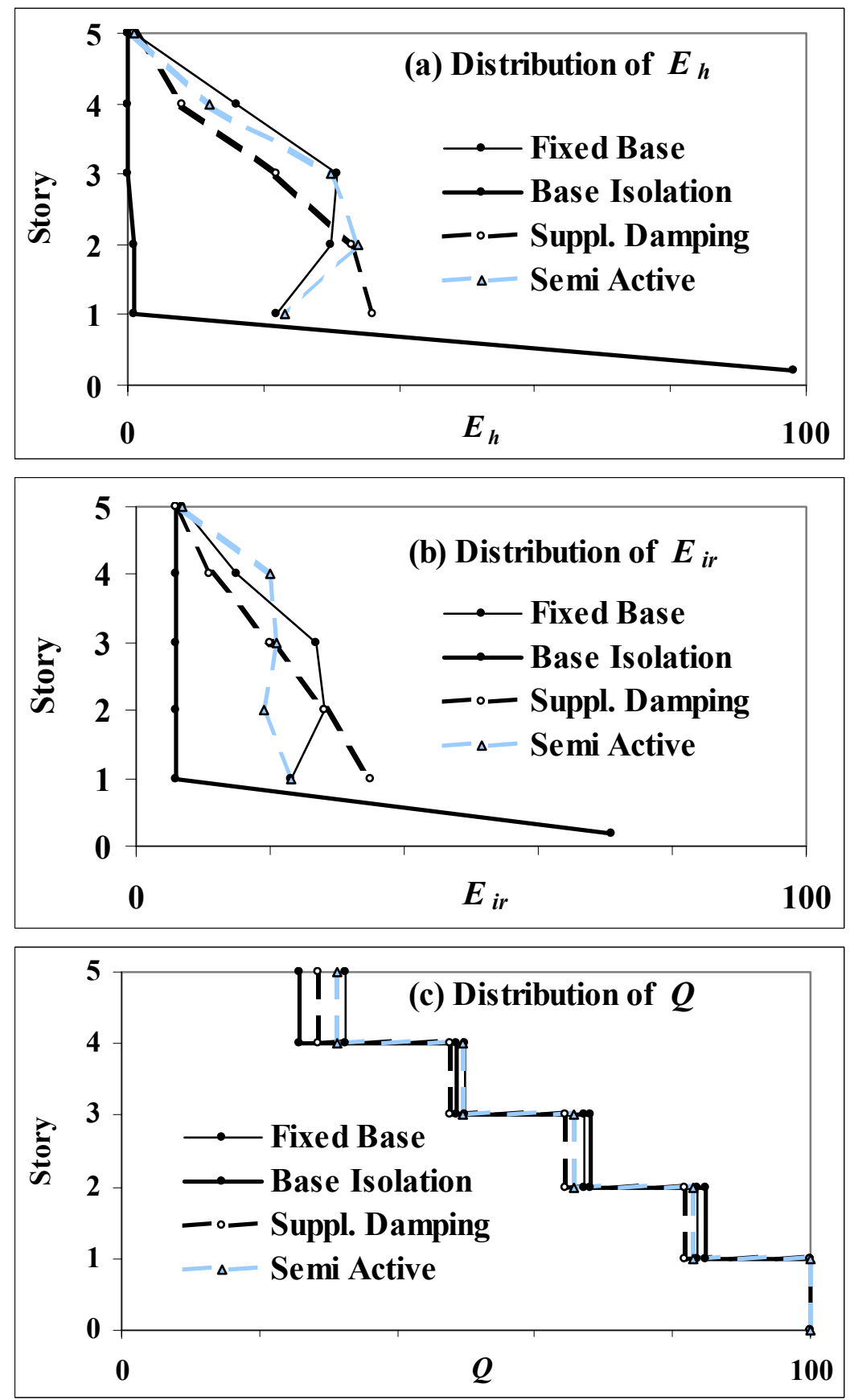

Figure 7.5. Distribution of (a) hysteretic energy $E_{h}$, (b) input energy $E_{i r}$, and (c) story shear $Q$ distributed in the stories of the 5-story building with fixed base, base isolation, supplemental damping, and semi-active control subjected to 20 records scaled to an $E P A=0.4 g$. Parameters for Bouc-Wen Model for the stories are: $A=1, \beta=\gamma=0.5, n=20$, and $\alpha=0.02$. Note that for the building with base isolation the percentage is given for the base shear of the super structure. 
Table 7.2. (a) Maximum drift, maximum relative displacement, ductility ratio, and maximum story shear for each story, and (b) maximum damping, maximum hysteretic, maximum controller, and maximum input energies for the four buildings (with fixed-base, base-isolation, supplemental damping, and semi-active control) subjected to the $\mathrm{S00E}$ component of El Centro, the Imperial Valley, $\mathrm{CA}$ earthquake of $\mathrm{May} 18,1940$ scaled to an $E P A=0.4 g$.

Table 7.2.a Response parameters

\begin{tabular}{|c|c|c|c|c|c|c|c|c|c|c|c|c|c|c|c|c|}
\hline \multirow[b]{2}{*}{1} & \multicolumn{4}{|c|}{ with fixed-base } & \multicolumn{4}{|c|}{ with base-isolation } & \multicolumn{4}{|c|}{ with supplemental damping } & \multicolumn{4}{|c|}{ with semi-active control } \\
\hline & 2 & 3 & 4 & 5 & 6 & 7 & 8 & 9 & 10 & 11 & 12 & 13 & 14 & 15 & 16 & 17 \\
\hline \multirow[t]{2}{*}{ Story } & Drift & $u_{r e l}$ & $\mu$ & $Q$ & Drift & $u_{\text {rel }}$ & $\mu$ & $Q$ & Drift & $u_{\text {rel }}$ & $\mu$ & $Q$ & Drift & $u_{\text {rel }}$ & $\mu$ & $Q$ \\
\hline & $(\mathrm{cm})$ & $(\mathrm{cm})$ & & $(\mathrm{KN})$ & $(\mathrm{cm})$ & $(\mathrm{cm})$ & & $(\mathrm{KN})$ & $(\mathrm{cm})$ & $(\mathrm{cm})$ & & $(\mathrm{KN})$ & $(\mathrm{cm})$ & $(\mathrm{cm})$ & & $(\mathrm{KN})$ \\
\hline 5 & 0.39 & 6.72 & 1.3 & 409 & 0.11 & 20.97 & 1.0 & 157 & 0.31 & 3.29 & 1.0 & 387 & 0.22 & 2.95 & 1.00 & 304 \\
\hline 4 & 1.15 & 6.40 & 3.3 & 625 & 0.19 & 20.87 & 1.0 & 307 & 0.56 & 2.98 & 1.6 & 577 & 0.46 & 2.73 & 1.31 & 560 \\
\hline 3 & 1.85 & 5.26 & 4.6 & 865 & 0.24 & 20.69 & 1.0 & 446 & 0.71 & 2.43 & 1.8 & 761 & 0.73 & 2.27 & 1.83 & 745 \\
\hline 1 & 1.62 & 1.62 & 3.2 & 1273 & 0.32 & 20.18 & 1.0 & 729 & 0.91 & 0.91 & 1.8 & 1192 & 0.75 & 0.75 & 1.49 & 1153 \\
\hline Base & - & - & - & - & 19.87 & 19.87 & 5.0 & 816 & - & - & - & - & - & - & - & - \\
\hline
\end{tabular}

Table 7.2.b Energy parameters

\begin{tabular}{|c|c|c|c|c|c|c|c|c|c|c|c|c|c|c|}
\hline \multirow[b]{2}{*}{1} & \multicolumn{3}{|c|}{ with fixed-base } & \multicolumn{3}{|c|}{ with base-isolation } & \multicolumn{4}{|c|}{ with supplemental damping } & \multicolumn{4}{|c|}{ with semi-active control } \\
\hline & 2 & 3 & 4 & 5 & 6 & 7 & 8 & 9 & 10 & 11 & 12 & 13 & 14 & 15 \\
\hline \multirow[t]{2}{*}{ Story } & $E_{d}$ & $E_{h}$ & $E_{i r}$ & $E_{d}$ & $E_{h}$ & $E_{i r}$ & $E_{d}$ & $E_{h}$ & $E_{c}$ & $E_{i r}$ & $E_{d}$ & $E_{h}$ & $E_{c}$ & $E_{i r}$ \\
\hline & $(\mathrm{KN}-\mathrm{m})$ & $(\mathrm{KN}-\mathrm{m})$ & $(\mathrm{KN}-\mathrm{m})$ & $(\mathrm{KN}-\mathrm{m})$ & $(\mathrm{KN}-\mathrm{m})$ & $(\mathrm{KN}-\mathrm{m})$ & $(\mathrm{KN}-\mathrm{m})$ & $(\mathrm{KN}-\mathrm{m})$ & $(\mathrm{KN}-\mathrm{m})$ & $(\mathrm{KN}-\mathrm{m})$ & $(\mathrm{KN}-\mathrm{m})$ & $(\mathrm{KN}-\mathrm{m})$ & $(\mathrm{KN}-\mathrm{m})$ & $\begin{array}{c}\mathrm{KN}- \\
\mathrm{m})\end{array}$ \\
\hline 5 & 10 & 2 & 20 & 0 & 0 & 21 & 12 & 0 & & 13 & 1 & 0 & 10 & 12 \\
\hline 4 & 31 & 41 & 72 & 0 & 0 & 21 & 39 & 3 & & 42 & 5 & 2 & 15 & 22 \\
\hline 3 & 54 & 108 & 163 & 0 & 0 & 21 & 69 & 8 & & 77 & 8 & 6 & 18 & 33 \\
\hline 2 & 63 & 116 & 179 & 0 & 0 & 20 & 98 & 12 & & 110 & 11 & 8 & 19 & 38 \\
\hline 1 & 61 & 83 & 144 & 1 & 0 & 20 & 122 & 14 & & 136 & 11 & 5 & 19 & 35 \\
\hline Base & - & - & - & 254 & 104 & 358 & - & - & & - & - & - & - & - \\
\hline Total & 218 & 351 & 578 & 255 & 104 & 360 & 340 & 37 & & 378 & 36 & 21 & 81 & 140 \\
\hline
\end{tabular}

${ }^{\mathrm{a}}$ Total input energy transmitted to stories 1 to 5 are $103 \mathrm{KN}-\mathrm{m}$. 
parameters: damping, hysteretic, controller, and input for each story of the four buildings subjected to the S00E component of El Centro, the Imperial Valley, CA earthquake of May 18, 1940 scaled to an $E P A=0.4 g$. To have a larger force in controllers, the weight parameters used in the analysis are selected as $r=10^{-5}$ and $q=10^{+6}$. Except for the baseisolated building, the total input energy is equal to the sum of the maximum input energies of all stories. For the base-isolated building, all stories behave elastically, and the base isolation system behaves inelastically. The maximum input energy for the stories occurs in the initial stages of the excitation, whereas the maximum input energy for the base isolation system occurs at the end of the excitation. Consequently, one cannot add up the input energies measured at different times to obtain the total input energy. The total input energy for stories 1 to 5 of the base-isolated building is $103 \mathrm{KN}$ $\mathrm{m}$ (see Table 7.2.b). The total input energy transmitted to the buildings with baseisolation, supplemental damping, and semi-active control are approximately $20 \%, 65 \%$, and $25 \%$ of the total input energy transmitted to the building with fixed base, respectively.

For the base-isolated building $\left(T_{b}=2.0 \mathrm{~s}\right)$ subjected to the El Centro accelerogram $\left(T_{p a}=\right.$ $0.26 \mathrm{~s}$ and $T_{p e}=0.86 \mathrm{~s}$, see Table 4.1), the base shear (see columns 5 and 9 of Table 7.2.a and Figure 7.6.c), and the total input energy (columns 4 and 7 of Table 7.2.b) are approximately $60 \%$ of those for the fixed base building. The story drifts (columns 2 and 6 of Table 7.2.a) of the base-isolated building are less than $30 \%$ of the story drift for the fixed-base building. The base-isolated building behaves like a rigid body (Figure 7.6.a) and all stories remain elastic during the excitation (column 8 of Table 7.2.a; Figures 7.6.b, 7.6.d, and 7.6.e). The results indicate that the input energy is dissipated in the base isolation system (columns 5 and 7 of Table 7.2.b).

The base shear for the building with semi-active control is approximately 90 percent of the base shear for the fixed-base building, whereas the input energy is approximately 20 percent. The maximum control forces generated in the buildings with semi-active control is $288 \mathrm{KN}$.

Table 7.3 shows the distribution of energy among various energy components for the four buildings subjected to the S00E component of El Centro, the Imperial Valley, CA earthquake of May 18, 1940 scaled to an $E P A=0.4 \mathrm{~g}$. The results indicate that providing base isolation, supplemental damping, or semi active dampers has a significant influence on the energy demand.

Finally, the first story drift and total input energy for the four buildings subjected to the S00E component of the $1940 \mathrm{El}$ Centro accelerogram scaled to an $E P A=0.4 \mathrm{~g}$ are compared in Figures 7.7 and 7.8, respectively. It is observed that both the drift and input energy of the buildings with base-isolation, supplemental damping, and semi-active control are less than those for the fixed-base building. According to Figure 7.7, baseisolation is the most effective system in reducing the base shear and drift for this building subjected to El Centro accelerogram. Results conclude that base-isolation, supplemental damping, and semi-active control are all effective in reducing the hysteretic energy demand for this building subjected to El Centro accelerogram. 

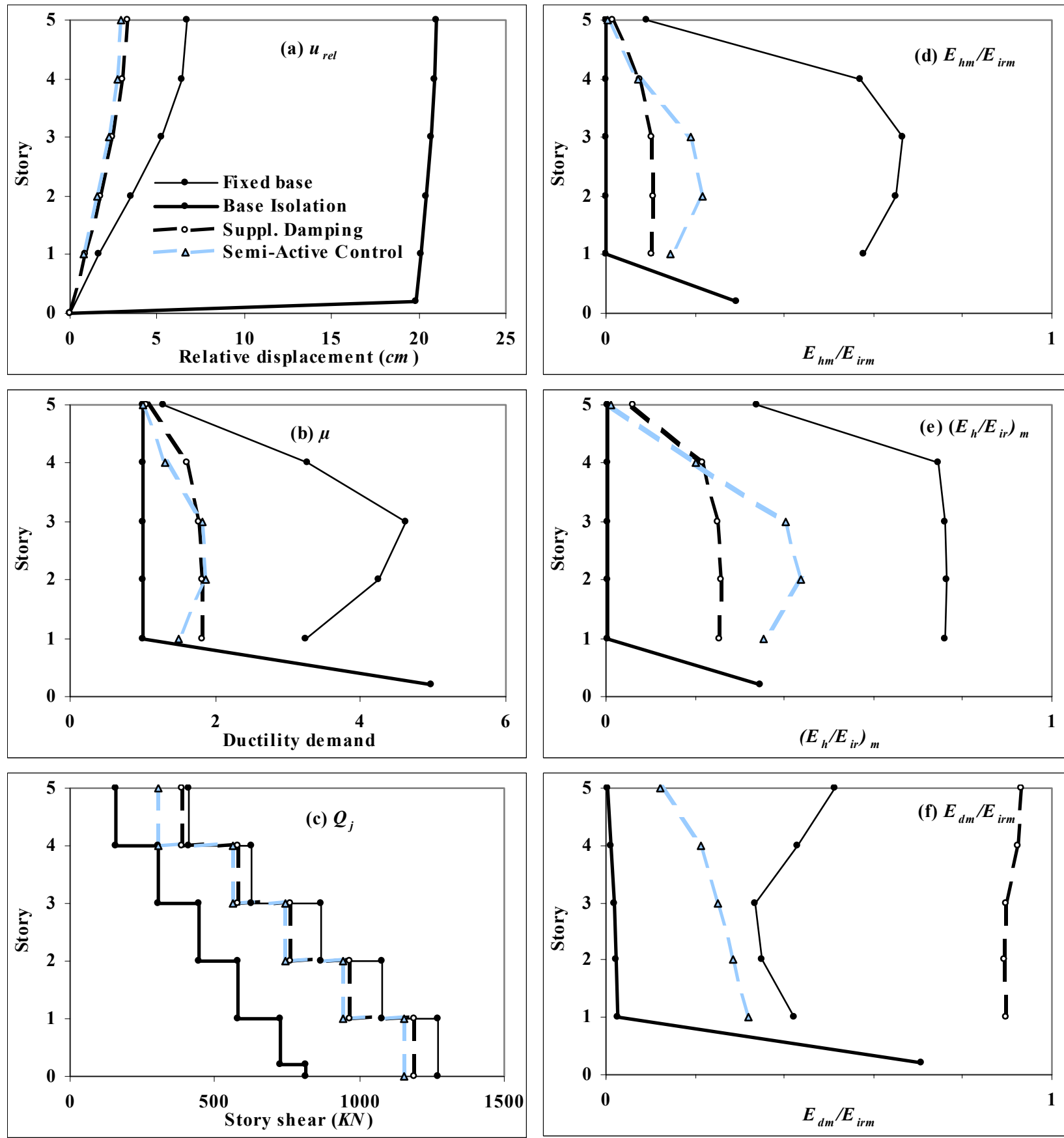

Figure 7.6. (a) Relative displacement, (b) ductility demand, (c) story shear, (d) $E_{h m} / E_{i r m},(\mathrm{e})\left(E_{h} / E_{i r}\right)_{m}$, and (f) $E_{d m} / E_{i r m}$ for the five-story buildings: fixed-base, base-isolated, semi-active with large control force, and semi-active with small control force with $u_{y l}=0.5 \mathrm{~cm}$ and $\xi_{1}=5 \%$ subjected to the S00E component of El Centro, the Imperial Valley earthquake of May 18, 1940 scaled to an $E P A=0.4 \mathrm{~g}$. Parameters for Bouc-Wen Model are: $A=1, \beta=\gamma=0.5, n=20$, and $\alpha=0.02$, and for the base isolation system are: $A=1, \beta=\gamma=0.5, n=3$, and $\alpha=0.6$ 
Table 7.3. The energy ratios $E_{k r} / E_{i r}, E_{d} / E_{i r}, E_{s} / E_{i r}, E_{h} / E_{i r}$, and $E_{c} / E_{i r}$ for the the four buildings (a) fixed-base, (b) base-isolated, (c) semi-active with small control forces, (d) and semi-active with large control forces subjected to the S00E component of El Centro, the Imperial Valley, CA earthquake of May 18, 1940 scaled to an $E P A=0.4 g$.

Table 7.3.a The building with fixed-base

\begin{tabular}{|c|c|c|c|c|c|}
\hline 1 & 2 & 3 & 4 & 5 & 6 \\
\hline Story & $\boldsymbol{E}_{\boldsymbol{k r m}} / \boldsymbol{E}_{\text {irm }}$ & $\boldsymbol{E}_{\boldsymbol{s m}} / \boldsymbol{E}_{\text {irm }}$ & $\boldsymbol{E}_{\boldsymbol{d m}} / \boldsymbol{E}_{\text {irm }}$ & $\boldsymbol{E}_{\boldsymbol{h m}} / \boldsymbol{E}_{\text {irm }}$ & $\boldsymbol{E}_{\text {dism }} / \boldsymbol{E}_{\text {irm }}$ \\
\hline \hline 1 & 0.90 & 0.51 & 0.03 & 0.09 & 0.60 \\
\hline 2 & 0.26 & 0.43 & 0.02 & 0.57 & 1.00 \\
\hline 3 & 0.09 & 0.33 & 0.01 & 0.67 & 1.00 \\
\hline 4 & 0.04 & 0.35 & 0.02 & 0.65 & 1.00 \\
\hline 5 & 0.01 & 0.42 & 0.02 & 0.58 & 1.00 \\
\hline Total & 0.10 & 0.38 & 0.02 & 0.62 & 1.00 \\
\hline
\end{tabular}

Table 7.3.b The building with base isolation system

\begin{tabular}{|c|c|c|c|c|c|}
\hline 1 & 2 & 3 & 4 & 5 & $\boldsymbol{6}$ \\
\hline Story & $\boldsymbol{E}_{\boldsymbol{k r m}} / \boldsymbol{E}_{\text {irm }}$ & $\boldsymbol{E}_{\boldsymbol{s m}} / \boldsymbol{E}_{\text {irm }}$ & $\boldsymbol{E}_{\boldsymbol{d m}} / \boldsymbol{E}_{\text {irm }}$ & $\boldsymbol{E}_{\text {hm }} / \boldsymbol{E}_{\text {irm }}$ & $\boldsymbol{E}_{\text {dism }} / \boldsymbol{E}_{\text {irm }}$ \\
\hline \hline 1 & 1.00 & 0.00 & 0.00 & 0.00 & 0.00 \\
\hline 2 & 0.99 & 0.01 & 0.01 & 0.00 & 0.01 \\
\hline 3 & 0.98 & 0.02 & 0.03 & 0.00 & 0.02 \\
\hline 4 & 0.97 & 0.02 & 0.04 & 0.00 & 0.02 \\
\hline 5 & 0.96 & 0.03 & 0.06 & 0.00 & 0.03 \\
\hline Base & 0.05 & 0.71 & 0.15 & 0.29 & 1.00 \\
\hline Total & 0.33 & 0.71 & 0.16 & 0.29 & 1.00 \\
\hline \hline
\end{tabular}

Table 7.3.c The building with supplemental damping

\begin{tabular}{|c|c|c|c|c|c|}
\hline 1 & $\mathbf{2}$ & $\mathbf{3}$ & $\mathbf{4}$ & $\mathbf{5}$ & $\boldsymbol{6}$ \\
\hline Story & $\boldsymbol{E}_{\boldsymbol{k r m}} / \boldsymbol{E}_{\text {irm }}$ & $\boldsymbol{E}_{\boldsymbol{s m}} / \boldsymbol{E}_{\text {irm }}$ & $\boldsymbol{E}_{\boldsymbol{d m}} / \boldsymbol{E}_{\text {irm }}$ & $\boldsymbol{E}_{\text {hm }} / \boldsymbol{E}_{\text {irm }}$ & $\boldsymbol{E}_{\text {dism }} / \boldsymbol{E}_{\text {irm }}$ \\
\hline \hline 1 & 0.32 & 0.93 & 0.04 & 0.02 & 0.95 \\
\hline 2 & 0.08 & 0.93 & 0.02 & 0.07 & 1.00 \\
\hline 3 & 0.03 & 0.90 & 0.02 & 0.10 & 1.00 \\
\hline 4 & 0.01 & 0.89 & 0.02 & 0.11 & 1.00 \\
\hline 5 & 0.00 & 0.90 & 0.02 & 0.10 & 1.00 \\
\hline Total & 0.03 & 0.90 & 0.02 & 0.10 & 1.00 \\
\hline \hline
\end{tabular}

Table 7.3.d The building with semi-active control

\begin{tabular}{|c|c|c|c|c|c|c|}
\hline 1 & 2 & 4 & 3 & 5 & 6 & 7 \\
\hline Story & $E_{\text {krm }} / E_{\text {irm }}$ & $E_{s m} / E_{i r m}$ & $E_{d m} / E_{i r m}$ & $E_{h m} / E_{i r m}$ & $E_{\text {dism }} / E_{i r m}$ & $E_{c m} / E_{i r m}$ \\
\hline 1 & 0.37 & 0.12 & 0.03 & 0.00 & 0.95 & 0.82 \\
\hline 2 & 0.16 & 0.21 & 0.05 & 0.07 & 1.00 & 0.72 \\
\hline 3 & 0.06 & 0.25 & 0.05 & 0.19 & 1.00 & 0.56 \\
\hline 4 & 0.02 & 0.28 & 0.06 & 0.22 & 1.00 & 0.50 \\
\hline 5 & 0.01 & 0.32 & 0.08 & 0.14 & 1.00 & 0.54 \\
\hline Total & 0.08 & 0.26 & 0.06 & 0.15 & 1.00 & 0.59 \\
\hline
\end{tabular}




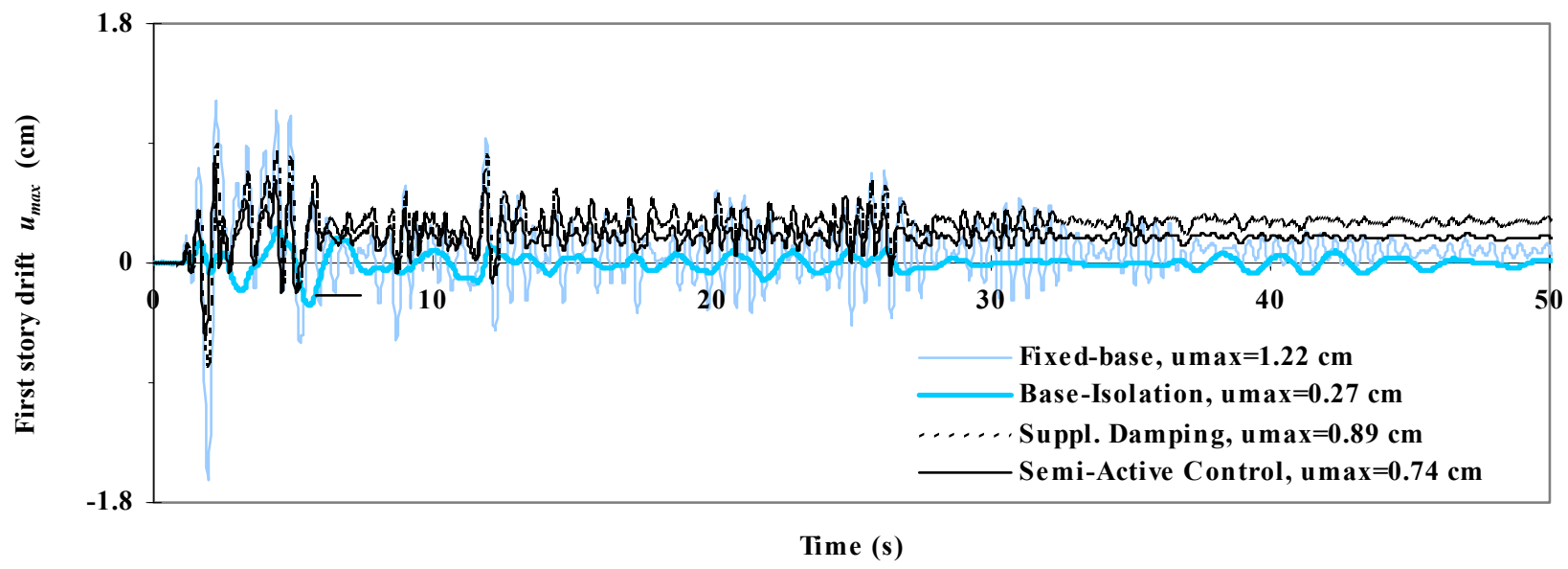

Figure 7.7. Drift time-histories for the first story of the buildings with fixed-base, base-isolation, supplemental damping, and semi-active control subjected to the S00E component of El Centro, the Imperial Valley, CA earthquake of May 18, 1940 scaled to an $E P A=0.4 g$. Parameters used for Bouc-Wen Model for the stories are $A=1, \beta=\gamma=0.5, n=20, \alpha=0.02$, and for the base isolation system are $A=1, \beta=\gamma=0.5, n=3, \alpha=0.6$. The total damping of the building with supplemental damping is $40 \%$. The weighting matrices for semi-active building are defined by $r=10^{-5}$ and $q=10^{+6}$.

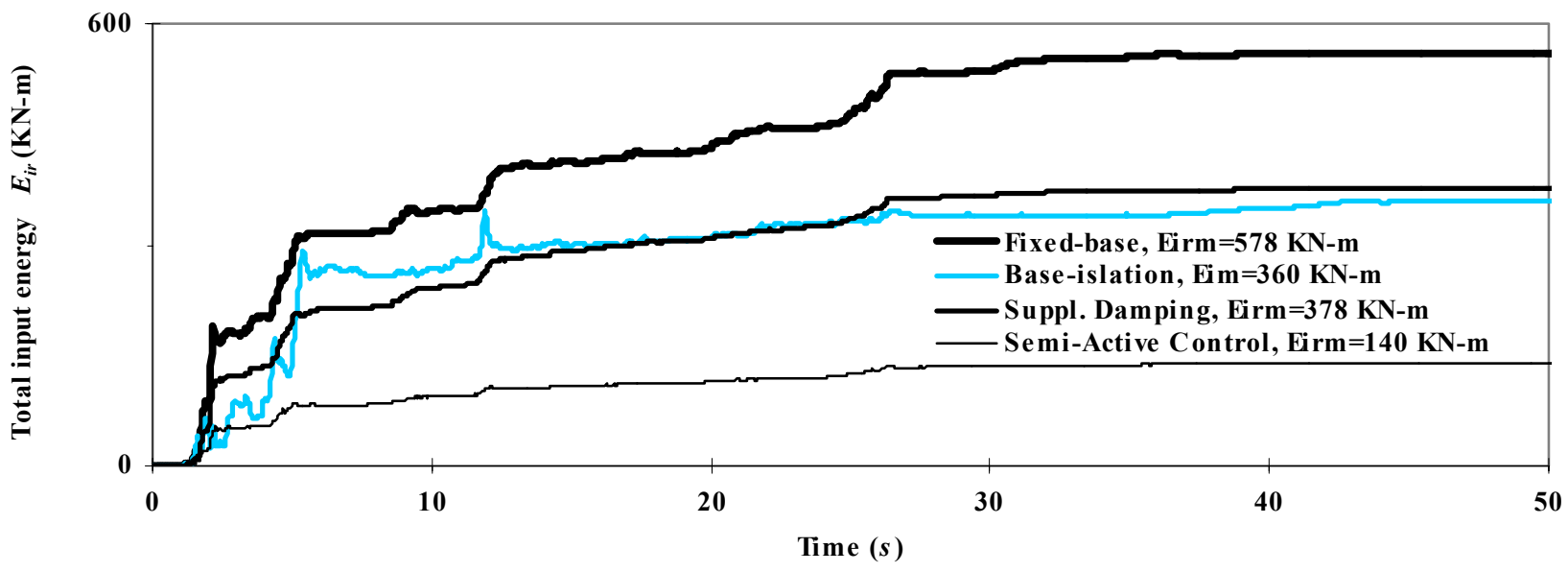

Figure 7.8. Total input energy time-histories for the five-story buildings with fixed-base, baseisolation, supplemental damping, and semi-active control subjected to the SOOE component of El Centro, the Imperial Valley, CA earthquake of May 18, 1940 scaled to an $E P A=0.4 g$. Parameters used for Bouc-Wen Model for the stories are $A=1, \beta=\gamma=0.5, n=20, \alpha=0.02$, and for the base isolation system are $A=1, \beta=\gamma=0.5, n=3, \alpha=0.6$. The total damping of the building with supplemental damping is $\mathbf{4 0 \%}$. The weighting matrices for semi-active building are defined by $r=10^{-}$ 5 and $q=10^{+6}$. 



\section{CONCLUSIONS}

Using 20 accelerograms, the distribution of earthquake input energy in a one and a fivestory building with fixed base, based isolation system, and semi-active control system are examined. The following observations and conclusions are presented:

\subsection{SDOF structures:}

1. Earlier studies on a few accelerograms indicated that structural properties: ductility, damping, and the post- to pre-yield stiffness ratio for bilinear behavior do not have a significant influence on the earthquake input energy. Using 20 accelerograms this study, however, shows that ductility, damping, and the shape of the hysteresis loop have a major influence on the input energy spectra and its distribution among various energy components. Results indicate that in estimating the energy parameters, the influences of the structural properties are as significant as the influences of ground motion characteristics.

2. This study shows that as the effective peak acceleration increases, the input energy also increases; indicating that the input energy is related to the intensity of ground motion. The energy ratios such as the ratio of the maximum hysteretic energy to the maximum input energy $E_{h m} / E_{i r m}$ are not affected by the effective peak acceleration. Therefore, scaling an accelerogram does not change the distribution of earthquake input energy among energy components. Results indicate that the influence of the duration of strong motion on the input and hysteretic energies is as significant as the influence of frequency content, particularly for non-linear structures. As the ductility ratio increases, the influence of the duration of strong motion on the input energy spectra becomes more significant, particularly in the vicinity of the predominant period $T_{p e}$.

3. For the 20 accelerograms used, the predominant period $T_{p a}$ (computed from the acceleration spectra) is different from $T_{p e}$ (computed from the energy spectra) indicating that the strength and energy demands do not necessarily occur at the same period. Therefore, in developing an energy-based design approach one should examine both strength and energy demands.

4. The study concludes that the elastic input energy spectra $E_{i r}$ do not necessarily provide a conservative estimate of the inelastic input energy spectra.

5. Three energy ratios based on hysteretic energy were compared: the maximum ratio of the hysteretic to input energy $\left(E_{h} / E_{i r}\right)_{m}$, the ratio of the maximum hysteretic energy to the maximum input energy $E_{h m} / E_{i r m}$, and the equivalent number of yield excursions $N_{e q}$. It is found that the $\left(E_{h} / E_{i r}\right)_{m}$ ratio reflects the damage potential associated with the largest yield excursion, and the $E_{h m} / E_{i r m}$ and 
$N_{e q}$ ratios reflect the damage potential associated with the total number of yield excursions and the cumulative inelastic deformation for the entire duration of accelerogram. The study shows that $\left(E_{h} / E_{i r}\right)_{m}$ is independent of the duration of strong motion and period of structure, whereas $E_{h m} / E_{\text {irm }}$ is independent of both only for periods less than $1 \mathrm{~s}$. Results show that as the duration of strong motion increases the equivalent number of yield excursions $N_{e q}$ increases; indicating more seismic vulnerability. Nonetheless, one cannot make a definitive conclusion from $N_{e q}$ spectra for comparing the damage potential of various structures.

6. It is observed that the number and the rate of yield excursions depend on the ground motion characteristics (intensity, frequency content, and duration of strong motion), and structural properties (period of structure, ductility, damping, and hysteretic behavior). The damage potential for the largest yield excursion is as significant as the total yield excursion in evaluating the damage potential of structures.

7. The results indicate that small damping ratios (less than 5\%) have a minor influence on the input energy and a major influence on the damage potential of structures. Therefore, input energy should not be considered as a sole damage index. For damping ratios greater than 5\%, however, damping reduces the input energy in the vicinity of the predominant period $T_{p e}$.

8. Earthquake input energy reflects the intensity of earthquake ground motion and is more appropriate for measuring the intensity than using the effective peak acceleration EPA (equation 1.1), Spectrum Intensity SI (equation 1.2), and Accelerogram Intensity $I_{E}$ (equation 4.6) since $E_{i r}$ considers both the characteristics of ground motion and the structural properties. The maximum ordinate of the elastic input energy spectrum with 5\% damping may be used for scaling the records to the same intensity.

\subsection{Five-story building with fixed base, base-isolation, supplemental damping, and semi-active control:}

1. For a given effective peak acceleration, the distribution of energy and story shear through the height of the five-story building (with fixed base, base-isolation, supplemental damping, and semi-active control) is mostly independent of the duration of strong motion and the frequency content of the accelerograms.

2. Total drift and total input energy for the building with base-isolation, supplemental damping, and semi-active control are significantly less than those for the fixed-base building. 
3. The ductility and hysteretic energy demands do not necessarily occur in the same story. The story shear is the largest in the first story, whereas ductility and energy dissipation may not be the largest in the first story.

4. Base-isolation is effective in reducing the damage potential of the 5-story structure by dissipating most of the earthquake input energy in the base isolation system. Nonetheless, if the period of the base-isolation system is close to the predominant period of the ground motion, the hysteretic energy demand and consequently the damage potential for the building with base-isolation will be larger than those for the building with fixed base. The predominant period of the ground motion primarily depends on the soil conditions. It also depends on the fault and path characteristics and epicentral distance (specially in near fault regions).

5. For the 5-story building with fixed base subjected to the S00E component of the El Centro accelerogram, as the yield deformation decreases, base shear decreases significantly, and the total input energy remains approximately the same. It is found that ductility has a pronounced influence on the distribution of input energy among energy components. 



\section{REFERENCES}

Akiyama H. (1985). "Earthquake-resistant limit-state design for buildings", the University of Tokyo Press, Tokyo, Japan.

Berg G.V. and Thomaides S.S. (1960). "Energy consumption by structures in strongmotion earthquakes", Proc. of the $2^{\text {nd }}$ World Conference on Earthquake Engineering, Tokyo, Japan, pp. 681-696.

Bouc R. (1967). "Forced vibration of mechanical systems with hysteresis", Proc. of $4^{\text {th }}$ conference on nonlinear oscillation, Prague, Czechoslovakia.

Bruneau M. and Wang N. (1996). "Some aspects of energy methods for the inelastic seismic response of ductile SDOF structures, Eng. Struc., 18(1), pp. 1-12.

Chopra A. (1995). "Dynamics of structures: Theory and applications to earthquake engineering", Perntice Hall.

Fajfar P., Vidic T., and Fischinger M. (1989). "Seismic design in medium- and longperiod structures”, Earthquake Eng. Struct. Dyn., 18, pp. 1133-1144.

FEMA 302 (1998). "NEHRP Recommended Provisions for Seismic Regulations for New Buildings and other structures: Part1-Provisions", Federal Emergency Management Agency, Washington, D.C.

Goel S.C. and Berg G.V. (1968). "Inelastic earthquake response of tall steel frames", $J$. Struct. Div., ASCE, 94(ST8), pp. 1907-1772.

Housner G.W. (1956). "Limit design of structures to resist earthquakes", Proc. of the $1^{\text {st }}$ World Conference on Earthquake Engineering, California, USA, 5, pp. 5-1 to 5-13.

IBC (2000). "International Building Code", The International Conference of Building Officials (I.C.B.O.), USA.

Kato B. and Akiyama H. (1982). "Seismic design of steel buildings", J. Struct. Div., ASCE, 108(ST8), pp. 1709-1721.

Khashaee P., Mohraz B., Sadek F., Lew H.S., and Gross J.L. (2001). "Energy-based approach for seismic design: Energy spectra", NISTIR 6599, Washington, D.C.

Kuwamura H. and Galambos T.V. (1989). "Earthquake load for structural reliability", $J$. Struct. Eng., ASCE, 115(6), pp. 1446-1462.

Kuwamura H., Kirino Y., and Akiyama H. (1994). "Prediction of earthquake energy input from smoothed Fourier amplitude spectrum", Earthquake Eng. Struct. Dyn., 23(10), pp. 1125-1137. 
Leelataviwat S., Goel S.C., and Stojadinovic B. (1999). "Toward performance-based seismic design of structures", Earthquake spectra, 15(3), pp. 435-461.

Loh C.-H. and Chung S.-T. (1993). "A three-stage identification approach for hysteretic systems", Earthquake Eng. Struct. Dyn., 22, pp. 129-150.

Manfredi G. (2001). "Evaluation of seismic energy demand", Earthquake Eng. Struct. Dyn., 30, pp. 485-499.

Miranda E. and Bertero V.V. (1994). "Evaluation of strength reuction factors for earthquake resistant design”, Earthquake Spectra, 10(2), pp. 357-379.

McKevitt W. E., Anderson D.L., and Cherry S. (1980). "Hysteretic energy spectra in seismic design", Proc. of the $2^{\text {nd }}$ World Conference on Earthquake Engineering, Vol. 7 , pp. 487-494.

Nakashima M., Saburi K., and Tsuji B. (1996). "Energy input and dissipation behaviour of structures with hysteretic dampers", Earthquake Eng. \& Struct. Dyn., 19(1), pp. 77-90.

Newmark N.E. and Rosenbluth E. (1971). "Fundamentals of Earthquake Engineering", Englewood Cliffs, New Jersey: Prentice-Hall, Inc.

Otani S. (1981). "Hysteresis Model of Reinforced Concrete for Earthquake Response Analysis", J. Faculty of Engineering, University of Tokyo, Series B, Vol. XXXVI-II, No. 2, pp. 407-441.

Park Y.J., Ang A. H. (1985). "Mechanistic seismic damage model for reinforced concrete”, J. Struct. Eng., ASCE, 111, pp.740-757.

Park, Y.J., Ang, A.H., and Wen Y.K. (1987), "Damage-limiting aseismic design of buildings", Earthquake Spectra, 3(1), pp. 1-26.

Pecknold D. A. and Riddle R. (1978). "Effect of initial base motion on response spectra", J. Eng. Mech. Div., 104(2), ASCE, pp. 485-491.

Penzien J. and Liu S.C. (1969). "Non-deterministic analysis of nonlinear structures subjected to earthquake excitations", Proc. of the $4^{\text {nd }}$ World Conference on Earthquake Engineering, Chilean Association on Seismology and Earthquake Engineering, Santiago, Chile, Vol. I, pp. A1-114 to A1-129.

Rahnama M. and Manuel L. (1996). "The effect of strong motion duration on seismic demands", Proc. of the $11^{\text {th }}$ World Conference on Earthquake Engineering, Mexico, paper No. 924. 
Ramberg W. and Osgood W.R. (1943). "Description of stress-strain curves by three parameters", U.S. National Advisory on Aeronautics, Technical Note 902.

SAC 95-06 (1995). "Technical report: Surveys and assessment of damage to buildings affected by the Northridge earthquake of January 17, 1994", Structural Engineers Association Of California, Applied Technology Council, and California Universities for Research in Earthquake Engineering.

Sadek F., Mohraz B., and Riley M.A. (2000). "Linear procedures for structures with velocity-dependent dampers", J. Struct. Eng., ASCE, 126(8), 887-895.

Saiidi M. and Sozen M.A. (1979). "Simple and Complex models for nonlinear seismic response of reinforced concrete structures", Civil Engineering Studies, Univ. of Illinois, Urbana, Illinois.

SEAOC (1995). "Vision 2000: Perormance Based Seismic Engineering of Buildings", Structural Engineers Association Of California.

Soong T. T. and Dargush G. F. (1997). "Passive energy dissipation systems in structural engineering”, John Wiley \& Son Ltd, ISBN: 0471968218.

Takeda T., Sozen M.A., Nielson N.N. (1970). "Reinforced concrete response to simulated earthquakes", J. Struct. Div., ASCE, 96, pp. 2557-2573.

Trifunac M.D. and Brady A.G. (1975). "A study on the duration of strong earthquake ground motion”, Bull. Seism. Soc. Amer., 65, pp.581-626.

Uang C.-M., Bertero V. V. (1990). "Evaluation of seismic energy in structures", Earthquake Eng. \& Struct. Dyn., 19(1), pp. 77-90.

Vinogradov O. and Pivovarov I. (1986). "Vibrations of a system with non-linear hysteresis", J. Sound and Vibration, 111(1), pp. 145-152.

Wen Y.K. (1976). "Method for random vibration of hysteretic systems", J. Eng. Mech. Div., ASCE, 102(2), pp. 249-263.

Wen Y.K. (1989). "Methods for random vibration for inelastic structures", App. Mech. Rev., ASME, 42(2), pp. 39-52.

Yang J. N., Li Z., and Vongchavalitkul S. (1992). "A generalization of optimal control theory: linear and nonlinear structures", NCEER-92-0026, 1(2), National Center for Earthquake Engineering Research, Buffalo, N.Y.

Ye L., and Otani S. (1999). "Maximum seismic displacement of inelastic systems based on inelastic systems based on energy concept", Earthquake Eng. Struct. Dyn., 28, pp. 1483-1499. 
Zahrah T.F. and Hall W.J. (1984). "Earthquake energy absorption in SDOF structures", $J$. Struct. Eng., ASCE, 110(8), pp. 1757-1772. 


\section{APPENDIX A. BOUC-WEN MODEL}

Different models are used to characterize the nonlinear behavior of structures such as Ramberg-Osgood (Ramberg and Osgood, 1943), Bouc-Wen (Bouc, 1967; Wen, 1976 and 1980), Penzien and Liu (Penzien and Liu, 1969), Takeda (Takeda, 1970), Sina (Saiidi and Sozen, 1979), and Q-Histeresis (Saiidi and Sozen, 1979), Otani (Otani, 1981), Vinodgradov-Pivovarov (Vinodgradov and Pivovarov, 1986). The Bouc-Wen model which is extensively used by researchers (see Wen, 1989) to represent the forcedeformation relationship is used in this study.

For the Bouc-Wen model, Figure A.1, the equation of motion can be written as

$$
\ddot{u}+2 \xi_{0} \omega_{0} \dot{u}+\alpha \omega_{0}^{2} u+(1-\alpha) \omega_{0}{ }^{2} u_{y} z=-\ddot{u}_{g}
$$

where

$$
\begin{aligned}
& u=\text { displacement } \\
& u_{y}=\text { yield displacement } \\
& \ddot{u}_{g}=\text { ground acceleration, } \\
& \xi_{0}=\text { viscous damping ratio, } \\
& \omega_{0}=\text { pre-yield natural frequency } \\
& \alpha=\text { post- to pre-yield stiffness ratio. }
\end{aligned}
$$

In the above equation, $z$ is a non-dimensional hysteretic parameter which is related to displacement $u$ through the following first-order non-linear differential equation

$$
\dot{z}=u_{y}^{-1}\left(A \dot{u}-\beta|\dot{u}| z|\dot{z}|^{n-1}-\gamma \dot{u}|z|^{n}\right)
$$

Parameters $\gamma$ and $\beta$ define the shape of the hysteretic loop (softening or hardening); parameter $A$ controls the restoring force amplitude and tangent stiffness, and $n$ defines the smoothness of the transition from elastic to inelastic range in the force-deformation relationship. This model can be used for a variety of materials. For example $A=1, \gamma=$ $\beta=0.5, n=20$ and $\alpha=0$ can approximately represent the elasto-plastic behavior. 


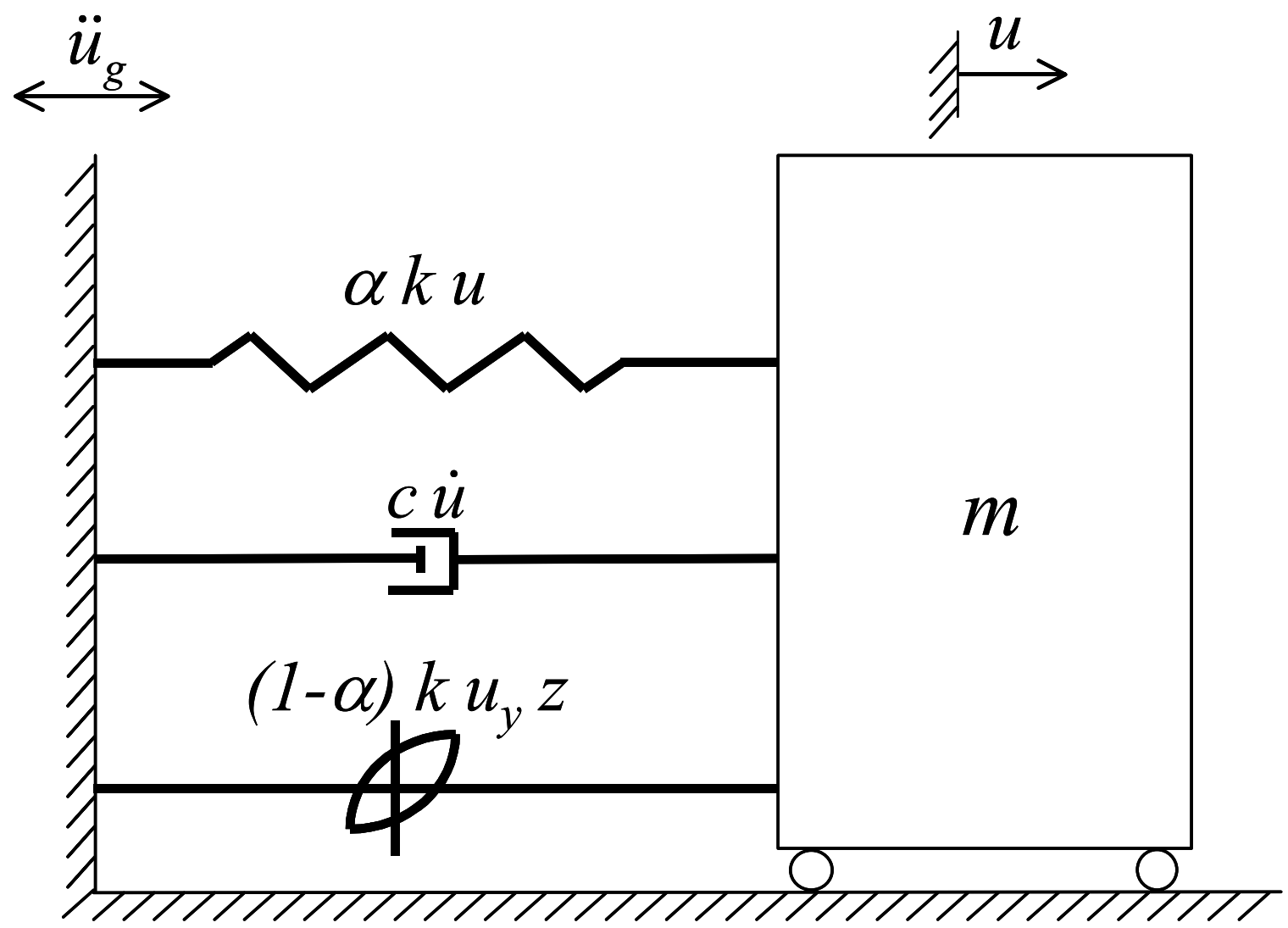

Figure A.1 Single degree of freedom system used for Bouc-Wen model 


\section{APPENDIX B. EARTHQUAKE INPUT ENERGY FOR MDOF STRUCTURES}

The equation of motion for an $n$ degree of freedom shear building (Figure 7.1.a) can be written as

$$
F_{i}(t)+F_{d}(t)+F_{s}(t)=-M r \ddot{u}_{g}(t)
$$

where $F_{i}$ is an $n$-dimensional inertia force vector, $F_{d}$ is an $n$-dimensional damping force vector, $F_{s}$ is an $n$-dimensional non-linear stiffness force vector, $M$ is the mass matrix, $r$ is an $n$-dimensional influence vector, and $\ddot{u}_{g}$ denotes ground acceleration.

Transposing the matrix equation (B.1), multiplying both sides by $d u=\dot{u} d t$ and integrating, we obtain the energy balance equation as

$$
\int_{0}^{u} F_{i}^{T} d u+\int_{0}^{u} F_{d}{ }^{T}(t) d u+\int_{0}^{u} F_{s}{ }^{T}(t) d u=-\int_{0}^{u} M r \ddot{u}_{g}(t) d u
$$

where $u$ is an $n$-dimensional relative displacement vector. The relative kinetic energy is

$$
E_{k r}=\int_{0}^{u} M \ddot{u}(t) d u=1 / 2 \dot{u}^{T} M \dot{u}
$$

The damping energy is given by

$$
E_{d}=\int_{0}^{t} F_{d}{ }^{T}(t) \dot{u} d t
$$

The absorbed energy vector is given by

$$
E_{a}=\int_{0}^{t} F_{s}^{T}(t) \dot{u} d t=E_{h}+E_{s}
$$

the elastic strain energy for the $j$ th story of building is

$$
E_{s j}=\frac{Q_{s j}{ }^{2}}{2 k_{j}}
$$


where $Q_{s j}$ and $k_{j}$ are the shear force and elastic stiffness of the $j$ th story, respectively. Once the elastic strain energy is obtained, the hysteretic energy can be computed from equation (B.5). Finally, the relative input energy is obtained as

$$
E_{i r}=-\int_{0}^{t} M r \ddot{u}_{g}(t) \dot{u} d t
$$

Therefore, the vector equation (B.2) can be written as

$$
E_{k r}+E_{d}+E_{s}+E_{h}=E_{i r}
$$




\section{APPENDIX C. LIST OF SYMBOLS}

$a_{\mu}$

$A$

$b_{\mu}$

$B$

$c$

$c_{b}$

$c_{\mu}$

$C$

$d_{\mu}$

$E_{a}$

$E_{c}$

$E_{d}$

$E_{d m}$

$E_{\text {dis }}$

$E_{\text {dism }}$

$E_{\text {dist }}$

$E_{d t}$

$E_{h}$

$E_{h m}$

$E_{h t}$

$E_{\text {ia }}$

$E_{\text {ir }}$

$E_{\text {irm }}$

$E_{i r t}$

$E_{k r}$

$E_{k r m}$

$E_{k r t}$

$E_{s}$

$E_{s m}$

$E_{s t}$

EPA

$f_{d}$

$f_{i}$

$f_{s}$

$F_{c}$

$F_{d}$

$F_{i}$

$F_{S}$
A regression parameter depending on the ductility and the duration of strong motion

Parameter of Bouc-Wen model describing tangent stiffness

A regression parameter depending on the ductility and the duration of strong motion

Control input matrix

Viscous damping coefficient of SDOF structure

Viscous damping coefficient for base-isolation system

A regression parameter depending on the ductility and the duration of strong motion

Viscous damping coefficient of each story of the structure

A regression parameter depending on the ductility and the duration of strong motion

Absorbed energy

Energy corresponding to energy

Equivalent viscous damping energy

Maximum equivalent viscous damping energy

Energy dissipated through damping and hysteretic behavior

Maximum dissipated energy through damping and hysteretic behavior

Total dissipated energy through damping and hysteretic behavior

Total equivalent viscous damping energy

Hysteretic (yielding or plastic strain) energy

Maximum hysteretic energy

Total hysteretic energy

Absolute input energy

Relative input energy

Maximum relative input energy

Total relative input energy

Relative kinetic energy

Maximum relative kinetic energy

Total relative kinetic energy

Elastic strain energy

Maximum elastic strain energy

Total elastic strain energy

Effective peak ground acceleration

Damping force

Inertia force

Restoring force

Control force

Damping force

Inertia force

Restoring force 


\begin{tabular}{ll}
$F_{y}$ & Yield force \\
$F S$ & Fourier Spectra \\
$g$ & Gravity acceleration of ground \\
$G$ & Feedback gain matrix \\
$H$ & Disturbance input vector \\
$I$ & Unit matrix \\
$I_{E}$ & Intensity of accelerogram \\
$I_{d}$ & Seismic Index \\
$J$ & Performance index \\
$k$ & Stiffness of the SDOF structure \\
$k_{b}$ & Stiffness of the base isolation system \\
$K$ & Stiffness for each story of the structure \\
$m$ & Mass of the SDOF structure \\
$m_{b}$ & Mass of the base for a base-isolated building \\
$n$ & A parameter for Bouc-Wen model controlling the smoothness of transition \\
& from elastic to inelastic region of the force-displacement curve \\
$N_{e q}$ & Equivalent number of yield excursions \\
$P$ & A matrix for the solution of Riccati equation \\
$P G A$ & Peak ground acceleration \\
$P G V$ & Peak ground velocity \\
$q$ & A scalar \\
$Q$ & Story shear; a weight matrix in Chapter 7 \\
$Q_{b}$ & Base shear \\
$r$ & A scalar \\
$R$ & Response modification factor; a weight matrix in Chapter 7 \\
$S_{v}$ & Spectral velocity \\
$S I$ & Spectrum Intensity \\
$t_{d b}$ & Bracketed duration of strong motion \\
$t_{d i}$ & Intensity-based duration of strong motion defined by Trifunac and Brady \\
$T_{b}$ & (1975) \\
$T_{G}$ & Natural period of the base isolation system \\
$T_{n}$ & Predominant period of the earthquake ground motion \\
$T_{p a}$ & Fundamental period of the structure \\
$T_{p e}$ & Predominant period of earthquake ground motion based on acceleration \\
$u$ & response spectra \\
$u_{g}$ & Predominant period of earthquake ground motion based on acceleration \\
$u_{m}$ & energy spectra \\
$u_{r e l}$ & Relative displacement; deformation \\
$u_{y}$ & Ground displacement \\
$u_{y l}$ & Maximum deformation \\
$\dot{u}$ & Relative displacement \\
$u_{t}$ & Yield deformation \\
$V_{E}$ & Yield deformation for the first story \\
& Relative velocity of the structure with respect to ground \\
& Absolute (total) acceleration of the structure with respect to ground \\
& Equivalent velocity \\
\hline &
\end{tabular}




$\begin{array}{ll}W & \text { Weight of the each floor of the structure } \\ z & \text { A non-dimensional hysteretic parameter } \\ \alpha & \text { Post- to pre- yield stiffness ratio } \\ \beta & \text { Parameter of Bouc-Wen model defining the shape of hysteresis loop } \\ \gamma & \text { Parameter of Bouc-Wen model defining the shape of hysteresis loop } \\ \mu & \text { Ductility ratio } \\ \mu_{\max } & \text { Maximum inter-story ductility ratio } \\ \xi & \text { Damping ratio; a mass vector in Chapter } 7 \\ \xi_{b} & \text { Damping ratio for base isolation system } \\ \omega_{0} & \text { Pre-yield frequency for Bouc-Wen model } \\ \xi_{0} & \text { Viscous damping ratio for Bouc-Wen model }\end{array}$

